UNIVERSIDADE DE SÃO PAULO

FACULDADE DE ECONOMIA, ADMINISTRAÇÃO E CONTABILIDADE DEPARTAMENTO DE ADMINISTRAÇÃO

PROGRAMA DE MESTRADO PROFISSIONAL EM EMPREENDEDORISMO

ANÁLISE DE RISCO NA INTRODUÇÃo DE NOVAS TECNOLOGIAS POR STARTUPS NO MERCADO BRASILEIRO

Pedro Marins Freire Teberga

Orientador: Prof. Dr. Fábio Lotti Oliva

SÃO PAULO 
Prof. Dr. Marco Antonio Zago

Reitor da Universidade de São Paulo

Prof. Dr. Adalberto Américo Fischmann

Diretor da Faculdade de Economia, Administração e Contabilidade

Prof. Dr. Roberto Sbragia

Chefe do Departamento de Administração

Prof. Dr. Martinho Isnard Ribeiro de Almeida

Coordenador do Programa de Mestrado Profissional em Empreendedorismo 
PEDRO MARINS FREIRE TEBERGA

\section{ANÁLISE DE RISCO NA INTRODUÇÃO DE NOVAS TECNOLOGIAS POR STARTUPS NO MERCADO BRASILEIRO}

Dissertação apresentada ao Departamento de Administração da Faculdade de Economia, Administração e Contabilidade da Universidade de São Paulo como requisito parcial para a obtenção do título de Mestre em Ciências.

Orientador: Prof. Dr. Fábio Lotti Oliva

\section{Versão Corrigida}

(versão original disponível na Biblioteca da Faculdade de Economia, Administração e Contabilidade)

\section{SÃO PAULO}


Autorizo a reprodução e divulgação total ou parcial deste trabalho, por qualquer meio convencional ou eletrônico, para fins de estudo e pesquisa, desde que citada a fonte.

\section{FICHA CATALOGRÁFICA}

Elaborada pela Seção de Processamento Técnico do SBD/FEA/USP

Teberga, Pedro Marins Freire

Análise de risco na introdução de novas tecnologias por startups no mercado brasileiro / Pedro Marins Freire Teberga. - São Paulo, 2016.

139 p.

Dissertação (Mestrado) - Universidade de São Paulo, 2016.

Orientador: Fábio Lotti Oliva.

1. Administração de risco 2. Empreendedorismo 3. Inovações tecnológicas I. Universidade de São Paulo. Faculdade de Economia, Administração e Contabilidade. II. Título.

CDD -658.155 


\section{SUMÁRIO}

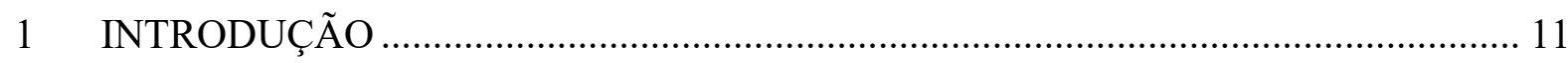

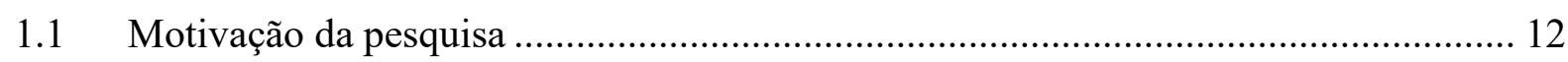

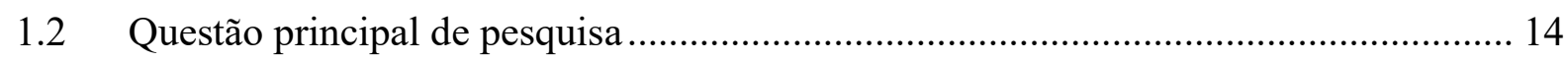

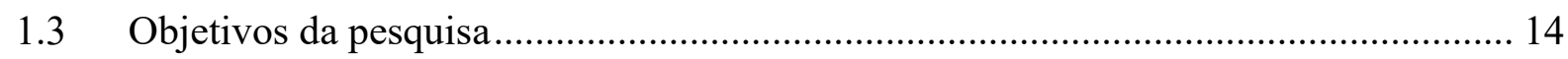

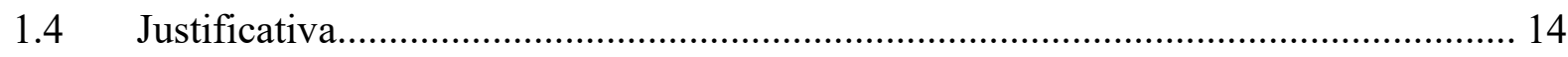



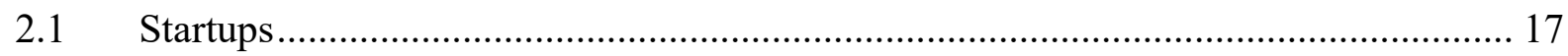

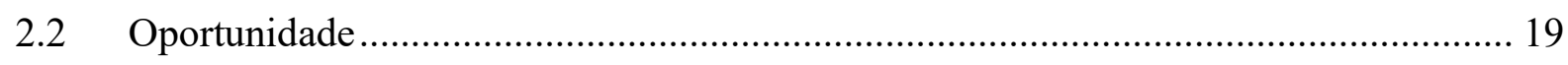

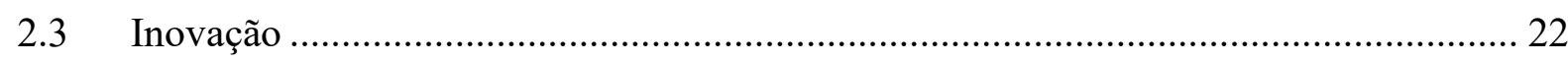

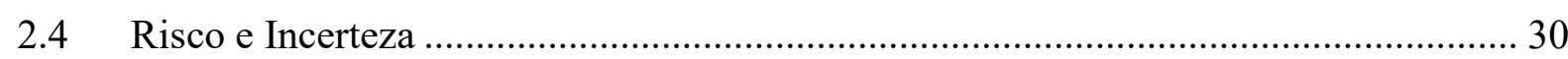

2.5 Avaliação dos riscos - Modelo NPVR e Maturity Level in Enterprise Risk

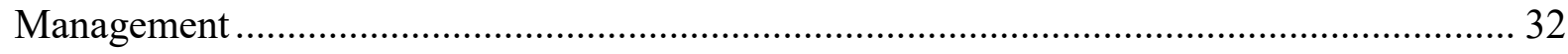

2.5.1 Avaliação de Risco de Mercado .......................................................................... 34

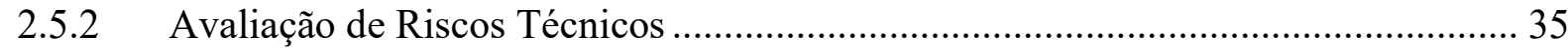

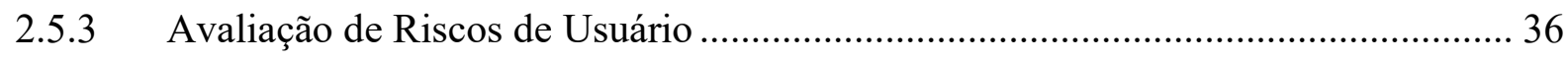

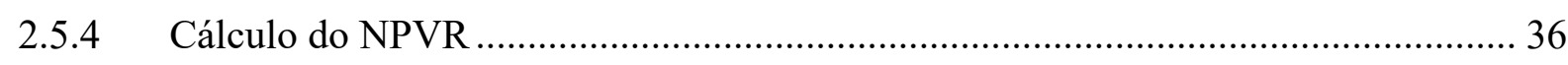

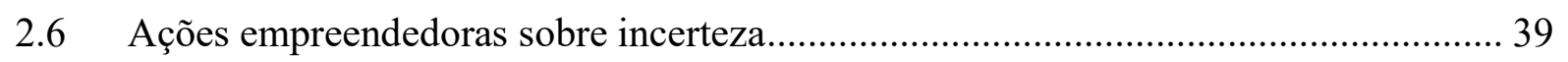

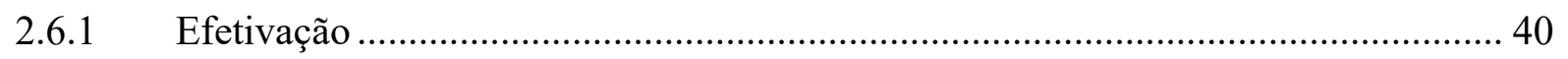

2.6.2 Lean Startup, Business Model Generation e Plano de Negócios ........................... 42

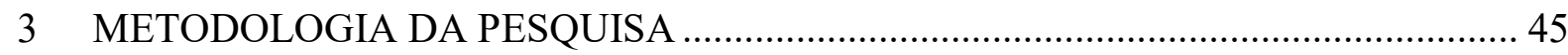

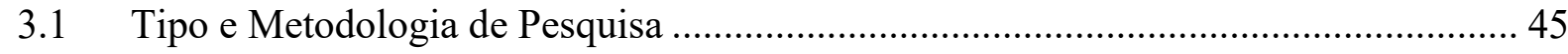

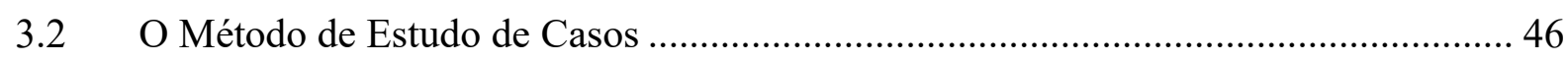

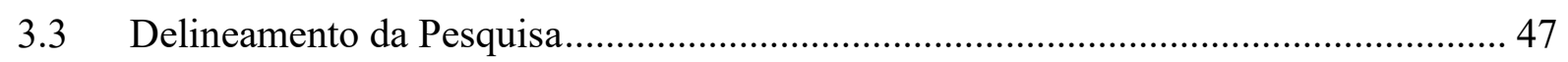

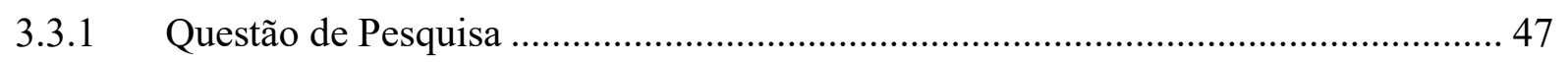

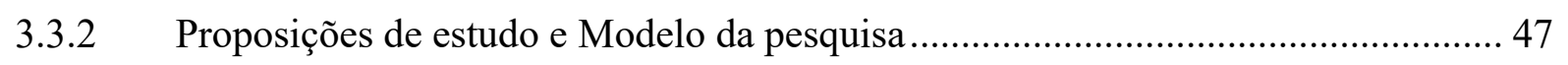

3.3.3 Unidade de Análise e Tipo de Estudo de Casos: Casos Múltiplos ........................... 49

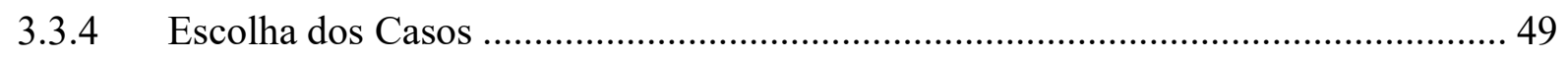

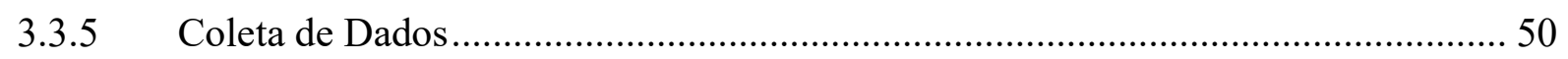

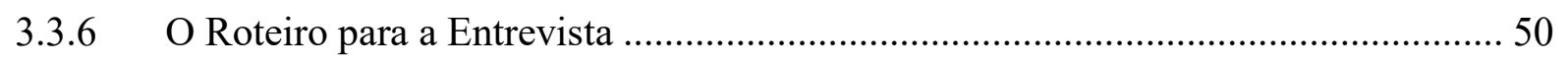

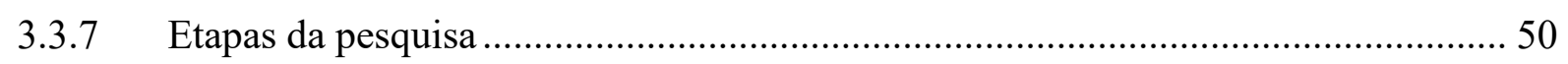

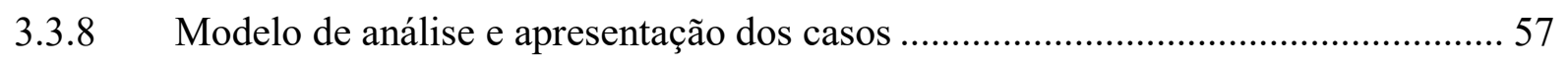

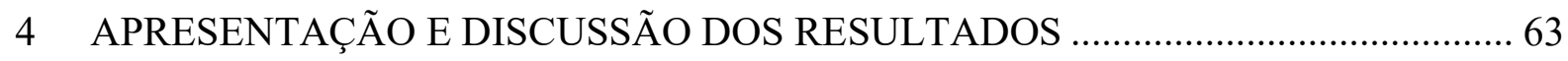

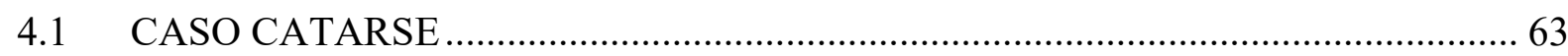

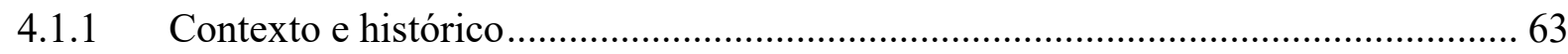

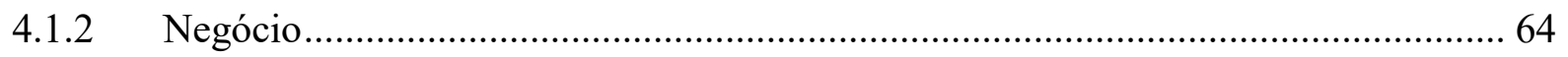




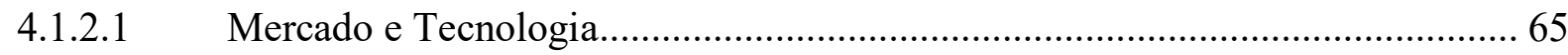

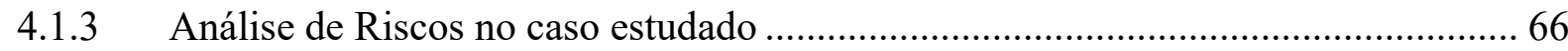

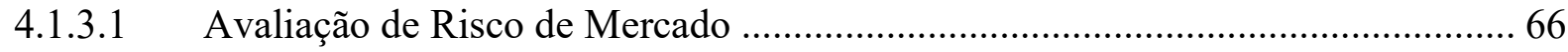



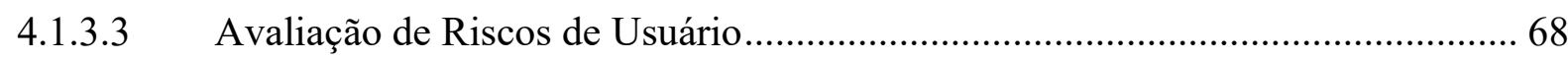

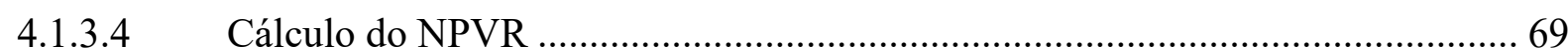

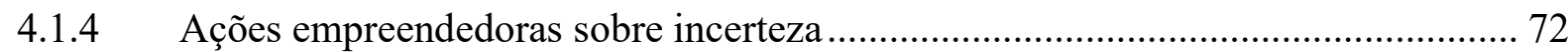

4.1.5 Aplicação do modelo de pesquisa no caso Catarse ……………………………….. 73

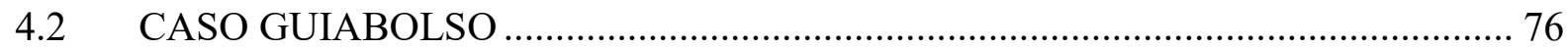

4.2.1 Contexto e histórico .............................................................................. 76



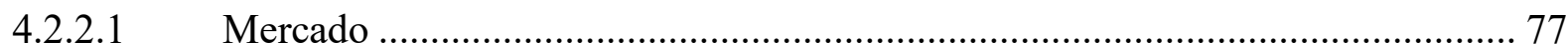

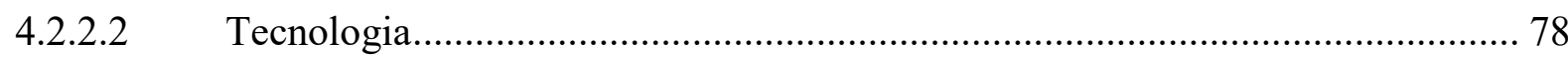

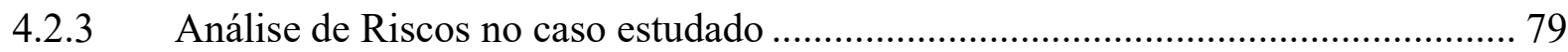

4.2.3.1 Avaliação de Risco de Mercado ………………………………………….... 80

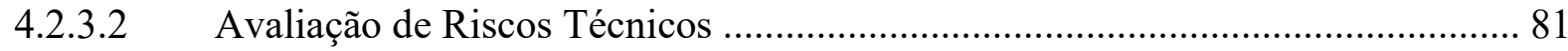

4.2.3.3 Avaliação de Riscos de Usuário …………………………………………..... 82

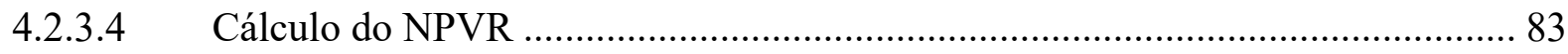

4.2.4 Ações empreendedoras sobre incerteza................................................................ 85

4.2.5 Aplicação do modelo de pesquisa sugerido no caso GuiaBolso …………………. 85

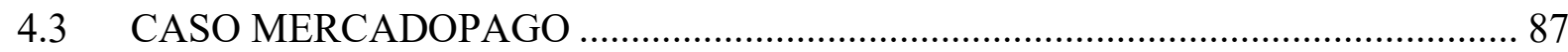

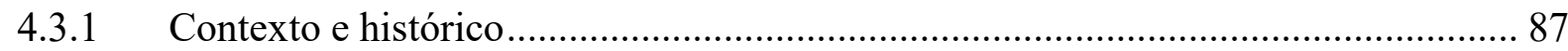

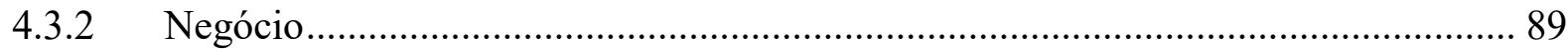

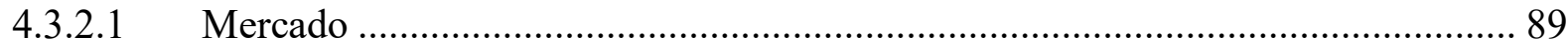

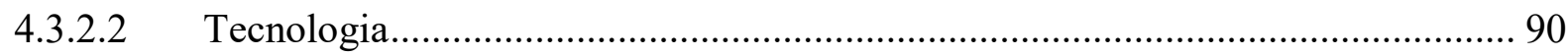

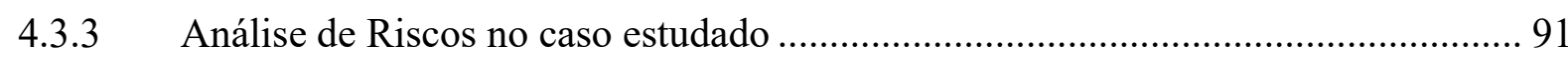

4.3.3.1 Avaliação de Risco de Mercado …………………........................................... 92

4.3.3.2 Avaliação de Riscos Técnicos ......................................................................... 94

4.3.3.3 Avaliação de Riscos de Usuário .................................................................... 95

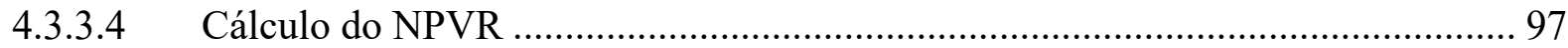

4.3.4 Ações empreendedoras sobre incerteza .................................................................. 99

4.3.5 Aplicação do modelo de pesquisa sugerido no caso MercadoPago .......................... 101

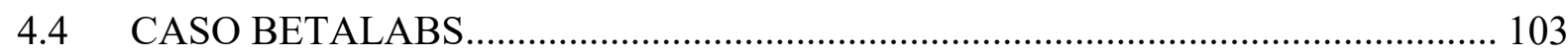

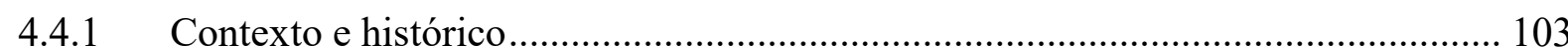

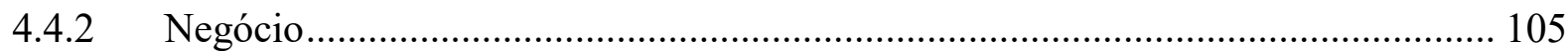

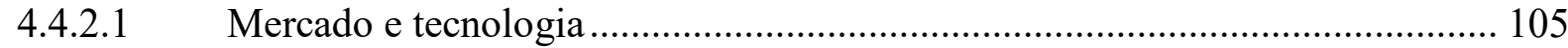

4.4.3 Análise de Riscos no caso estudado .................................................................... 106 
4.4.3.1 Avaliação de Risco de Mercado ........................................................................... 107

4.4.3.2 Avaliação de Riscos Técnicos ......................................................................... 108

4.4.3.3 Avaliação de Riscos de Usuário .......................................................................... 109

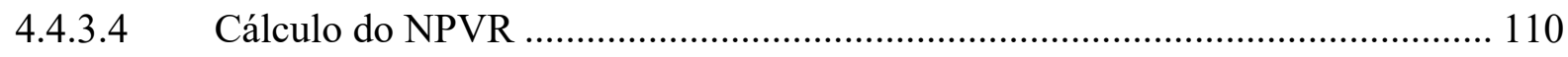

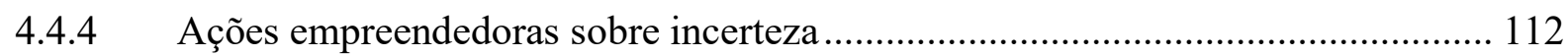

4.4.5 Aplicação do modelo de pesquisa sugerido no caso Betalabs ............................... 113

4.5 Análise da experiência do empreendedor - Caso Polinize ......................................... 114

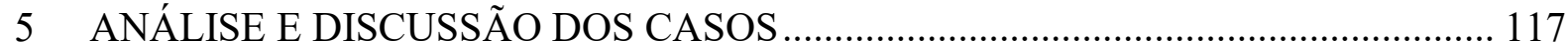

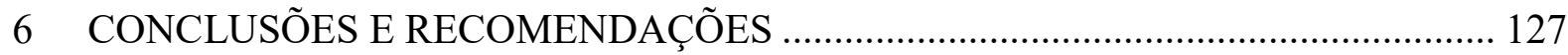

6.1 Limitações da pesquisa e recomendações para trabalhos futuros ............................. 131

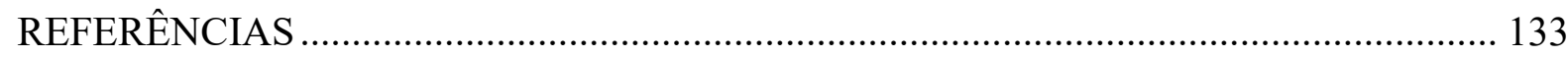




\section{LISTA DE FIGURAS}

Figura 1 - Organização da revisão bibliográfica ............................................................... 17

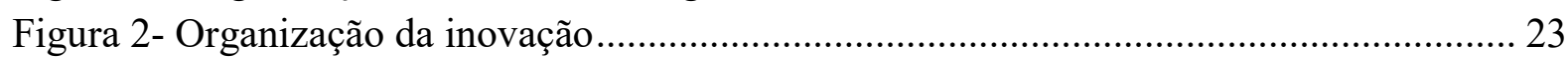

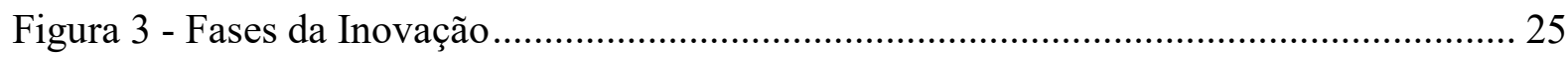

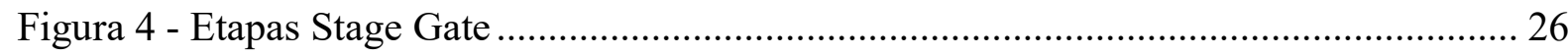

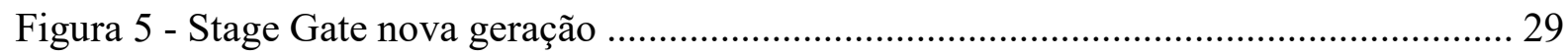

Figura 6 - Maturity Level in Enterprise Management............................................................. 38

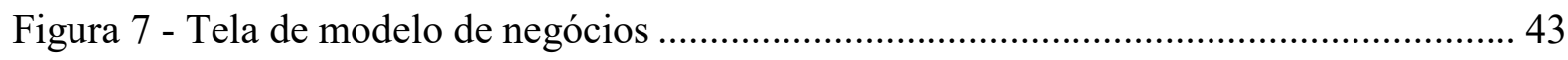

Figura 8 - O modelo de pesquisa................................................................................... 48

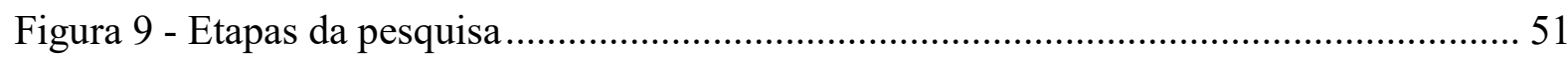

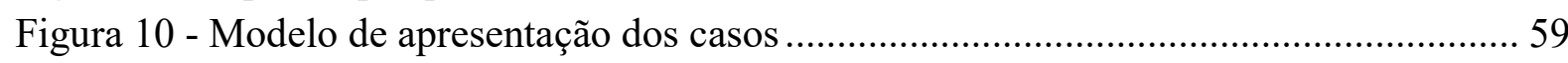

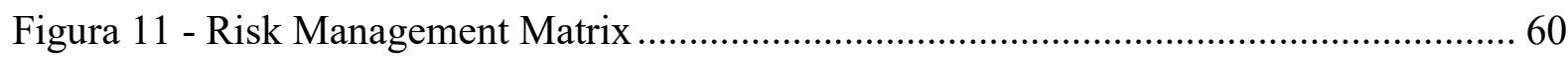

Figura 12 - Fluxograma de apresentação do modelo de funcionamento do site Catarse ........ 65

Figura 13 - Representação dos riscos do caso Catarse ........................................................ 70

Figura 14 - Exemplo de modelo para orientação de campanha ............................................ 71

Figura 15 - Risk Management Matrix - Catarse..................................................................... 74

Figura 16 - Linha do tempo do GuiaBolso........................................................................... 76

Figura 17 - Representação dos riscos do caso GuiaBolso................................................... 84

Figura 18 - Risk Management Matrix - GuiaBolso............................................................. 86

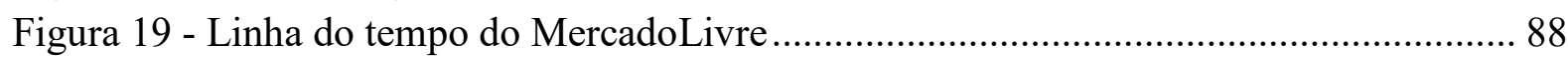

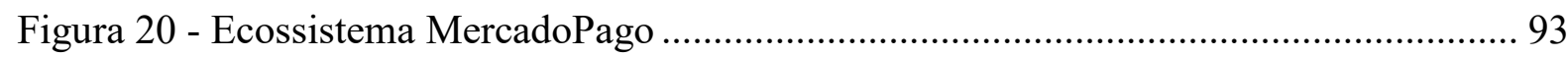

Figura 21 - Representação dos riscos do caso MercadoPago................................................. 98

Figura 22 - Risk Management Matrix - MercadoPago .......................................................... 101

Figura 23 - Representação do sistema ERP ofertado pela Betalabs..................................... 104

Figura 24 - Representação dos riscos do caso Betalabs .................................................... 111

Figura 25 - Risk Management Matrix - Betalabs ................................................................. 113

Figura 26 - Risk Management Matrix - Polinize .......................................................... 115

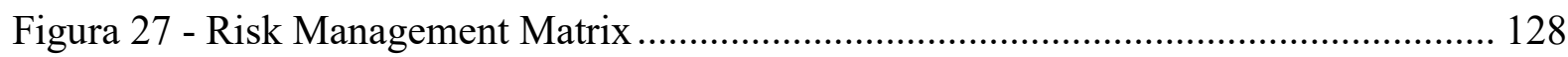




\section{LISTA DE TABELAS}

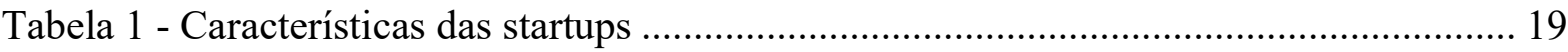

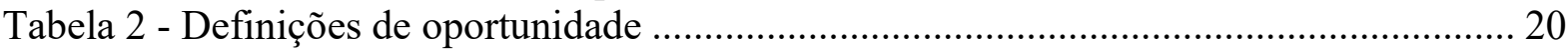

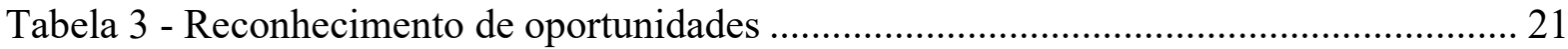

Tabela 4 - Stage Gate tradicional e Stage Gate próxima geração ......................................... 28

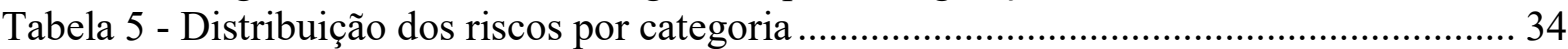

Tabela 6 - Critérios para avaliação de riscos da cadeia de valor e segmento de mercado ...... 35

Tabela 7- Critérios para avaliação de riscos de inovação e recursos ...................................... 35

Tabela 8 - Critérios para avaliação de riscos de interação e especificação ............................. 36

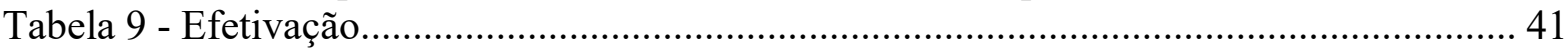

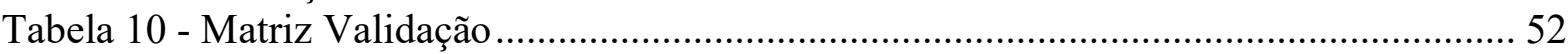

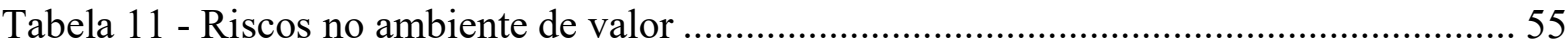

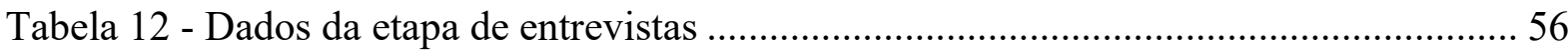

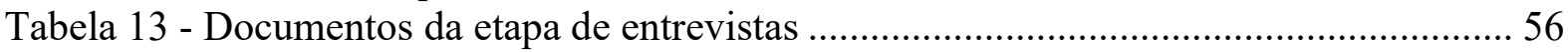

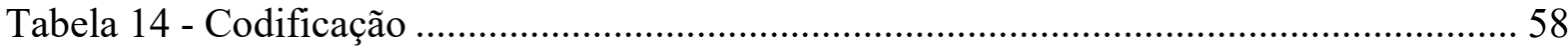

Tabela 15- Critérios para avaliação de riscos da cadeia de valor e segmento de mercado ..... 66

Tabela 16 - Critérios para avaliação de riscos de inovação e recursos ................................. 67

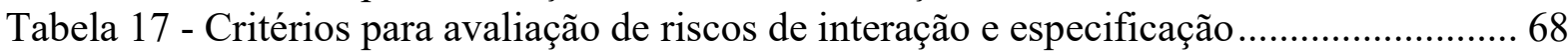

Tabela 18 - Resumo da avaliação dos riscos do Catarse ........................................................ 69

Tabela 19 - Critérios para avaliação de riscos da cadeia a de valor e segmento de mercado . 80

Tabela 20 - Critérios para avaliação de riscos de inovação e recursos ................................... 81

Tabela 21 - Critérios para avaliação de riscos de interação e especificação ............................. 82

Tabela 22 - Resumo da avaliação dos riscos do GuiaBolso................................................. 83

Tabela 23 - Critérios para avaliação de riscos da cadeia de valor e segmento de mercado .... 92

Tabela 24 - Critérios para avaliação de riscos de inovação e recursos .................................. 94

Tabela 25 - Critérios para avaliação de riscos de interação e especificação.......................... 95

Tabela 26 - Resumo da avaliação dos riscos do MercadoPago.............................................. 97

Tabela 27 - Critérios para avaliação de riscos da cadeia de valor e segmento de mercado.. 107

Tabela 28 - Critérios para avaliação de riscos de inovação e recursos ................................. 108

Tabela 29 - Critérios para avaliação de interação e especificação ....................................... 109

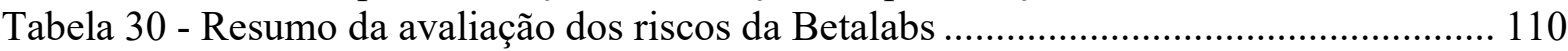

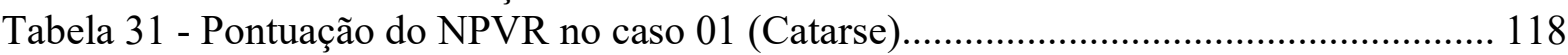

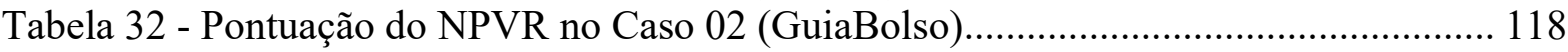

Tabela 33 - Pontuação do NPVR no Caso 03 (MercadoPago) ............................................. 119

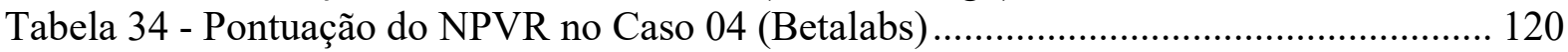

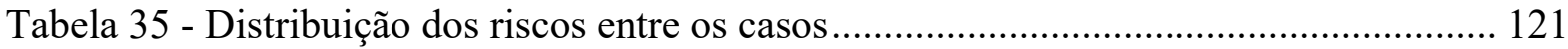

Tabela 36 - Distribuição das ações empreendedoras entre os casos .................................... 121

Tabela 37 - Distribuição dos elementos de comunicação entre os casos ................................ 122

Tabela 38 - Distribuição dos elementos de desenvolvimento de produto entre os casos...... 122

Tabela 39 - Riscos observados em cada caso ..................................................................... 122

Tabela 40 - Riscos no ambiente de valor ......................................................................... 139 


\section{LISTA DE ABREVIATURAS}

ERP - Enterprise Resource Planning

NPV - Net Present Value

NPVR - Net Present Value Risk-Adjusted

PCI-SSC - Payment Card Industry Security Standards Council

ROI - Return On Investment

TI - Tecnologia da Informação

VPL - Valor Presente Líquido 


\section{RESUMO}

O cenário volátil da inovação tecnológica demonstra a necessidade de processos para controle de risco, como forma de garantir a sua viabilidade. O presente trabalho teve como objetivo propor diretrizes para o gerenciamento de riscos na introdução de novas tecnologias por startups no mercado brasileiro. $\mathrm{O}$ estudo propôs categorias conceituais relacionadas à gestão de riscos em startups, com base principal na abordagem do NPVR (Net Present Value RiskAdjusted). A metodologia contou com quatro estudos de caso comparativos: MercadoPago, GuiaBolso, Catarse e Betalabs, que tiveram seus dados coletados por meio de entrevistas com os principais gestores e documentos fornecidos pelas organizações. A análise de dados foi realizada a partir do modelo de Miles, Huberman e Saldaña (2014), por meio do qual se deu a condensação dos dados; a visualização dos dados; e, a elaboração e verificação de conclusões. Entre os principais resultados, destacam-se a proposição de uma matriz dedutiva-indutiva para o gerenciamento de riscos e incertezas em startups, que traz elementos que propiciam o cálculo do valor presente líquido ajustado ao risco do desenvolvimento de um novo produto ou serviço, assim como aporte do nível de maturidade da gestão de risco das empresas estudadas, configurando a Startup Risk Management Matrix.

Palavras chave: Administração de risco, Empreendedorismo, Inovações tecnológicas. 


\begin{abstract}
The volatile scenario of technological innovation demonstrates the need for risk controlling processes, in order to ensure its viability. This Master's thesis proposes a conceptual framework for risk management in the introduction of new technologies by startups in Brazil, aiming to provide the guidelines for the improvement of this process. The study comes up with conceptual categories related to risk management in startups, mainly based on the NPVR (Net Present Value) approach. The methodology included four comparative case studies: MercadoPago, Catarse, Betalabs and GuiaBolso, which had their data collected through interviews with key managers and documents provided by the organizations. Data analysis was based on Miles, Huberman, and Saldana (2014) model, whereby data were condensed; data were visualized; and conclusions developed and checked. Among the main results, there is the proposition of a deductive-inductive matrix for the management of uncertainties and risks in startups, which brings elements that provide the calculation of the net present value adjusted to the risk of developing a new product or service, as well as the contribution of the level of risk management maturity of the studied companies, setting up the Startup Risk Management Matrix.
\end{abstract}

Key words: Risk management, New technologies, Entrepreneurship. 


\section{INTRODUÇÃO}

Impulsionada pela globalização dos mercados, pelos avanços tecnológicos e pelas mudanças constantes das necessidades dos clientes, a inovação de produto é atualmente prioridade na estratégia de muitas empresas. Nos últimos 50 anos, por exemplo, verificou-se que os ciclos de vida dos produtos tornaram-se mais curtos, encolhendo cerca de $400 \%$ em uma ampla variedade de categorias. Todavia, conseguir bons resultados nesse contexto é difícil, visto que em média $46 \%$ dos recursos que as empresas dedicam à concepção, desenvolvimento e lançamento de produtos não geram retornos (COOPER, 2000).

De acordo com Davis (2002), desenvolvimento de produto é visto, muitas vezes, como atividade secundária, especialmente nas indústrias de tecnologia. Entretanto, segundo o autor, não atribuir importância estratégica para essa etapa é também não considerar o fato de que inovações tecnológicas bem sucedidas não são, na maioria dos casos, produtos comercialmente bem sucedidos.

Sommer, Loch e Dong (2009), por sua vez, afirmam que descobertas nos campos da inovação e gestão de projetos têm demonstrado que lidar com a incerteza da inovação requer abordagens diferentes da clássica literatura de gestão de riscos.

Nesse cenário, observa-se também que empreendedores têm poucas condições para se dedicar ao planejamento do negócio, visto que a elevada incerteza limita o valor de um investimento maior em pesquisa de mercado, por exemplo. Soma-se a essa perspectiva negativa, o fato de que grande parte dos empreendedores possuírem conhecimento reduzido da indústria em que pretendem atuar, sendo que em muitos casos, isso ocorre porque a indústria é tão recente que não existem ainda especialistas no setor. Nessa dinâmica, empresários precisam ser habilidosos para se adaptar aos constantes imprevistos e também ter desenvoltura para selecionar as oportunidades que surgem durante o desenvolvimento da empresa, pois frequentemente se deparam com eventualidades que lhes obrigam a ajustar ou renovar completamente a ideia original do negócio (BHIDE, 2000).

Dentro desse quadro, nota-se que o empreendedor geralmente aloca pouco tempo para o estágio inicial de desenvolvimento de produtos, uma vez que esse é território desconhecido e com uma combinação de detalhes técnicos complexos e de informações com alta imprecisão que limitam sua capacidade de influenciar a direção dessa etapa de forma significativa. Seguindo essa linha, os fatores de risco do projeto também são constantemente apresentados 
de forma pouco precisa, o que dificulta a tomada de decisão dos gestores que não são especialistas no assunto (DAVIS, 2002).

Analisando esse cenário, esse estudo apresenta um roteiro conceitual e operacional integrado na gestão de projetos e adequado à realidade da maioria dos empreendedores do ramo de startups, com a finalidade de apoiar o desenvolvimento de novos produtos - desde a prospecção da ideia até o lançamento - com maior enfoque na avaliação do risco do negócio, proporcionando assim uma visão holística que possibilita o aumento da velocidade da entrada do produto no mercado, da sua probabilidade de sucesso, bem como a redução das despesas em inovações que tem maiores chances de falhar. Dentro desse contexto, os casos analisados sugerem que o quadro proposto por essa pesquisa é relevante e pode ajudar a preencher a lacuna entre os riscos do projeto e gestão da inovação.

Explicada brevemente a problematização do trabalho, na próxima seção é apresentada a motivação da pesquisa.

\subsection{Motivação da pesquisa}

De acordo com um estudo da Insights (2014), as duas principais ações, citadas por empreendedores, responsáveis pelo encerramento das atividades de uma startup foram: 1) criar produtos que resolvem problemas interessantes, mas que não atendem a uma necessidade do mercado; 2) tempo e dinheiro alocados de maneira inadequada. Dentro desse contexto, duas motivações guiaram o desenvolvimento desta pesquisa. A primeira foi contribuir com o ambiente acadêmico e a segunda foi discutir um problema com implicações para a realidade do empreendedor. Nessa linha, será compartilhado um exemplo empírico que ilustra as situações investigadas nesta dissertação.

Em 2012, a Polinize, empresa em que trabalho, lançou uma plataforma que tinha como objetivo ser uma rede social acadêmica. A ideia era de proporcionar um ambiente onde o professor teria um perfil para publicar gratuitamente seus artigos e qualquer atividade relacionada com o ambiente universitário, de modo a interligar pessoas com interesses próximos e aumentar a exposição do professor nessa rede de acordo com o seu engajamento.

A facilidade em compreender esse modelo, todavia, não deve ser confundida com a visão de que o seu desenvolvimento seguiu um trajeto simples e previsível. Com restrição financeira e pouca experiência, utilizamos os recursos acessíveis, tais como rede de contatos, para o desenvolvimento da tecnologia. Associando ao campo acadêmico, esse tipo de ação 
empreendedora está alinhado à teoria proposta por Saravasthy (2001) da efetivação, descrita como a seleção de meios disponíveis ao empreendedor para criação de efeitos.

Com pouca informação sobre que tipo de plataforma construir, qual seria a melhor estrutura do site, design, entre outros aspectos, dependemos fortemente da nossa rede para complementar as nossas competências e até mesmo fazer o primeiro teste da plataforma. Como não tínhamos tempo e recursos para desenvolver pesquisas de mercado, optamos por uma abordagem de mídia para expor e testar o produto. Os primeiros testes revelaram um problema não previsto: tivemos um número considerável de usuários cadastrados, que chegou a cinco mil em menos de seis meses, mas devido à falta de entendimento de um fator comportamento/cultural - os usuários não eram engajados - decidimos pivotar o projeto.

O episódio dos testes deixou claro que existem problemas dificilmente previstos pelo empreendedor. A literatura, por sua vez, oferece poucos estudos que retratam situações como essa. Loch, Solt e Bailey (2008), por exemplo, argumentaram que a gestão de novas iniciativas deve ser baseada em uma combinação de aprendizado por tentativa-e-erro (a redefinição flexível do modelo de negócio, a partir de novas informações emergentes do processo de implementação) e selecionismo (a execução de vários ensaios paralelos e a escolha da melhor abordagem ex post).

Com base nos aprendizados obtidos a partir da primeira experiência, em 2013, a Polinize lançou outro serviço, uma plataforma em que professores, escolas ou empresas podiam comercializar cursos ou utilizá-la como um ambiente de treinamento online. Como já dito, esse novo projeto foi criado a partir do retorno que tivemos dos usuários da experiência anterior. Ou seja, o contato com os primeiros clientes nos proporcionou um maior entendimento dos mesmos, diminuindo o "risco do usuário" (que será detalhado na revisão bibliográfica). Além disso, o conhecimento que foi gerado na produção da primeira plataforma aumentou a experiência da equipe, reduzindo o "risco técnico" e por fim, a exposição que tivemos outrora, nos proporcionou um maior entendimento do mercado e o estabelecimento de parcerias, diminuindo o risco total do segundo lançamento. O resultado foi a consolidação de um modelo de negócio rentável e que correspondeu às expectativas.

Dentro desse contexto, este estudo, motivado pelo histórico exposto, propõe uma abordagem de gerenciamento da inovação tecnológica, baseada na minimização ou eliminação de riscos que possam impedir ou reduzir o sucesso de um empreendimento.

Dessa forma, a pesquisa visou aumentar o entendimento sobre o seguinte fenômeno: como os empreendedores gerenciam o desenvolvimento de um produto e os aspectos que representam riscos nesse processo. 


\subsection{Questão principal de pesquisa}

A fim de responder à problemática apresentada anteriormente, foi proposta a seguinte questão principal de pesquisa:

Quais são os riscos na introdução de novas tecnologias no mercado, quão expostas estão as startups a esses riscos e como é possível gerenciá-los?

\subsection{Objetivos da pesquisa}

Proposto o problema que orientou o desenvolvimento desta pesquisa, o objetivo geral é: Analisar os riscos no processo de desenvolvimento de um produto em startups. Para tanto, os objetivos específicos são:

1. Identificar os riscos no processo de desenvolvimento de um produto em startups.

2. Apresentar os tratamentos dos riscos no processo de desenvolvimento de um produto em startups.

3. Propor uma sistematização da análise dos riscos no processo de desenvolvimento de produtos em startups.

\subsection{Justificativa}

A justificativa desta pesquisa possui ligação com três questões principais: a relevância do tema; a contribuição; e a viabilidade do método aplicado para sua realização. Quanto à relevância do tema, é fato que em uma sociedade baseada no conhecimento, a inovação é a força motriz da economia. Nesse contexto, observa-se que entre as nações com semelhantes estruturas econômicas, a correlação entre empreendedorismo e crescimento econômico é significativamente alta (REYNOLDS, ET AL., 2000).

Todavia, de um modo geral, os setores da denominada nova economia são aqueles em que a volatilidade e os riscos estão presentes em maior escala e com maior intensidade, em termos de severidade (probabilidade de ocorrência associada ao grau de impacto dos riscos), causando consequências em grande parte muito rigorosas (HALL; HULLET, 2002).

Mesmo diante desse cenário de alto risco, o empreendedorismo é um fenômeno que se amplia tanto no ambiente acadêmico quanto no empresarial. Em 1985, por exemplo, de 
acordo com a Fundação Kauffman (2015) em torno de 250 cursos em faculdades americanas ensinavam empreendedorismo. Em 2008, essa oferta se expandiu para 5.000 e aproximadamente 400.000 alunos tinham aulas de empreendedorismo nos Estados Unidos naquele ano. Essa tendência também é visualizada no Brasil onde o número de startups encontra-se em expansão e chegou a 4.151 ao final de 2015 (TOZETTO, 2016).

Todavia, cerca de $25 \%$ das startups brasileiras são descontinuadas antes do primeiro ano de vida; e a metade delas, em menos de quatro anos (ARRUDA, 2014). A taxa de mortalidade do ambiente empreendedor pode estar associada a uma série de efeitos não desejáveis como o aumento da aversão ao risco. Dentro desse contexto, por exemplo, em 2015, cerca de $80 \%$ dos brasileiros concordavam que abrir um negócio era uma opção desejável de carreira de acordo com o relatório Global Entrepreneurship Monitor (2015). Por outro lado, dados da mesma pesquisa também indicaram que os brasileiros são receosos com relação a se comprometer realmente na abertura de uma empresa. Observou-se uma redução na proporção daqueles que enxergavam oportunidades no ambiente em que atuam para 42\%, assim como entre os que afirmavam não ter medo de fracassar para 50\%.

Nessas circunstâncias, torna-se relevante compreender quais são os principais riscos que envolvem a introdução de uma inovação no mercado, as ações centrais para mitigá-los e a dinâmica do setor tecnológico que, por estar inserido em um ambiente empresarial menos maduro, pouco pode se amparar no conhecimento até então produzido sobre o empreendedorismo tradicional. Isso implica em investigar quais as estratégias que estão sendo utilizadas e de que modo são úteis para auxiliar as startups nos desdobramentos de seus processos de gestão no desenvolvimento de um novo produto.

Em relação à relevância acadêmica, um estudo bibliométrico sobre riscos que analisou publicações científicas entre 2000 - 2012 (POLO; PEIXE; GALEGALE, 2013), demonstrou um crescimento das publicações sobre esse tema a partir de 2006, configurando assim essa área de pesquisa como crescente e em processo de consolidação. Todavia dentro dos periódicos analisados, os relacionados a finanças e economia possuíram uma incidência maior em comparação com os demais periódicos. Dessa forma, esse estudo também é uma contribuição para o entendimento dos demais tipos de riscos enfrentados pelas organizações.

No que se refere à viabilidade, no desenvolvimento desta pesquisa optou-se pela utilização de estudos de casos múltiplos que possibilitou a captura de evidências inseridas em diferentes contextos, resultando assim em um estudo conclusivo.

Quanto à contribuição, esse estudo procurou associar conceitos relacionados a risco e sua contextualização no ambiente das startups, originando o framework Risk Management 
Matrix que proporciona um guia prático direcionado à criação e ao gerenciamento de um negócio inovador. O empreendedor ao estudar essa matriz é capaz de visualizar em que estágio está o seu negócio e ter um guia de como viabilizá-lo mais rapidamente.

O cálculo dos riscos por meio da fórmula do NPVR (DAVIS, 2002) e o mapeamento dos riscos particulares pela Maturity Level in Enterprise Risk Management (OLIVA, 2015), possibilitam ao empreendedor concluir se o seu projeto é viável por meio de uma representação visual dos atuais riscos e outros elementos que podem influenciar o desenvolvimento do produto, sendo especialmente útil na execução de uma análise estratégica sobre um novo empreendimento. Dessa forma, a Risk Management Matrix, pode ser consultada regularmente durante o processo de desenvolvimento a fim de verificar a evolução dos riscos do projeto e guiar ações para mitigá-los. 


\section{REFERENCIAL TEÓRICO}

Este capítulo busca revisar as teorias abordadas nesses estudos representadas pela figura 1. A primeira seção está orientada a apresentar o conceito de startups, assim como as características inerentes a esse tipo de organização. De acordo com o diagrama, as startups fazem parte do meio onde são encontradas oportunidades.

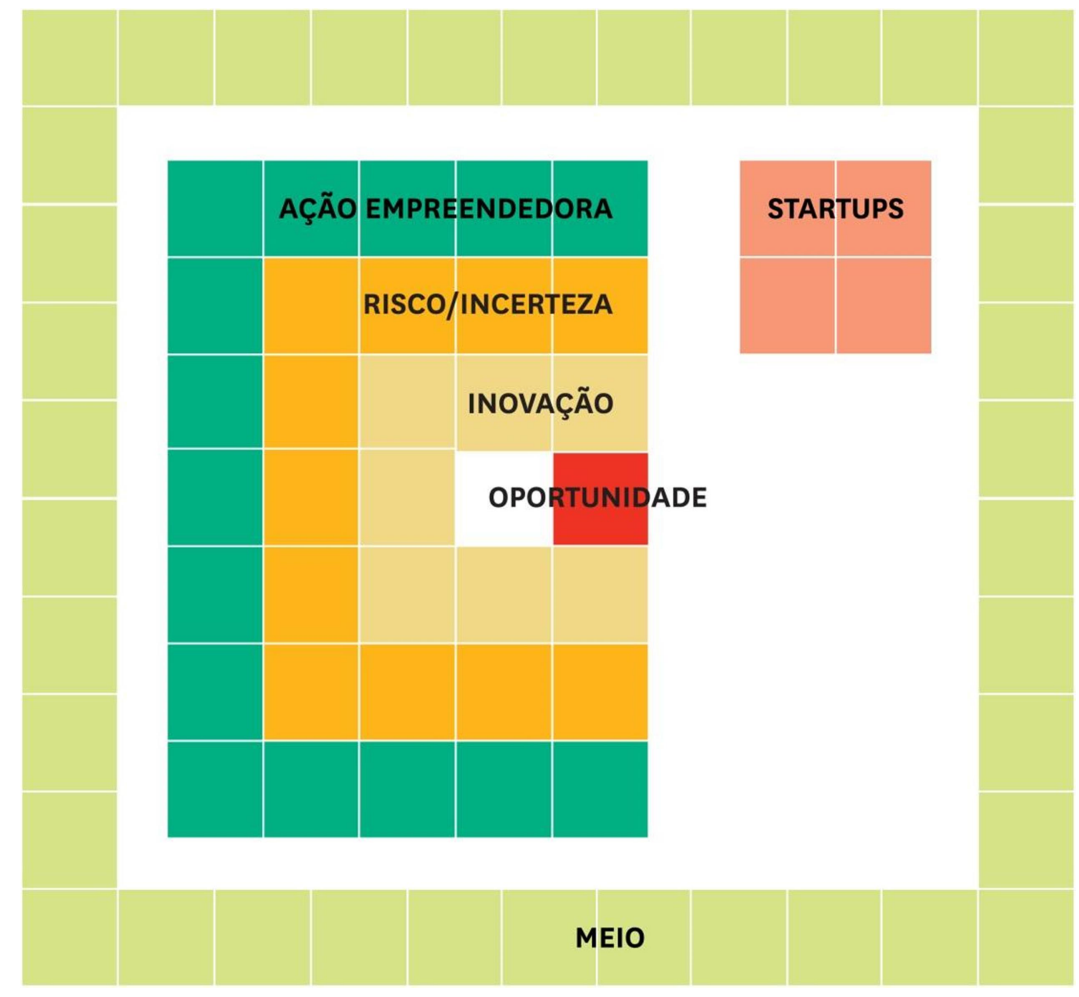

Figura 1 - Organização da revisão bibliográfica

A segunda seção, portanto, apresenta diferentes conceitos de oportunidade e os processos associados ao seu reconhecimento e exploração. As oportunidades trazem consigo a inovação e os riscos/incertezas, que são os dois elementos abordados em seguida. A quinta seção apresenta as principais abordagens gerenciais para a tomada de decisão por startups em contextos incertos, onde se observa a necessidade de um conjunto de teorias que explique como os empreendedores gerenciam incertezas no desenvolvimento de um produto.

\subsection{Startups}

De acordo com Blank e Dorf (2012), uma startup é uma organização temporária em busca de um modelo repetível, escalável e rentável de negócio. Segundo Cusumano (2013), 
startups geralmente se concentram em mercados capazes de se tornarem grandes e lucrativos, procurando identificar necessidades dos clientes que não estão preenchidas ou mal atendidas.

Para Graham (2012), somente ser uma empresa recém-fundada não faz um negócio uma startup. O fator essencial é o potencial de crescimento. Todo o resto associado à startup decorre do seu acelerado crescimento.

Giardino et al. (2014) definem uma startup como uma pequena empresa que explora novas oportunidades de negócio, trabalhando para resolver um problema em um mercado altamente volátil. Ou seja, diferentemente de uma empresa consolidada, em que o mercado está bem definido e a base da competição é compreendida, startups trabalham sobre hipóteses, que são testadas com clientes para a formulação de fatos (BLANK; DORF, 2012).

Segundo Ries (2011) por operar nesse tipo de ambiente de incerteza, as teorias de estratégia, planejamento e pesquisa de mercado não se aplicam às startups, pois essas teorias são voltadas para empresas consolidadas em que o histórico operacional auxilia a previsão do futuro.

Desse modo, ao mesmo tempo em que apresentam certas vantagens, como flexibilidade e agilidade para a tomada de decisões, startups têm algumas limitações como de recursos e capital humano. Assim, eventuais decisões equivocadas na compreensão do mercado na qual está inserida podem resultar em consequências graves, ou até mesmo o seu fim. (CHRISTENSEN; 2013).

Em uma revisão da literatura, Giardino et al. (2014), propuseram as seguintes características de uma startup, apresentadas na Tabela 1: 
Tabela 1 - Características das startups

\begin{tabular}{|c|c|}
\hline Característica & Descrição \\
\hline Falta de recursos & Recursos econômicos e físicos extremamente limitados. \\
\hline Alta reatividade & Capacidade de reação rápida às mudanças de mercado e de tecnologia. \\
\hline Inovação & Precisam se concentrar em explorar segmentos altamente inovadores do mercado. \\
\hline Incerteza & Lidam com um ecossistema altamente incerto sob diversas perspectivas. \\
\hline Rápida evolução & Startups de sucesso têm como objetivo crescer e se expandir rapidamente. \\
\hline Pressão do tempo & O ambiente incerto muitas vezes as obriga a trabalhar sob pressão constante. \\
\hline $\begin{array}{l}\text { Dependência de } \\
\text { terceiros }\end{array}$ & $\begin{array}{l}\text { Devido à falta de recursos, dependem fortemente de soluções externas, como } \\
\text { softwares Open Source, outsourcing, etc. }\end{array}$ \\
\hline Equipe pequena & Começam com um pequeno número de indivíduos. \\
\hline Um produto & Usualmente as atividades da empresa gravitam em torno de um produto/serviço. \\
\hline $\begin{array}{l}\text { Equipe com baixa } \\
\text { experiência }\end{array}$ & $\begin{array}{l}\text { Boa parte da equipe de desenvolvimento é formada por pessoas com menos de } \\
\text { cinco anos de experiência e muitas vezes recém-formados. }\end{array}$ \\
\hline Empresa nova & A criação da empresa foi recente. \\
\hline Organização completa & $\begin{array}{l}\text { São geralmente centradas no fundador e todos na empresa têm grandes } \\
\text { responsabilidades, sem necessidade de uma gestão superior. }\end{array}$ \\
\hline Alto risco & Taxa de falência de startups é elevada. \\
\hline Não autossustentável & $\begin{array}{l}\text { Especialmente em sua fase inicial, precisam de financiamento externo para } \\
\text { sustentar suas atividades. }\end{array}$ \\
\hline $\begin{array}{l}\text { Pouca experiência de } \\
\text { trabalho }\end{array}$ & A base de uma cultura organizacional não está presente inicialmente. \\
\hline
\end{tabular}

Fonte: Giardino et al.(2014)

O primeiro passo para a criação de uma startup é a identificação de uma oportunidade, sendo esse um processo contínuo, pró-ativo e essencial para a formação de uma empresa. Apesar de esse conceito ser importante no estudo do empreendedorismo, ainda existem discussões sobre o que o constitui, bem como sobre a sua origem. Dessa maneira, o próximo tópico apresentará algumas definições de oportunidade.

\subsection{Oportunidade}

O objetivo desse tópico é apresentar diferentes conceitos de oportunidade e os processos associados ao seu reconhecimento e exploração. O intuito é convergir para um modelo teórico que propicie um instrumento para abordar o problema de pesquisa dessa dissertação.

Hansen, Shrader e Monllor (2011) examinaram dezenove anos de definições de oportunidade empresarial e processos relacionados com oportunidades, onde foram encontrados cinquenta e seis artigos em seis publicações com foco em empreendedorismo. A partir disso, os autores aglomeraram as definições conceituais semelhantes e desenvolveram 
seis definições de oportunidade e oito definições de processos relacionados à oportunidade. Por meio disso, foi possível gerar uma visão menos fragmentada da literatura. Essas definições são expostas na Tabela 2:

Tabela 2 - Definições de oportunidade

\begin{tabular}{l|l}
\hline \multicolumn{1}{c|}{ Visão } & \multicolumn{1}{c}{ Elementos comuns } \\
\hline Uma oportunidade é a & Novo/novidade; produto; \\
possibilidade de introduzir um & possibilidade; valor interno/lucro; \\
novo produto no mercado, com o & necessidade de mercado/demanda \\
intuito de se obter lucro. & de mercado.
\end{tabular}

Uma oportunidade é uma situação na qual os empreendedores visualizam ou criam novos frameworks do tipo meios-fins.
Introduzir; novo/novidade; produto; possibilidade; valor interno/lucro; necessidade de mercado/demanda de mercado.
Uma oportunidade é uma ideia que deve ser desenvolvida na forma de um negócio.

Uma oportunidade é uma percepção de um empreendedor de meios viáveis para obter e atingir benefícios.

Uma oportunidade é uma habilidade de um empreendedor em criar uma solução para um problema.

Uma oportunidade é a possibilidade de servir os consumidores diferentemente e melhor.
Nova forma de negócio; ideia/ideia de negócio; progressão do desenvolvimento.

Percepção; empreendedor; possibilidade; valor interno/lucro.

Empreendedor; demanda de mercado/necessidades de mercado; resolvendo um problema; processo criativo/criatividade

Possibilidade; valor para o mercado.

Autores
Alsos e Kaikkonen (2004);
Companys e McMullen (2007);
DeTienne e Chandler (2007); Dutta
e Crossan (2005); Eckhardt e
Ciuchta (2006); Eisenhauer (1995);
Gaglio (2004); Ko e Butler (2003);
Lee e Venkataraman (2006);
Plummer, Haynie e Godesiabois
(2007); Smith, Matthews e
Schenkel (2009).
Alsos e Kaikkonen (2004);
Companys e McMullen (2007);
DeTienne e Chandler (2007); Dutta
e Crossan (2005); Eckhardt e
Ciuchta (2006); Eisenhauer (1995);
Gaglio (2004); Ko e Butler (2003);
Lee e Venkataraman (2006);
Plummer, Haynie e Godesiabois
(2007); Smith, Matthews e
Schenkel (2009).
Anderson (2000); Ardichvili,
Cardozo e Ray (2003); Davidsson,
Hunter e Klofsten (2004); Dimov
(2007).
Brunetto e Farr-Wharton (2007);
Casson e Wadeson (2007); Dimov
(2003); Gnyawali e Fogel (1994);
Krueger (2000).
Chandler, Detienne e Lyon (2003). \\ Alsos e Kaikkonen (2004); \\ Companys e McMullen (2007) \\ e Crossan (2005); Eckhardt e \\ Ciuchta (2006); Eisenhauer (1995); \\ Gaglio (2004); Ko e Butler (2003); \\ (2007); Smith, Matthews e \\ Schenkel (2009). \\ Companys e McMullen (2007); \\ DeTienne e Chandler (2007); Dutta \\ Crossan (2005); Eckhardt \\ Ciuchta (2006); Eisenhauer (1995); \\ Lee e Venkataraman (2006); \\ Plummer, Haynie e Godesiabois \\ Anderson (2000); Ardichvili, \\ Cardozo e Ray (2003); Davidsson, \\ Hunter e Klofsten (2004); Dimov \\ Casson e Wadeson (2007); Dimov \\ Krueger (2000) \\ Chandler, Detienne e Lyon (2003).
}

Alsos e Kaikkonen (2004)

Fonte: Hansen; Shrader e Monllor (2011)

A abordagem apresentada é considerada importante para os fins deste estudo, pois define duas possibilidades para a geração de oportunidades: eventos externos ou a ação do empreendedor. Hansen, Shrader e Monllor (2011), além de definirem a oportunidade por múltiplas visões, propuseram diferentes abordagens sobre os processos relacionados ao reconhecimento de oportunidades, apresentadas na Tabela 3: 
Tabela 3 - Reconhecimento de oportunidades

\begin{tabular}{|c|c|c|}
\hline Visão & Elementos comuns & Autores \\
\hline $\begin{array}{l}\text { Um processo cognitivo de } \\
\text { reconhecimento de uma ideia e } \\
\text { transformação dessa ideia em } \\
\text { conceito de negócio. }\end{array}$ & $\begin{array}{l}\text { Reconhecer/perceber/identificar; } \\
\text { transformar uma ideia. }\end{array}$ & $\begin{array}{l}\text { Alsos e Kaikkonen (2004); } \\
\text { Anderson (2000); Davidsson, } \\
\text { Hunter e Klofsten (2004); Kickul e } \\
\text { Gundry (2000); Lumpkin e } \\
\text { Lichtenstein (2005) }\end{array}$ \\
\hline $\begin{array}{l}\text { Um processo de escanear ou estar } \\
\text { alerta }\end{array}$ & Escanear/pesquisa/alerta. & $\begin{array}{l}\text { Casson e Wadeson (2007); } \\
\text { Eisenhauer (1995); McCline, Bhat } \\
\text { e Baj (2000); Yu (2000) }\end{array}$ \\
\hline $\begin{array}{l}\text { Um processo cognitivo de articular } \\
\text { uma demanda a uma oferta }\end{array}$ & Demanda; suprimento. & $\begin{array}{l}\text { Ardichvili, Cardozo e Ray (2003); } \\
\text { Grégoire e Shepherd (2004, 2005), } \\
\text { Koen e Kleinschmidt (2005); } \\
\text { Schindehutte, Morris e Kocak } \\
(2008)\end{array}$ \\
\hline Percepção de uma necessidade & $\begin{array}{l}\text { Processo cognitivo; } \\
\text { necessidade de mercado/demanda; } \\
\text { sugestões externas de necessidades. }\end{array}$ & Haugh (2007) \\
\hline $\begin{array}{l}\text { Um processo criativo de geração de } \\
\text { novas alternativas }\end{array}$ & Criatividade. & $\begin{array}{l}\text { Gaglio (2004); Hills, Shrader e } \\
\text { Lumpkin (1999) }\end{array}$ \\
\hline $\begin{array}{l}\text { Um caso especial de resolução de } \\
\text { um problema }\end{array}$ & Resolução de um problema. & $\begin{array}{l}\text { Gaglio e Taub (1992); Harper } \\
\text { (2008) }\end{array}$ \\
\hline $\begin{array}{l}\text { Percepção de uma possibilidade de } \\
\text { criar um novo negócio ou melhorar } \\
\text { um existente }\end{array}$ & $\begin{array}{l}\text { Processo cognitivo (reconhecer/ } \\
\text { identidade/etc.); melhorar ou } \\
\text { transformar um negócio; novas } \\
\text { formas de negócios; possibilidade; } \\
\text { lucro. }\end{array}$ & $\begin{array}{l}\text { Craig e Lindsey (2001); Hills, } \\
\text { Lumpkin e Singh (1997); Ropo e } \\
\text { Hunt (1995) }\end{array}$ \\
\hline $\begin{array}{l}\text { Um processo de construção social } \\
\text { com uma janela de tempo }\end{array}$ & $\begin{array}{l}\text { Processo. } \\
\text { Cognitivo; seleção; tempo; } \\
\text { construção social. }\end{array}$ & Fletcher (2004) \\
\hline
\end{tabular}

Fonte: Hansen; Shrader e Monllor (2011)

Nota-se que as oportunidades estão relacionadas à inovação à medida que ela ocorre mais frequentemente quando um problema e um meio para resolvê-lo são associados. A inovação está atrelada, portanto, com a gestão de oportunidades que combina elementos como criatividade, conhecimento e empreendedorismo, ou seja, é uma etapa complexa, pois requer o desenvolvimento de processos com a finalidade de trazer a ideia para o mercado, sendo esses processos diretamente relacionados com as incertezas enfrentadas pelos empreendedores. 


\subsection{Inovação}

Esse tópico estabelece o referencial teórico que sintetiza elementos oriundos de diversos campos conceituais da inovação e, além disso, é descrito o ambiente em que a inovação é mais recorrente e as fases de seu desenvolvimento.

Aulet (2013) afirma que inovação pode ser definida como:

Inovação = Invenção * Comercialização

Ou seja, a inovação não é a soma de invenção e comercialização, mas uma multiplicação. Se houver comercialização, mas sem invenção (=0 invento), ou invenção, sem comercialização (comercialização $=0$ ), então não há inovação.

Segundo Oliva et al. (2014), a inovação não ocorre fora do contexto ou isoladamente a partir de uma situação, mas sim a partir de fontes de ideias que já estavam dentro da organização e que são testadas e aplicadas.

Garcia e Calantone (2002), por sua vez, afirmam que o processo de inovação compreende o desenvolvimento tecnológico de uma invenção combinado com sua introdução no mercado. Esse processo é naturalmente iterativo e possui diversos graus, que tornam necessária uma tipologia para descrever os diferentes modelos.

Inovações, muitas vezes, criam demandas previamente não reconhecidas pelo consumidor. Estas novas demandas cultivam novas indústrias com novos concorrentes, canais de distribuição e atividades de marketing (GARCIA; CALANTONE, 2002).

De acordo com Garcia e Calantone (2002) existem duas variáveis para classificar o tipo de inovação de produto: a perspectiva macro ou micro e a descontinuidade tecnológica ou de mercado, explicadas a seguir.

Perspectiva macro: é quando o produto introduz uma novidade para o mundo, para o mercado ou para a indústria. Já a perspectiva micro ocorre quando a inovação é uma novidade para a própria empresa ou para o cliente.

Descontinuidade tecnológica ou de mercado: relacionada à origem da descontinuidade introduzida pela inovação. Produtos podem ser inovadores por estarem ligados a novos espaços do mercado e requererem novas habilidades mercadológicas da organização. Por outro lado, novos produtos podem surgir por meio de avanços tecnológicos e científicos, ou uma combinação de ambas as perspectivas (GARCIA; CALANTONE, 2002).

Garcia e Calantone (2002) propõem um método para uniformização da nomenclatura utilizada na determinação do grau de inovação. A tipologia proposta apresenta quatro tipos de inovação, representadas pela Figura 2: 


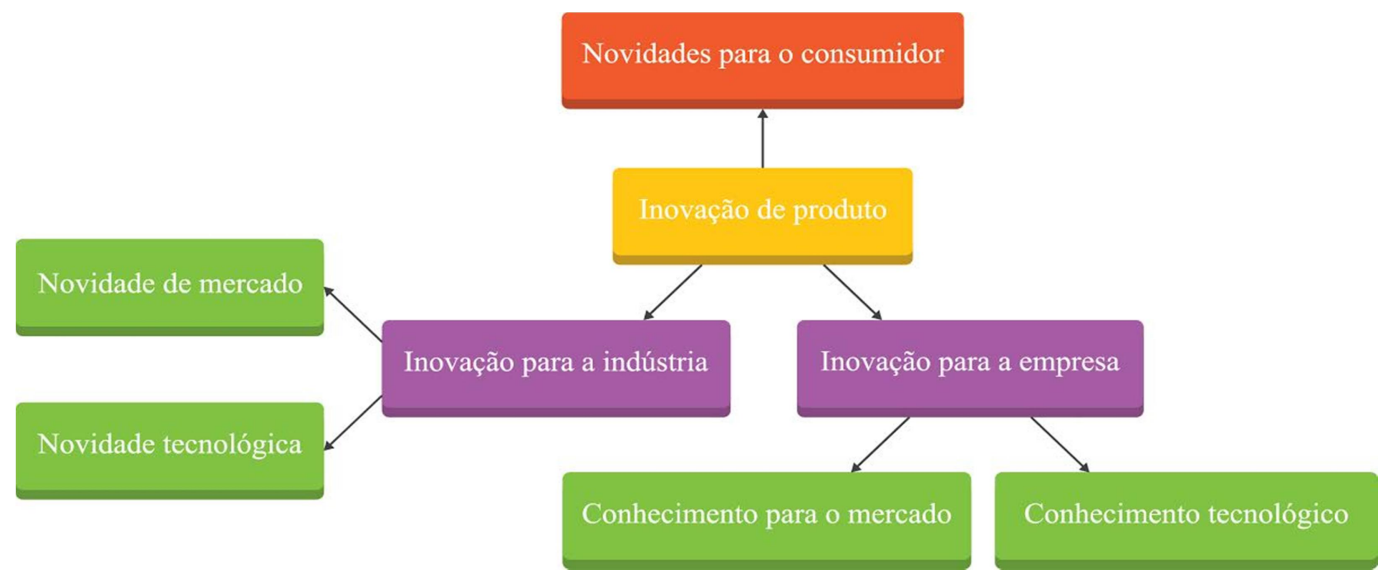

Figura 2- Organização da inovação

Fonte: Garcia e Calantone (2002)

1) Radical, que introduz macro descontinuidades tecnológicas e de mercado, pois criam uma demanda previamente não reconhecido pelo consumidor. Esta nova demanda gera novas indústrias com novos concorrentes e canais de distribuição, por exemplo. Reforçando essa definição, Leifer, O‘Connor e Rice (2001), afirmam que a inovação radical é um produto ou serviço que apresenta desempenho sem precedentes;

2) Novo produto, que introduz somente um tipo de macro descontinuidade: ou tecnológica, ou de mercado;

3) Incremental, que apresenta micro descontinuidades tecnológicas, de mercado, ou ambas, e que fornecem novos recursos, benefícios ou aperfeiçoamentos de uma tecnologia existente para um mercado já existente; e,

4) Inovações Imitativa. A inovação ocorre apenas na primeira empresa a lançar o produto no mercado. Inovações rivais são designadas imitações. São novas para a empresa, mas não para o mercado.

A inovação é um desafio complexo para as organizações, pois relaciona elementos tecnológicos com a dinâmica de mercado, ou seja, são diversas variáveis que podem impedir o sucesso de uma tecnologia. Galia e Legros (2004) sugerem que as principais dificuldades relacionadas à inovação são:

-Falta de informações sobre a tecnologia, que pode ser causada pela ausência de prospecção tecnológica;

-Falta de informações sobre o mercado, causada pela inexistência de processos de mapeamento de oportunidades e/ou inteligência competitiva ineficaz;

-Falta de informações sobre o consumidor, devido ao processo de prospecção de tendências de consumo inexistente ou não efetivo; e, 
-Falta de pessoal qualificado.

Seguindo essa linha, Garcia, Bardhi e Friedrich (2007), afirmam que no desenvolvimento de estratégias de desenvolvimento, as empresas, muitas vezes, ignoram as respostas comportamentais dos consumidores às inovações. De acordo com os autores, programas de marketing, com frequência, se concentram nas vantagens dos atributos dos produtos sobre os concorrentes. No entanto, a comercialização de uma inovação requer que a empresa resolva não apenas isso, mas também a mentalidade do consumidor em relação ao novo produto, por exemplo.

Todavia, é plausível que certos problemas não sejam efetivamente encontrados até o lançamento em si. Isto pode ser explicado pelo fato de que a inovação envolve um processo de aprendizagem (GALIA; LEGROS, 2004).

Com relação ao ambiente de inovação, segundo Stringer (2000), o tamanho corporativo é inversamente correlacionado com o crescimento por meio da inovação. Historicamente, de acordo com o autor, as pequenas empresas têm produzido 2,4 vezes mais inovações por empregado comparado às grandes empresas.

Isto pode estar relacionado com o fato de que inovações radicais exigem mudanças na capacidade de produção, distribuição e relacionamento com os clientes. Essas mudanças ameaçam o status quo e perturbam os sistemas de hierarquias sociais, característicos de grandes empresas, e por isso encontram mais barreiras (STRINGER, 2000).

Outro fator importante para a inovação ocorrer em pequenas empresas é que os inovadores tendem a ser empreendedores, que buscam empresas onde possam ter mais independência no seu trabalho. Startups são mais ágeis, menos burocráticas e mais rápidas em testar o mercado para adaptar o produto até torná-lo bem-sucedido, o que atrai esse perfil de candidato (STRINGER, 2000).

Utterback (1996), por sua vez, sugere que a taxa de inovação na indústria ocorre nos seus primeiros anos, como pode-se observar na Figura 3. Este é um período chamado de "fase fluída", na qual pioneiros do mercado propõem elevada variedade de designs, com concorrência crescente e alta instabilidade mercadológica. Durante essa fase de alta inovação de produto, pouca atenção é dada aos processos, por isso, a taxa de inovação nesse período é significativamente menor. 


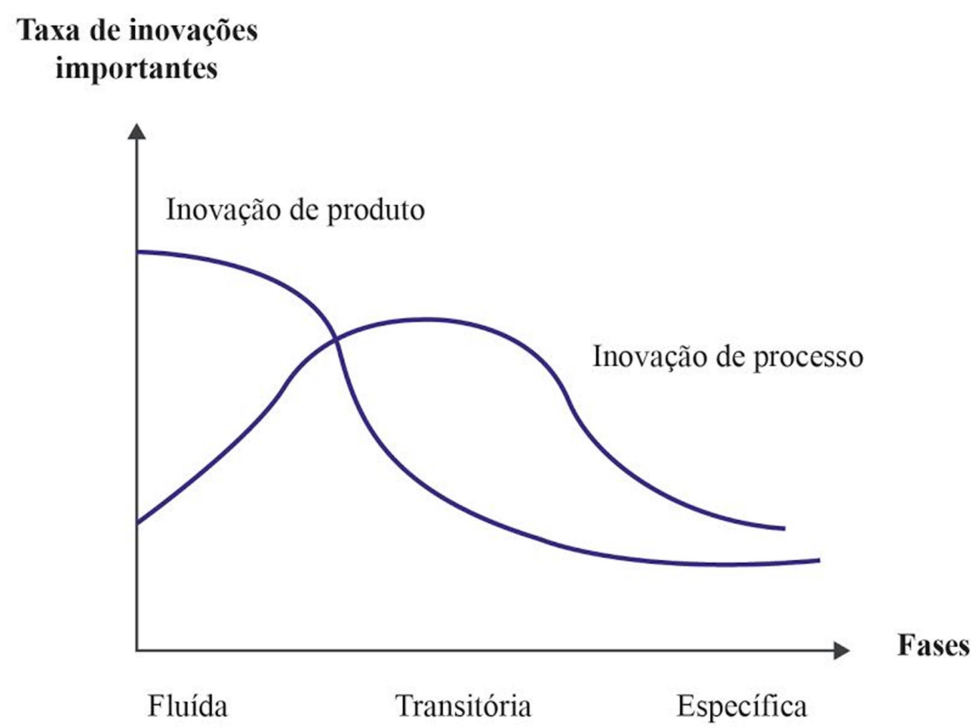

Figura 3 - Fases da Inovação

Fonte: Utterback (1996)

O período de fluidez, de acordo com esse modelo, dá lugar a uma "fase de transição", na qual a taxa de inovação de produto diminui e a taxa de processos se acelera. Neste ponto, a variedade de produtos começa a ser substituída por projetos padronizados que serão produzidos em maior escala (UTTERBACK, 1996).

A esse estágio segue a fase específica, na qual o esforço se concentra nas melhorias incrementais na qualidade e produtividade, com produção em larga escala e elevada especialização para a produção de modelos específicos (UTTERBACK, 1996).

Ou seja, a competitividade alcançada por meio da inovação logo volta ao ponto de partida, na medida em que os demais competidores as copiam para si (TIDD; BESSANT; PAVITT, 2008). Daí a necessidade de a organização estar sempre buscando se renovar para manter sua vantagem competitiva.

Dentro desse contexto, com relação ao gerenciamento da inovação, um dos modelos mais relevantes é o proposto por Cooper (1990) denominado Stage-Gate® que é um sistema formado por uma série de estágios, com cada um deles constituído por um conjunto de atividades. Cada estágio é projetado para reunir informações com o fim de reduzir as incertezas do processo. De acordo com o autor, o sistema de Stage-Gate produz resultados positivos em termos de obtenção de novos produtos e serviços para o mercado com rapidez, eficiência e rentabilidade. 


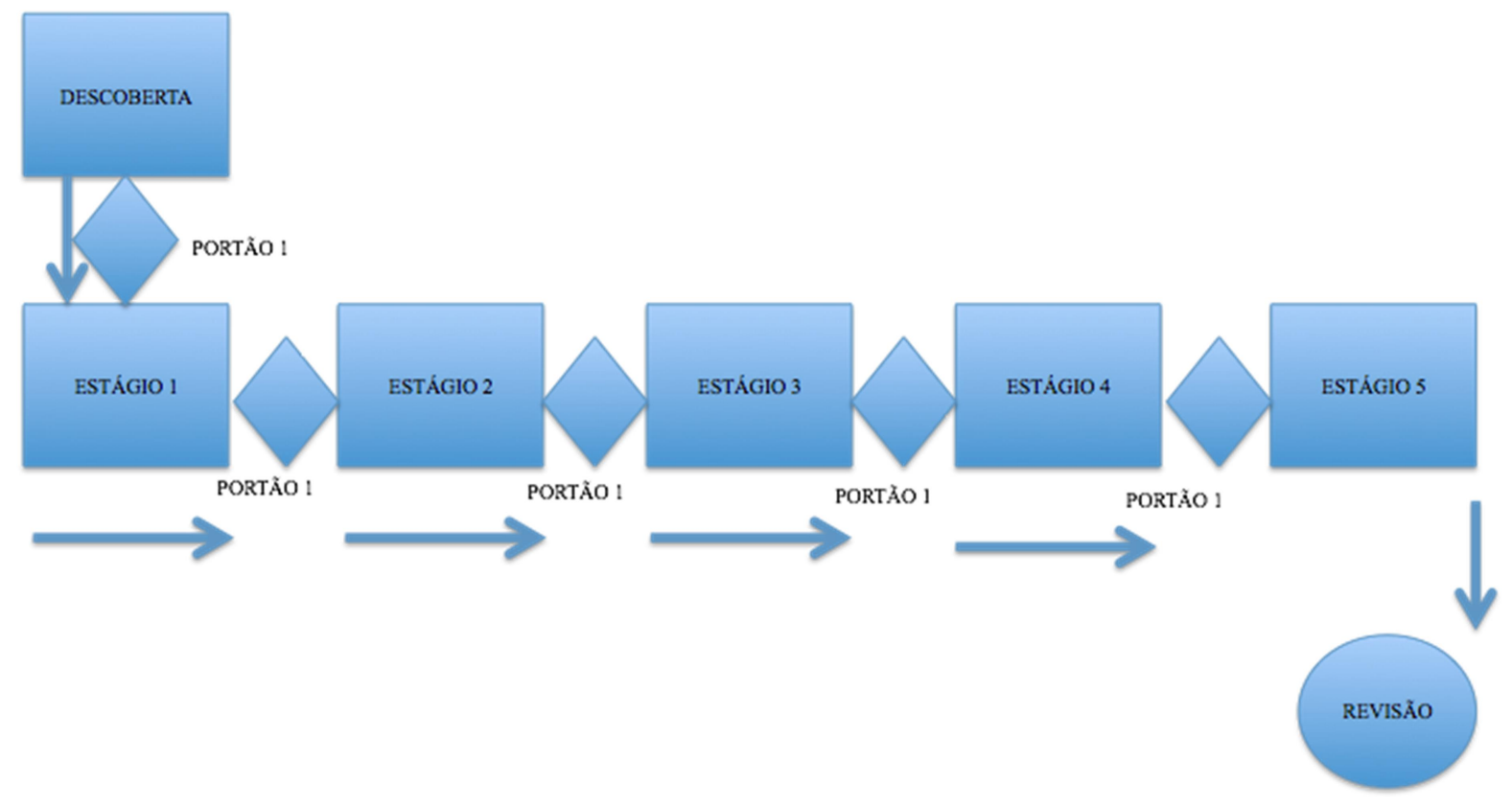

Figura 4 - Etapas Stage Gate

Fonte: Cooper (1990)

Na Figura 4, pode-se observar os cinco estágios e os cinco pontos de tomada de decisão (portões) até o lançamento do produto:

Estágio 0 - etapa destinada para a seleção de oportunidades de negócios.

Portão 1 - onde são verificados o alinhamento estratégico do produto e sua aceitação pelo mercado (por meio de contatos com clientes, grupos foco e teste de conceito) e a capacidade de desenvolvimento técnico da empresa.

Estágio 1 - etapa de investigação rápida e desenho do escopo do projeto. É uma fase de pouco investimento e com objetivo de realizar uma avaliação preliminar do mercado e seu potencial. Além disso, pode-se projetar os custos e a viabilidade de desenvolvimento e tempo de execução. Essa etapa proporciona, assim, uma breve avaliação em um curto espaço de tempo, de modo que o projeto pode ser reavaliado mais profundamente no portão 2 .

Portão 2 - esse portão é essencialmente uma repetição do portão 1, pois nele o projeto é reavaliado, mas levando em consideração as informações obtidas na Fase 1. Nesta etapa tem-se uma visão mercadológica detalhada do produto e sua especificação técnica.

Estágio 2 - essa é a etapa final antes do desenvolvimento do produto. Devem ser realizadas pesquisas de mercado para determinar as necessidades do cliente que definem os requisitos do produto e, além disso, desenhado um plano de ação detalhado (tanto técnico, quanto comercial) para as próximas etapas. 
Portão 3 - é o ponto de tomada de decisão final antes do início do desenvolvimento. Este é o último momento onde se pode cancelar o projeto. Ocorre uma análise financeira detalhada, envolvendo uma abordagem de fluxo de caixa descontado, por exemplo.

Estágio 3 - essa etapa consiste no desenvolvimento do novo produto. Além disso, as operações são mapeadas e o plano de lançamento para a próxima fase é definido.

Portão 4 - onde ocorre a autorização para a realização da etapa de testes detalhados do produto.

Estágio 4 - etapa de verificação e validação do novo produto proposto e sua comercialização.

Portão 5 - ponto de validação dos ajustes finais para garantir um lançamento bem sucedido.

Estágio 5 - etapa do lançamento, que marca o início da operação comercial.

De acordo com Cooper (2014), o sistema Stage-Gate original foi criado na década de 1980, com base num estudo com "intra-empreendedores" bem sucedidos em grandes corporações. Todavia, ao longo dos anos, o Stage-Gate evoluiu para poder se adequar ao novo ritmo de competição da economia, tornando-se mais lean, flexível e rápido, por meio da incorporação do desenvolvimento interativo (espirais) composto de ciclos de construçãoteste-revisão. A Tabela 4, a seguir, apresenta uma comparação entre a tradicional versão do Stage-Gate com a versão atualizada. 
Tabela 4 - Stage Gate tradicional e Stage Gate próxima geração

\begin{tabular}{|c|c|c|}
\hline Contexto & Stage-Gate tradicional & Próxima Geração Stage-Gate \\
\hline Situação & $\begin{array}{l}\text { Mercado Maduro; } \\
\text { Mercado e consumidor } \\
\text { conhecidos; } \\
\text { Conhecimento sobre a tecnologia; } \\
\text { Pequeno risco de mercado ou de } \\
\text { tecnologia. }\end{array}$ & $\begin{array}{l}\text { Mercado existente e de } \\
\text { crescimento rápido; } \\
\text { Grande incerteza de mercado e de } \\
\text { tecnologia. }\end{array}$ \\
\hline Tipo do produto & $\begin{array}{l}\text { Novo item em uma linha de } \\
\text { produtos, melhoria do produto, } \\
\text { modificação ou } \\
\text { renovação. }\end{array}$ & $\begin{array}{l}\text { Inovação, iniciativa de maior } \\
\text { risco. }\end{array}$ \\
\hline Necessidades dos clientes & $\begin{array}{l}\text { Bem definidas e estáveis ao longo } \\
\text { do tempo. } \\
\text { (via pesquisa de mercado } \\
\text { tradicional). }\end{array}$ & Pouco definidas. \\
\hline Tamanho do mercado & $\begin{array}{l}\text { Grande e definido. Pode estar } \\
\text { amadurecido ou mesmo em } \\
\text { declínio. }\end{array}$ & $\begin{array}{l}\text { Não necessariamente grande, mas } \\
\text { crescente. }\end{array}$ \\
\hline Competição & $\begin{array}{l}\text { Muitos concorrentes, produtos } \\
\text { indiferenciados, tendendo a } \\
\text { comoditização. }\end{array}$ & $\begin{array}{l}\text { Alguns concorrentes iniciais, sem } \\
\text { solução dominante. }\end{array}$ \\
\hline Maturidade da tecnologia & Madura, bem definida. & Tecnologia recente. \\
\hline Riscos técnicos & $\begin{array}{l}\text { Poucos riscos; Obstáculos técnicos } \\
\text { podem ser } \\
\text { superados facilmente. }\end{array}$ & $\begin{array}{l}\text { Número maior de riscos que } \\
\text { provavelmente podem ser } \\
\text { superados. }\end{array}$ \\
\hline
\end{tabular}

Fonte: Cooper (2014)

Nessa nova proposta, a definição do produto geralmente é inferior a 50\% no início do seu desenvolvimento e sua evolução ocorre de acordo com o feedback dos clientes durante as diversas fases de experimentação.

Cada ciclo de construção-teste-revisão sugerido por esse modelo e apresentado na Figura 5, pode ser resumido da seguinte forma:

Construção - cada iteração procura mostrar ao cliente uma versão-beta para avaliação.

Teste - procura entender a avaliação do cliente sobre essas versões para conseguir a partir desse retorno avançar no desenvolvimento do produto.

Feedback - coleta feedback do usuário sobre todas as versões do produto. 
Revisão - Redefinição da proposta de valor e nova concepção do produto (com base no feedback para assim recomeçar o ciclo).

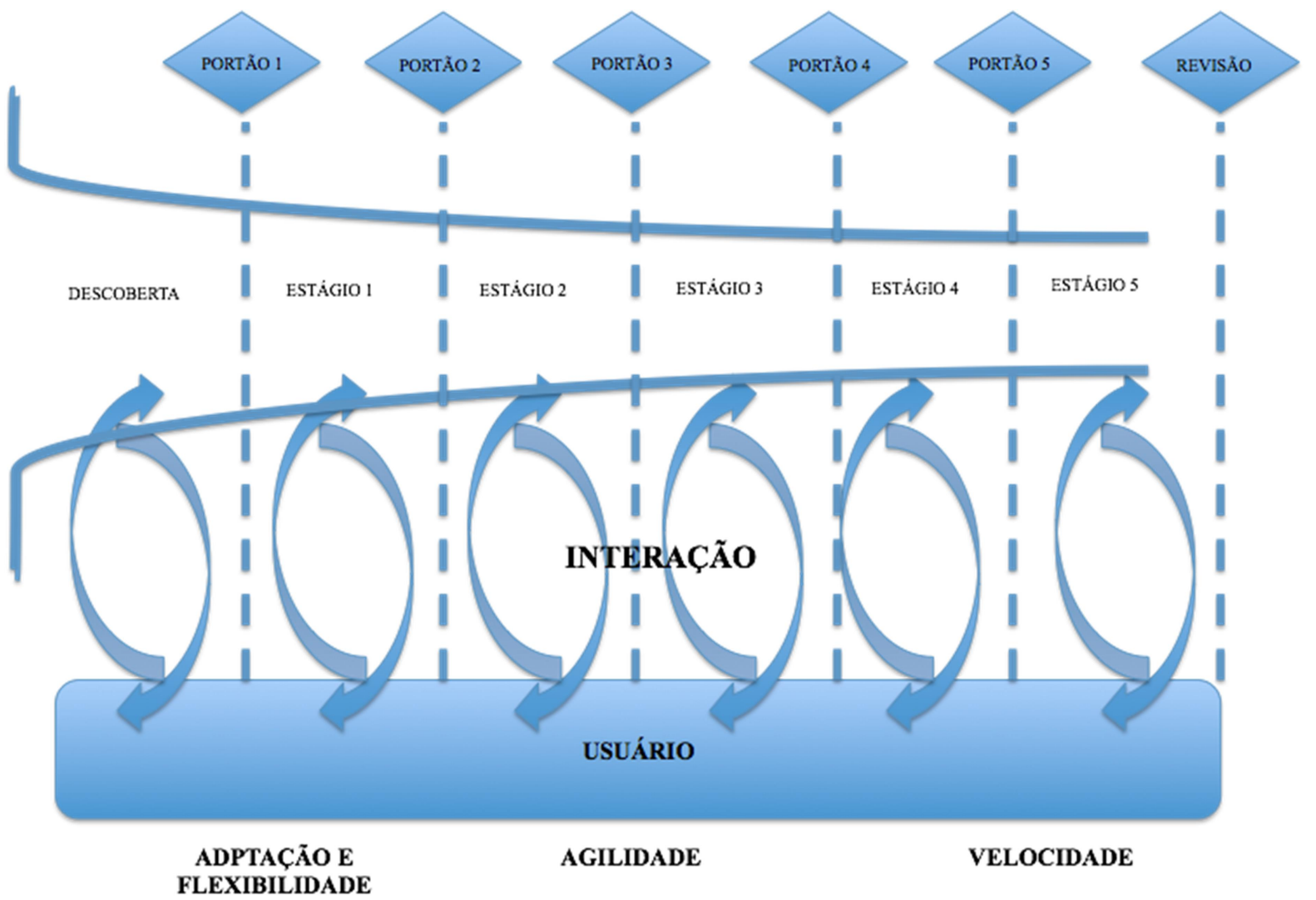

Figura 5 - Stage Gate nova geração

Fonte: Cooper (2014)

Nesse formato, o processo de introdução de um novo produto, da ideia ao lançamento, é visto como uma série de etapas concebida para recolher informações que reduzem a incerteza e risco do projeto.

Conforme pode-se observar, a intensificação da concorrência internacional e as rápidas mudanças tecnologias fizeram o processo de inovação mais complexo e o seu resultado consideravelmente mais incerto. Nesse contexto, a inovação bem-sucedida é em grande medida uma questão de identificação e controle de riscos. Dessa maneira, apresentadas as abordagens de inovação, o próximo tópico explora as dimensões de risco e incerteza. 


\subsection{Risco e Incerteza}

O objetivo desse tópico é de apresentar um conceito inicial de risco e incerteza para tornar claro ao leitor o que é considerado quando esses termos são citados na pesquisa.

Todas as organizações enfrentam incertezas e o desafio de seus administradores é determinar até quando aceitá-las e definir como essas incertezas podem interferir no esforço para gerar valor às partes interessadas. Incertezas representam riscos e oportunidades, com potencial para destruir ou agregar valor (COSO, 2007).

A incerteza é uma propriedade da natureza que resiste à quantificação, e, portanto, não pode ser efetivamente reduzida a probabilidades e cenários (DAVIS, 2002). Risco, por sua vez, é calculável e pode ser expresso em termos de probabilidades (NOHRIA; STEWART, 2006).

O risco é representado pela possibilidade de que um evento ocorra e afete negativamente a realização dos objetivos (COSO, 2007).

Segundo Jorion (2009), os riscos podem ser classificados em três categorias: "known knowns", "known unknowns", e "unknown unknowns":

- Known knowns: Um sistema de medição de riscos impecável, onde os riscos são perfeitamente medidos. Isto implica a identificação correta de todos os fatores de riscos e a medição adequada da sua distribuição. Neste caso, as perdas ainda podem ocorrer devido à combinação de azar com exposição excessiva.

Nessa linha, Blank e Dorf (2012) afirmam que empresas estabelecidas executam modelos de negócio onde os clientes, os seus problemas e as características do produto necessárias são knowns. Em contraste, startups operam no modo "pesquisa", em busca de um modelo de negócios repetível e rentável. A busca de um modelo de negócio exige regras, roteiros e conjuntos de habilidades e ferramentas diferentes, a fim de minimizar os riscos e otimizar chances de sucesso.

- Known unknowns: Considera que os sistemas de gestão de riscos têm inúmeros pontos cegos. Primeiro, o gerente de risco pode ignorar fatores de risco importantes. Em segundo lugar, a distribuição de fatores de risco, incluindo volatilidades e correlações, pode ser medida de forma imprecisa. De acordo com Kahneman (2012), essa questão pode ser ilustrada da seguinte maneira: as chances de que um pequeno negócio sobreviva, por cinco anos, nos Estados Unidos são de aproximadamente 35\%. Mas os indivíduos que abrem esse tipo de negócio não acreditam que as estatísticas se apliquem a eles. Segundo o autor, os empresários americanos tendem a acreditar que estão numa linha de negócios promissora: de 
acordo com a opinião dos empresários as chances de sucesso para "qualquer negócio como o seu" eram avaliadas em 60\% — quase o dobro do valor verdadeiro. (KAHNEMAN, 2012)

- Unknown unknowns: A última categoria de riscos engloba eventos totalmente fora do âmbito da maioria dos cenários, sendo então impossível prevê-los. Como exemplo, a instabilidade política de um país que pode impactar sua economia em curto período de tempo.

Outra divisão dos riscos pode ser encontrada em COSO (2007), que os estabelecem em quatro categorias:

- Estratégico - metas de alto nível;

- Operações - utilização eficaz e eficiente dos recursos;

- Relatórios - confiabilidade dos relatórios;

- Compliance - conformidade com leis e regulamentos aplicáveis.

Adaptando o framework de COSO, Kambil e Mahidhar (2005) desenvolveram uma classificação em quatro categorias de riscos gerais:

Riscos estratégicos: tais como deficiências de demanda e problemas em fusões.

Riscos Operacionais: como excesso de custos, problemas de contabilidade, falhas nos controles internos e falhas na cadeia de suprimentos.

Riscos financeiros: tais como a elevada dívida, reservas inadequadas para gerir os aumentos nas taxas de juros, má gestão financeira e perdas comerciais.

Riscos externos: tais como crises do setor específicas de cada país, questões políticas ou econômicas.

Nesse trabalho, os riscos estratégicos foram abordados com maior amplitude. Dessa forma, uma definição mais profunda desse tipo de risco foi exposta abaixo:

Riscos estratégicos são aqueles que as empresas aceitam voluntariamente, a fim de gerar retornos superiores. São diferentes dos riscos evitáveis, porque eles não são indesejáveis. Uma estratégia com altos retornos esperados, geralmente exige que a empresa assuma riscos significativos e gerenciar esses riscos é um fator-chave na captura de ganhos potenciais (KAPLAN; MIKES, 2012).

Riscos estratégicos não podem ser geridos por meio de um modelo de controle baseado em regras. Em vez disso, a empresa precisa de um sistema de gestão de riscos concebido para reduzir a probabilidade de que os riscos assumidos se materializem, aprimorando a sua capacidade de gerenciar ou conter os eventos de riscos, caso eles ocorram (KAPLAN; MIKES, 2012). 
Conclui-se que o gerenciamento de riscos possibilita aos administradores tratar com eficácia as incertezas, bem como os riscos e as oportunidades a elas associadas, a fim de melhorar a capacidade de geração de valor (COSO, 2007).

\subsection{Avaliação dos riscos - Modelo NPVR e Maturity Level in Enterprise Risk Management}

No desenvolvimento de um novo produto para o mercado, o risco estratégico possui maior relevância, por envolver pontos importantes para a adesão do produto. Dentro desse contexto, de acordo com Oliva (2015) os riscos de um negócio podem ser de diferentes naturezas e podem ter diferentes graus de importância para cada agente.

Nesse sentido, Davis (2002) desenvolveu a visão da Net Present Value Risk Analysis (NPVR), ou valor presente líquido (VPL) ajustado ao risco do desenvolvimento de um novo produto, um modelo que oferece ferramentas quantitativas destinadas a aumentar o ROI (Return On Investment) ampliando a probabilidade de sucesso de um produto. Essa visão é vantajosa, na medida em que modelos mais tradicionais como árvores de decisão e as opções reais são complexos e requerem informações que podem não estar prontamente disponíveis no início do processo de desenvolvimento.

Ao se concentrar em algumas áreas críticas de avaliação, os principais riscos do negócio são expostos e a previsibilidade no desenvolvimento de novos produtos é ampliada. O modelo NPVR depende do uso de experiência e julgamento, para avaliar subjetivamente o risco relativo. Todavia, ao invés de exigir uma estimativa de probabilidade, as pontuações são escalonadas em alta, média e baixa. Assim, ao contar com um vocabulário simples, o modelo evita as discussões comuns e improdutivas que podem ocorrer sobre a precisão das estimativas. As avaliações qualitativas podem ser facilmente convertidas em valores numéricos após um consenso. No modelo NPVR, isso é feito através da atribuição de ranking mais positivo (alta chance de sucesso) ao valor 5, e de ranking mais negativo (baixa probabilidade de sucesso) ao valor de 1, numa escala de 1 a 5 .

Usando essas avaliações, os tomadores de decisão podem comparar o valor presente líquido (VPL) ajustado ao risco (NPVR) ao VPL tradicional. Isso permite aos gestores compreenderem qual parte do NPV (Net present value) de um negócio proposto está em risco, focando nos principais pontos, permitindo assim que diversos projetos sejam avaliados de forma rápida e consistente. 
Para isso, Davis (2002) determinou duas divisões de riscos necessárias para o desenvolvimento de sua metodologia, que contribuem para determinar os riscos e suas classificações:

- Categoria de produto;

- Técnica, mercadológica e de usuário;

Nessa linha, a divisão por categoria de produto possui quatro itens:

New Ventures - são os "novos para o mundo", que representam o primeiro de seu tipo e necessitam da criação de um mercado totalmente novo - por exemplo, MP3 players. Apesar de novos empreendimentos serem mais frequentemente associados com startups, o termo é igualmente aplicável à inovação em empresas estabelecidas. Estes produtos representam cerca de $10 \%$ de todos os produtos novos.

Novas categorias - são "novos para a empresa" e incluem novas linhas de produtos, que têm como alvo um mercado estabelecido em que a empresa não compete atualmente - por exemplo, a entrada da Sony em computadores pessoais com seus produtos VAIO.

Novas plataformas - frequentemente são adições às linhas de produtos existentes, embora os próprios produtos possam ser bastante inovadores. Plataformas criam a base para futuros produtos derivados, proporcionando um melhor conhecimento do mercado e knowhow de fabricação. Por exemplo, a maioria dos celulares, tais como a linha 5xxx Nokia, são a base de plataforma.

Novos produtos - são derivados de melhorias e revisões de produtos existentes, incluindo reduções de custos - por exemplo, as evoluções de impressoras jato de tinta da Hewlett-Packard.

A Tabela 5 foi desenvolvido por Davis (2002) após pesquisar 200 empresas, e indica a distribuição dos riscos - de mercado, técnico ou de usuário - em cada uma dessas categorias. 
Tabela 5 - Distribuição dos riscos por categoria

\begin{tabular}{cc|c|c|c}
\hline & $\begin{array}{c}\text { Risco de Mercado } \\
(\mathrm{M})\end{array}$ & Risco Técnico (T) & Risco de Usuário (U) & Total \\
\hline New Ventures & 0.45 & 0.1 & 0.45 & 1 \\
$\begin{array}{c}\text { Novas } \\
\text { Categorias }\end{array}$ & 0.4 & 0.2 & 0.4 & 1 \\
$\begin{array}{c}\text { Novas } \\
\text { Plataformas }\end{array}$ & 0.35 & 0.35 & 0.3 & 1 \\
$\begin{array}{c}\text { Novos Produtos } \\
\text { Derivados }\end{array}$ & 0.3 & 0.6 & 0.1 & 1 \\
\hline
\end{tabular}

Fonte: Davis (2002)

Adicional à divisão por categoria, o autor define os riscos de mercado, tecnológico e de usuário apresentados a seguir.

\subsubsection{Avaliação de Risco de Mercado}

A verdadeira inovação disruptiva acontece em ambientes em que o produto final e sua proposta de valor, preço, marketing, canais de vendas, e, mais importante, seus clientes são, na melhor das hipóteses, suposições (COOPER; VLASKOVITS, 2013).

Dessa maneira, o maior risco e, portanto, a maior causa de fracasso de startups não é o desenvolvimento de um novo produto, mas o desenvolvimento de clientes e mercados. Startups não falham porque não têm um produto; falham porque faltam clientes e um modelo financeiro comprovado (BLANK, 2013).

Nesse contexto, o risco de mercado engloba qualquer elemento da cadeia de valor exigido para que um novo produto atinja seus clientes potenciais. Isso inclui fatores como capacidade da força de vendas, canais de distribuição, capacidade de fabricação e suporte ao cliente. Cada elemento deve ser compreendido e avaliado. Além disso, o sucesso será influenciado pela presença atual da empresa no segmento de mercado-alvo.

Critérios de pontuação para riscos de mercado são resumidos a seguir (Tabela 6): 
Tabela 6 - Critérios para avaliação de riscos da cadeia de valor e segmento de mercado

\begin{tabular}{|c|c|c|}
\hline Pontuação & Avaliação da cadeia de valor & Avaliação do segmento de mercado \\
\hline Alta & $\begin{array}{l}\text { Todos os requisitos da cadeia de } \\
\text { valor existem internamente na } \\
\text { empresa }\end{array}$ & $\begin{array}{l}\text { Empresa é líder de mercado no } \\
\text { segmento de mercado-alvo }\end{array}$ \\
\hline Média & $\begin{array}{c}\text { Todos os requisitos da cadeia de } \\
\text { valor existentes, alguns por meio de } \\
\text { parceiros }\end{array}$ & $\begin{array}{l}\text { Empresa vende outros produtos para } \\
\text { clientes no segmento de mercado }\end{array}$ \\
\hline Baixa & $\begin{array}{l}\text { Algumas ou todas as necessidades da } \\
\text { cadeia de valor não estão presentes } \\
\text { dentro da empresa ou com parceiros } \\
\text { existentes }\end{array}$ & $\begin{array}{l}\text { Novo segmento de mercado, ou a } \\
\text { empresa não tem presença no } \\
\text { segmento de mercado-alvo }\end{array}$ \\
\hline
\end{tabular}

Fonte: Davis (2002)

Uma pontuação mediana é um aviso de que os pressupostos considerados precisam ser revisados, enquanto uma pontuação baixa exige que uma estratégia seja desenvolvida para aumentar a probabilidade de sucesso, antes da aprovação. Se a estratégia não for identificada na proposta ou se os recursos adequados não estiverem disponíveis dentro da empresa, parceiros externos podem fornecer parte da solução.

\subsubsection{Avaliação de Riscos Técnicos}

Riscos técnicos estão relacionados com o produto, bem como as capacidades de desenvolvimento da empresa. Mede-se a experiência da equipe em projetos semelhantes e o quanto é completa com relação às necessidades internas para o desenvolvimento do produto. Pontuação destes fatores está resumida na Tabela 7:

Tabela 7- Critérios para avaliação de riscos de inovação e recursos

\begin{tabular}{|c|c|c|}
\hline Pontuação & Avaliação da Inovação & Avaliação de Recursos \\
\hline Alta & $\begin{array}{c}\text { Utilização incremental de tecnologia bem } \\
\text { entendida }\end{array}$ & $\begin{array}{l}\text { Equipe de desenvolvimento com } \\
\text { experiência em projeto semelhante }\end{array}$ \\
\hline Média & $\begin{array}{l}\text { Nova tecnologia, protótipos desenvolvidos e } \\
\text { testados }\end{array}$ & $\begin{array}{l}\text { Nova equipe de desenvolvedores } \\
\text { com alguma experiência em } \\
\text { projetos semelhantes }\end{array}$ \\
\hline Baixa & $\begin{array}{l}\text { Nova tecnologia, fase de prova de conceito } \\
\text { com teste limitado }\end{array}$ & $\begin{array}{l}\text { Equipe incompleta e limitada } \\
\text { experiência em projetos } \\
\text { semelhantes }\end{array}$ \\
\hline
\end{tabular}

Fonte: Davis (2002) 
Riscos de inovação devem ser avaliados não só em termos da tecnologia em si, mas também do grau em que a tecnologia é integrada aos processos existentes internamente.

\subsubsection{Avaliação de Riscos de Usuário}

Enquanto o risco de mercado determina a capacidade da empresa para vender e dar suporte ao produto, e risco técnico determina sua capacidade para construir o produto, o risco do usuário determina a probabilidade de que a empresa esteja desenvolvendo o produto certo. Avaliação de risco do usuário se concentra no grau em que os atributos de interação do usuário com o produto são conhecidos e o grau em que as especificações de design e desempenho são entendidas. Critérios desses atributos são resumidos na Tabela 8:

Tabela 8 - Critérios para avaliação de riscos de interação e especificação

\begin{tabular}{c|c|c}
\hline Pontuação & Avaliação da Interação & Avaliação da Especificação \\
\hline Alta & $\begin{array}{c}\text { Pesquisa com o usuário primário } \\
\text { realizada ou planejada antes do } \\
\text { desenvolvimento }\end{array}$ & $\begin{array}{c}\text { Extensão de design de produto e } \\
\text { especificação de desempenho } \\
\text { existentes }\end{array}$ \\
Média & $\begin{array}{c}\text { Pesquisa com o usuário não } \\
\text { realizada, mas pesquisa com um } \\
\text { produto secundário realiza }\end{array}$ & $\begin{array}{c}\text { Nova especificação de design e } \\
\text { desempenho no segmento de } \\
\text { mercado existente }\end{array}$ \\
Baixa & $\begin{array}{c}\text { Pesquisa com usuário não } \\
\text { realizada, atributos do usuário } \\
\text { atribuídos por equipe interna }\end{array}$ & $\begin{array}{c}\text { Novo design e especificação de } \\
\text { desempenho no segmento do } \\
\text { Novo Mercado }\end{array}$ \\
\hline
\end{tabular}

Fonte: Davis (2002)

\subsubsection{Cálculo do NPVR}

A partir dos dados coletados pelo modelo apresentado posteriormente, o NPVR é calculado da seguinte forma:

$\mathrm{NPVR}=((\mathrm{aM}+\mathrm{bM}+\mathrm{cT}+\mathrm{dT}+\mathrm{eU}+\mathrm{fU}) / 10) \times$ Valor Presente Líquido

Onde a, b, c, d, e, f são as avaliações da cadeia de valor, segmento de mercado, inovação, recursos, capacidades de interação e de especificação, respectivamente, sendo que cada um desses itens deve ser classificado em uma escala de 1 a 5 . Os valores para a ponderação de risco, M (de mercado), T (técnico) e U (usuário), são escolhidos de acordo com a categoria do produto.

Conclui-se assim que modelo NPVR fornece, por exemplo, insights sobre como a pesquisa do usuário pode afetar as estimativas de sucesso de um produto. A realização de 
pesquisa do usuário, no início do ciclo de desenvolvimento, deve melhorar a avaliação do risco de interação e mudar a probabilidade de sucesso nessa área, de baixa para alta.

De fato, não há garantia de que o produto será bem-sucedido em termos absolutos, se a pesquisa for realizada (por exemplo), mas na comparação de propostas dentro de uma categoria, aquelas com pontuações mais altas são mais propensos a ter sucesso do que aquelas com pontuações baixas. Uma análise semelhante pode ser realizada para avaliar a mitigação de riscos de mercado, de usuário e técnico.

Complementar a essa visão, para avaliar os riscos dos casos apresentados nesse estudo considerou-se a abordagem de Oliva (2015) apresentada na Maturity Level in Enterprise Risk Management que propõe que os riscos de um negócio podem ser de diferentes naturezas e ter diferentes graus de importância para cada agente, sendo que o ambiente de negócios inclui várias organizações e forças macro e micro ambientais. Também é relevante considerar que nesses ambientes atuam diversos agentes. As forças ambientais no microambiente são manifestadas pelo poder de negociação, o oportunismo, a inovação e a estratégia de seus agentes. A Figura 6 apresenta a distribuição dos riscos segundo o autor: 


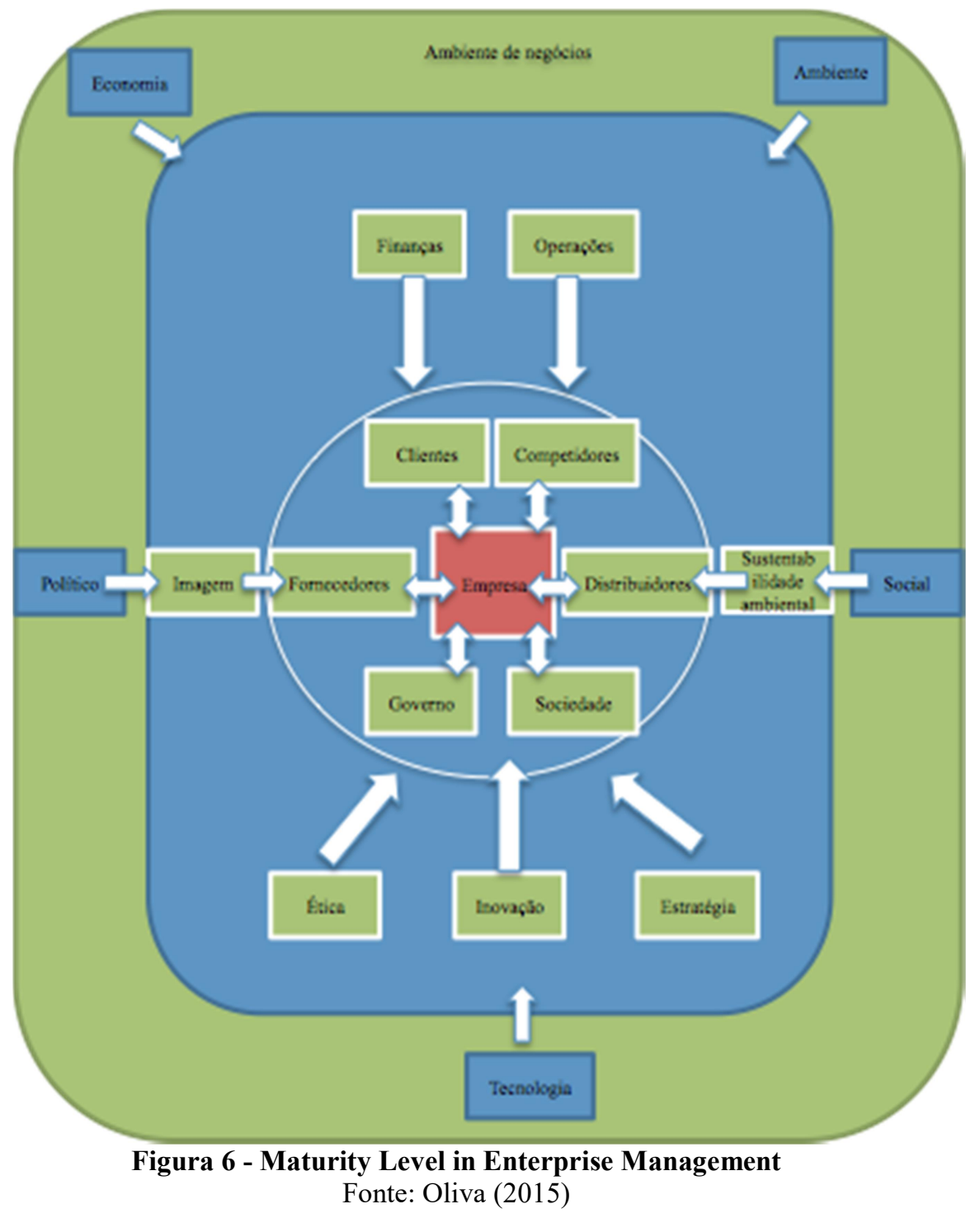

Esse esquema é relevante, pois ilustra as partes interessadas na organização e os tipos de riscos possíveis decorrentes da relação com cada uma das partes.

De fato, uma característica importante das decisões de desenvolvimento de inovação emergentes (tecnologias que ainda estão em um estágio inicial) é que elas envolvem muitas incertezas. Por um lado, esse elevado grau de incerteza possibilita uma grande variedade de oportunidades que uma nova tecnologia pode oferecer. Por outro lado, essa incerteza pode representar uma ameaça, pois é difícil a projeção de cenários sobre o seu desempenho. Em outras palavras, a incerteza pode tanto estimular como desestimular os empresários no que tange ao desenvolvimento e implementação de novas tecnologias, sendo necessárias ações para guiar o processo decisório dos empreendedores. Nessa linha, na próxima seção são apresentadas abordagens no campo de estudo da estratégia e empreendedorismo que auxiliam a criação de novos negócios sob incerteza. 


\subsection{Ações empreendedoras sobre incerteza}

Nesse capítulo são apresentadas as principais abordagens gerenciais para a tomada de decisão por startups em contextos incertos e observadas na análise dos casos estudados: selecionismo, aprendizado por tentativa-e-erro, efetivação, lean startup, plano e modelo de negócio.

É fato que startups começam com incertezas e recursos limitados. Dessa maneira, o empreendedor tem pouca razão para dedicar muito esforço no planejamento e pesquisa anterior ao lançamento de um produto. Em mercados novos, o planejamento pode custar caro também devido à natureza transitória das oportunidades, pois no intervalo entre o começo da pesquisa e seu fim, a oportunidade da startup pode desaparecer (BHIDE, 2000).

Com elevada incerteza e planejamento limitado, os empresários muitas vezes encontram surpresas que os obrigam a modificar ou reformular completamente a ideia do negócio original (BHIDE, 2000).

Diante desse cenário de complexidade imprevisível, Sommer e Loch (2004), propuseram duas ações: aprendizado por tentativa-e-erro e selecionismo. Selecionismo referese à condução de diversas soluções em paralelo para a escolha da melhor posteriormente. Tentativa-e-erro refere-se ao aprendizado de forma flexível, por meio de um planejamento que se ajusta às novas informações que são obtidas com o decorrer da implementação do projeto.

Alinhado com essa visão, Cusumano (2013) afirma que startups precisam demonstrar flexibilidade na estratégia, nos modelos de negócios e na tecnologia. Segundo o autor, startups na maioria das vezes, erram na estratégia de produto e no modelo negócio nos estágios iniciais. Assim o foco e a flexibilidade, que parecem antagônicos, são muitas vezes fundamentais para o sucesso. A fórmula certa emerge ao longo do tempo, por meio de tentativa-e-erro.

Nesse contexto, a literatura retrata várias abordagens empreendedoras para a tomada de decisões em ambientes de incerteza, incluindo conceitos que acentuam a importância e efeito positivo de planejamento e controle, como o da lógica da efetivação apresentada a seguir. 


\subsubsection{Efetivação}

Quando se trata de startups, a maioria dos mercados são nascentes ou simplesmente inexistentes. Nesse cenário, faz-se necessária a compreensão de como tomar decisões na ausência de metas pré-existentes. Diferente de um sistema causal, adotado por empresas mais estabelecidas, em que o planejamento é mais factível de controle e onde a partir de um objetivo a empresa define meios para alcançá-los, Sarasvathy (2001) definiu o processo de efetivação como selecionar um dado conjunto de meios e descobrir os possíveis efeitos que podem ser criados a partir deles.

Dew et al.(2009), baseado no estudo de Sarasvathy (2001), sugeriram que a efetivação está construída sobre os seguintes princípios apresentados na Tabela 9: 
Tabela 9 - Efetivação

\begin{tabular}{|c|c|c|}
\hline Questão & Sistema causal & Sistema efetivo \\
\hline Visão do futuro & $\begin{array}{l}\text { Preditiva. Lógica causal molda o } \\
\text { futuro como uma } \\
\text { continuação do passado. Daí a } \\
\text { previsão exata } \\
\text { é necessária e útil. }\end{array}$ & $\begin{array}{c}\text { Criação. A abordagem efetiva vê o futuro } \\
\text { como algo que pode } \\
\text { acontecer a partir de ações de agentes } \\
\text { motivados. A predição, } \\
\text { neste contexto, não é considerada } \\
\text { relevante. }\end{array}$ \\
\hline $\begin{array}{l}\text { Base para a tomada de } \\
\text { ações }\end{array}$ & $\begin{array}{l}\text { Os objetivos devem ser definidos para } \\
\text { então selecionar os meios necessários } \\
\text { para atingi-los. }\end{array}$ & $\begin{array}{c}\text { Meios são a base para decisões e novas } \\
\text { oportunidades. }\end{array}$ \\
\hline $\begin{array}{l}\text { Atitudes em relação } \\
\text { contingências } \\
\text { inesperadas }\end{array}$ & $\begin{array}{l}\text { Evitar: Seleção de alternativas é } \\
\text { limitada } \\
\text { àquelas que estão de acordo com o } \\
\text { cumprimento } \\
\text { do objetivo principal. }\end{array}$ & $\begin{array}{l}\text { Alavancar: Alternativas são escolhidas } \\
\text { pela sua flexibilidade. Contingências } \\
\text { podem se transformar em oportunidades. }\end{array}$ \\
\hline Pré-disposição ao risco & $\begin{array}{c}\text { Retorno esperado: A abordagem causal } \\
\text { é orientada para } \\
\text { a maximização da oportunidade } \\
\text { (com o nível ajustado de risco), mas } \\
\text { não se pauta } \\
\text { pelo risco de perdas. }\end{array}$ & $\begin{array}{l}\text { Perda suportável: A abordagem efetiva é } \\
\text { orientada para não perder } \\
\text { além daquilo que é suportável. Aqui, o } \\
\text { cálculo é pautado } \\
\text { pelo potencial de perda. }\end{array}$ \\
\hline $\begin{array}{l}\text { Atitude em relação a } \\
\text { entidades externas }\end{array}$ & $\begin{array}{c}\text { Competição: A abordagem causal } \\
\text { preocupa-se com a } \\
\text { competição e limita o relacionamento } \\
\text { com clientes } \\
\text { e fornecedores ao necessário. }\end{array}$ & $\begin{array}{l}\text { Parceria: A abordagem efetiva preocupa-se } \\
\text { em criar mercado } \\
\text { conjuntamente com clientes, fornecedores } \\
\text { e até mesmo, } \\
\text { com prováveis competidores. }\end{array}$ \\
\hline
\end{tabular}

Fonte: Dew et al. (2009)

De acordo com Dew et al. (2009), a efetivação é um importante mecanismo para a ação empreendedora, pois oferece uma explicação mais realista, do que as teorias tradicionais de planejamento e além disso, pode ser vista como uma abordagem gerencial para as incertezas, complementando o conjunto formado pelo aprendizado por tentativa-e-erro e o selecionismo. Todavia, ainda dentro desse contexto, três outras abordagens foram observadas como opções para o empreendedor: Lean Startup, Modelo de Negócio e Plano de negócio.

Segundo Blank (2013), o modelo de negócio “canvas" é um dos princípios da metodologia do Lean Startup (RIES, 2011), visto que o empreendedor no começo de uma empresa possui apenas uma série de hipóteses não comprovadas que são sintetizadas em um quadro (Canvas), proposto por Osterwalder e Pigneur (2010). Essa abordagem considera que um modelo de negócio é constituído por nove elos: segmento de mercado, proposição de valor, canais de distribuição, relacionamento com o cliente, fontes de renda, atividades-chave, parceiros-chave, recursos e custos, que serão explicados a seguir. 


\subsubsection{Lean Startup, Business Model Generation e Plano de Negócios}

De acordo com Gage (2012), cerca de três quartos das startups nos EUA não retornam o capital dos investidores. Nesse cenário, segundo Blank (2013), uma perspectiva de contrapeso importante, que pode tornar o processo de iniciar um projeto menos arriscado, emergiu. É a metodologia do Lean startup, desenvolvida por Ries (2011) que defende a experimentação ao invés do planejamento elaborado, a opinião do cliente sobre a intuição, e o design iterativo ao contrário do desenvolvimento tradicional.

Ao invés de um documento estático de negócios tradicional que procura identificar a maioria das incógnitas de uma empresa com antecedência (como a descrição do tamanho de uma oportunidade, o problema a ser resolvido, a solução que o novo empreendimento vai proporcionar, além de uma previsão de cinco anos de faturamento, lucros e fluxo de caixa), a proposta do Lean Startup é de obtenção de feedback constantes dos clientes, para assim construir um produto de acordo com a real necessidade deles. (BLANK, 2013).

De acordo com Ries (2011), uma startup pode fazer ajustes constantes no seu modelo de negócio seguindo um ciclo de construção-mensuração-aprendizado e por meio desse processo decidir o momento de realizar uma mudança na sua estratégia de negócio (pivotar) ou mantê-la. Para auxiliar esse processo, Ries (2011) sugere a construção de um produto viável mínimo que é uma versão mais simples do produto ideal que permite validar o processo de construção-mensuração-aprendizado com um mínimo esforço e com a menor quantidade de tempo de desenvolvimento. De fato, o produto mínimo viável carece de muitos recursos que podem revelar-se essenciais mais tarde, todavia o seu objetivo inicial é de testar hipóteses fundamentais do negócio.

Nesse contexto de articulação de uma oportunidade de negócio, o empresário também pode obter auxílio na estruturação da estratégia por meio do Canvas, apresentado na Figura 7, proposto por Osterwalder e Pigneur (2010), que de forma ágil, resume em um diagrama como a empresa cria valor para si e para seus clientes. 


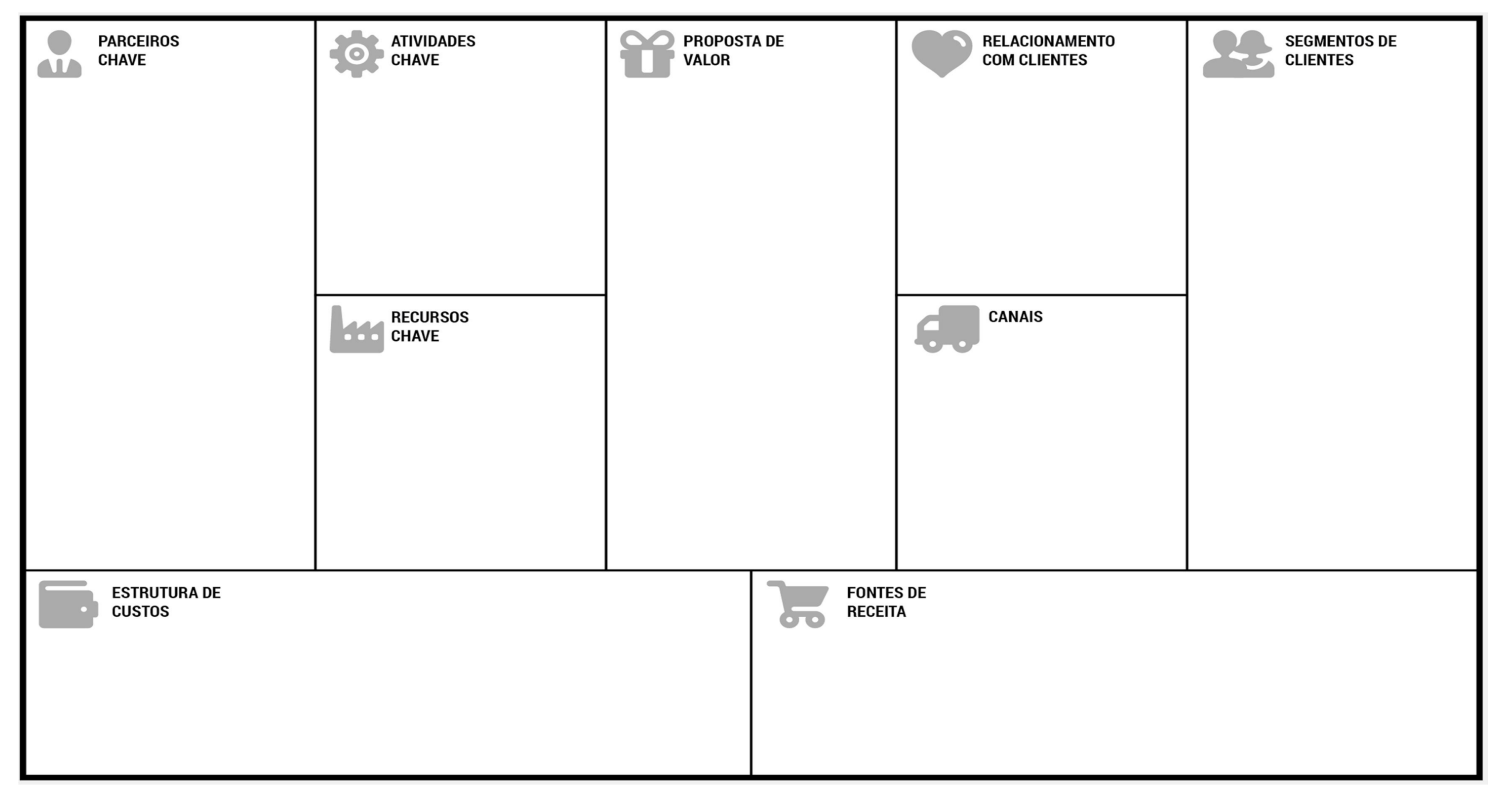

Figura 7 - Tela de modelo de negócios

Fonte: Osterwalder, Pigneur (2010)

Nessa figura, a proposição de valor descreve o pacote de produtos e serviços que criam valor para um segmento de clientes específico. Ela resolve um problema do cliente ou satisfaz uma necessidade. Algumas proposições de valor podem ser inovadores e representar um produto disruptivo. Outras podem ser semelhantes às existentes no mercado, mas com recursos e atributos adicionais (OSTERWALDER; PIGNEUR, 2010).

Os segmentos de clientes, por sua vez, definem os grupos de pessoas ou organizações que uma empresa pretende alcançar e servir. A fim de melhor satisfazer os clientes, uma empresa pode agrupá-los em segmentos distintos, com necessidades, comportamentos ou outros atributos em comum. Um modelo de negócio pode definir um ou vários segmentos de clientes grandes ou pequenos, e uma organização deve fazer uma decisão consciente sobre quais segmentos pretende servir e quais segmentos ignorar. Uma vez tomada essa decisão, um modelo de negócio deve ser cuidadosamente projetado em torno de uma forte compreensão das necessidades específicas desse segmento (OSTERWALDER; PIGNEUR, 2010).

Os canais descrevem como uma empresa se comunica e atinge os seus clientes. Canais são pontos de contato com o cliente e desempenham um papel importante na experiência de compra, servindo para aumentar a consciência sobre produtos e serviços.

O relacionamento descreve os tipos de relações que uma empresa estabelece com segmentos específicos de clientes e devem ser construídas pelos seguintes motivos: aquisição de clientes, fidelização e aumento das vendas (OSTERWALDER; PIGNEUR, 2010). 
Fontes de receita representa o dinheiro que uma empresa gera em cada segmento de clientes. A empresa deve entender o valor que cada segmento de clientes está disposto a pagar (OSTERWALDER; PIGNEUR, 2010).

As parcerias-chave descrevem a rede de fornecedores e parceiros que constituem o modelo de negócio. A criação de alianças pode aperfeiçoar modelos de negócios e reduzir o risco da organização (OSTERWALDER; PIGNEUR, 2010).

Os recursos-chave descrevem os ativos mais importantes necessários para um negócio. Estes recursos permitem que uma empresa crie sua proposta de valor, alcance o mercado, mantenha relações com os segmentos de clientes e obtenha receitas. Recursos-chave podem ser físicos, financeiros, intelectuais ou humanos e podem ser próprios ou adquiridos de parceiros-chave. Atividades principais, por sua vez, descrevem o que de mais importantes uma empresa deve fazer (OSTERWALDER; PIGNEUR, 2010).

A estrutura de custo descreve todos os custos incorridos para operar um modelo de negócio. Tais custos podem ser calculados de forma relativamente fácil após a definição de recursos-chave, atividades-chave e parcerias-chave (OSTERWALDER; PIGNEUR, 2010).

Por fim, o empreendedor pode utilizar um recurso mais tradicional, que demanda mais tempo para ser confeccionado que é o plano de negócio. Esse documento consiste em análise profunda da indústria, do cliente, da concorrência, da oferta e apresenta também uma descrição detalhada do produto, do plano de marketing, de operações, de finanças e desenvolvimento, bem como da equipe e dos riscos que envolvem o projeto. (ZACHARAKIS; SPINELLI; TIMMONS, 2011). Blank (2013), entretanto, pondera que um plano de negócios, por ser muitas vezes um exercício de pesquisa feito em isolamento pelo empreendedor, pode originar produtos sem aceitação pelo mercado, pois essa abordagem parte da premissa de que é possível responder à maioria das interrogações de um empreendimento com pouco ou nenhuma interação com o futuro cliente. 


\section{METODOLOGIA DA PESQUISA}

Este capítulo apresenta os procedimentos técnicos, o tipo de pesquisa e o modelo de pesquisa utilizado, bem como a descrição das etapas para análise dos resultados.

\subsection{Tipo e Metodologia de Pesquisa}

A pesquisa empírica realizada neste trabalho foi de natureza qualitativa e conduzida pelo método de estudos de casos múltiplos. Segundo Creswell (2010) a pesquisa qualitativa é um meio para explorar o significado que os indivíduos atribuem a um problema. A pesquisa nesse caso possui um estilo indutivo, um foco no significado individual e na importância da interpretação da complexidade de uma situação, por meio da análise de conteúdo.

De acordo com Strauss e Corbin (2008), pesquisa qualitativa produzem resultados que não podem ser encontrados por meio de quantificação. Nesse trabalho foi estudado um fenômeno de funcionamento organizacional em que a parte mais importante da análise é interpretativa, o que o enquadra em pesquisa qualitativa.

Segundo Godoy (1995a), pesquisadores qualitativos estão preocupados com o processo e não simplesmente com os resultados ou produto. Dessa forma, os quadros teóricos da pesquisa são construídos aos poucos, pois partem de questões ou focos de interesse amplos, que vão se tornando mais diretos e específicos no transcorrer da investigação. Segundo a autora ainda, quando o pesquisador lida com problemas pouco estudados e para que ocorra o entendimento de um fenômeno por inteiro a pesquisa exploratória e a análise qualitativa são as mais adequadas.

A natureza exploratória e qualitativa da pesquisa empírica proposta é justificável, uma vez que, objetivando a ampliação dos conhecimentos a respeito de risco de introdução de novas tecnologias no mercado por startups, pretende-se observar a sua implementação e utilização dentro do contexto empresarial, buscando identificar novos aspectos envolvidos e relações entre estes e perspectivas levantadas na literatura, procurando-se delinear modelos teóricos que descrevam o fenômeno.

Esse enfoque é válido uma vez que o que se pretende estudar é um campo acadêmico relativamente novo, existindo ainda poucos trabalhos a ele relacionados. Dessa maneira, é possível dizer que o estudo desse fenômeno ainda se encontra em seus estágios iniciais, de construção de teoria, sendo justificado um estudo exploratório com objetivo de oferecer propostas para um modelo teórico. 
O que se pretende é proporcionar uma visão geral da introdução de novas tecnologias no mercado por startups e suas principais características, oferecendo uma análise do contexto e obtendo assim indicações de questões ou hipóteses para futuras pesquisas mais aprofundadas.

\subsection{O Método de Estudo de Casos}

De acordo com Godoy (1995b) o estudo de caso se caracteriza como um tipo de pesquisa cujo objetivo é uma analisa profunda de uma unidade. Visa ao exame detalhado de um ambiente, de um simples sujeito ou de uma situação em particular.

Bogdan (1994) define que o estudo de caso pode ser representado como um funil, em que o início do estudo seria as extremidades mais largas do funil, momento em que o pesquisador busca fontes de dados e procura organizá-las e explorá-las. Dessa maneira, a medida que vão conhecendo melhor o tema de estudo, tomam decisões sobre os aspectos específicos do contexto, indivíduos ou fontes. Ou seja, de uma fase ampla de exploração passam para uma área mais restrita de análise de dados.

De acordo com Yin (2010), o estudo de caso é o método preferido quando procura-se estudar o "como" e "por que" de um evento, quando o investigador tem pouco controle sobre os eventos e quando o enfoque está sobre um fenômeno contemporâneo da vida real. Isso ocorre porque essas questões lidam com os vínculos operacionais que necessitam ser traçados ao longo do tempo. O estudo de caso permite que o pesquisador retenha características significativas dos eventos da vida real, como por exemplo, os processos organizacionais.

Grégoire et al. (2006) constataram que o estudo de caso é o método de pesquisa que aparece com mais regularidade no estudo sobre empreendedorismo. Assim sendo, é adequado neste trabalho, porque em sua pesquisa empírica buscou-se descrever e analisar os riscos de introdução de novas tecnologias no mercado por startups. Além disso, este trabalho procurou responder a perguntas do tipo como? e por que? (Como é possível gerenciá-los? Por que ocorrem?). As perguntas do tipo quais? (Quais são os riscos de introdução de novas tecnologias no mercado, quão expostas estão as startups a esses riscos) que são de caráter exploratório e, portanto, também são adequadas a estudos de caso. 


\subsection{Delineamento da Pesquisa}

De acordo com Yin (2010) para o estudo de caso são necessários 5 componentes:

1. as questões de estudo;

2. as proposições;

3. as unidades de análise;

4. a lógica que une os dados às proposições; e

5. os critérios para interpretar as constatações.

Esses itens são apresentados a seguir.

\subsubsection{Questão de Pesquisa}

De acordo com Creswell (2010) a questão de pesquisa conduz à necessidade de um estudo. Ela pode provir de uma experiência que os pesquisadores tiveram em suas vidas pessoais ou em seus locais de trabalho, como é o caso desse estudo.

A fim de dirigir a realização do estudo, foi colocada a seguinte questão principal, elaborada com base no objetivo principal da pesquisa:

Quais são os riscos de introdução de novas tecnologias no mercado, quão expostas estão as startups a esses riscos e como é possível gerenciá-los?

\subsubsection{Proposições de estudo e Modelo da pesquisa}

Segundo Yin (2010) cada proposição dirige atenção para algo que deve ser examinado na pesquisa. Como exemplo, citado pelo próprio autor, em um estudo onde a questão seja: como e porque as organizações colaboram umas com as outras para proporcionar serviços conjuntos? Uma das proposições pode ser: as organizações colaboram porque obtêm benefícios mútuos. Dessa maneira, a proposição reflete um aspecto teórico e indica onde encontrar evidências relevantes.

As proposições do estudo, derivadas do estudo teórico são as seguintes:

Os riscos na introdução de uma nova tecnologia no mercado por uma startup estão associados aos seguintes fatores:

- Ao tipo do produto - New Ventures, Novas categorias, Novas plataformas e Novos produtos; -Do entendimento da tecnologia;

-Do entendimento do mercado; 
-Do entendimento do usuário.

Além dessas, são apresentadas as seguintes proposições adicionais, que têm a finalidade de flexibilizar o plano de pesquisa e permitir descobertas adicionais, o que é justificado pela natureza exploratória da pesquisa.

-Os riscos no desenvolvimento de produto por startup podem ocorrer por outros motivos além dos citados no modelo NPVR, como os elementos do Canvas, exemplificados a seguir:

-Falta de uma proposição de valor bem definida;

-Ausência de definição de segmento de cliente;

-Ausência de canais de distribuição.

-Os riscos podem envolver outros itens não apresentados na abordagem NPVR e na análise do Canvas;

-Os riscos são percebidos de maneira diferente por cada startup;

-O tratamento dos riscos está associado a aspectos do contexto onde estão inseridos.

Com base nessas proposições foi delineado o modelo de pesquisa, exibido na Figura 8:
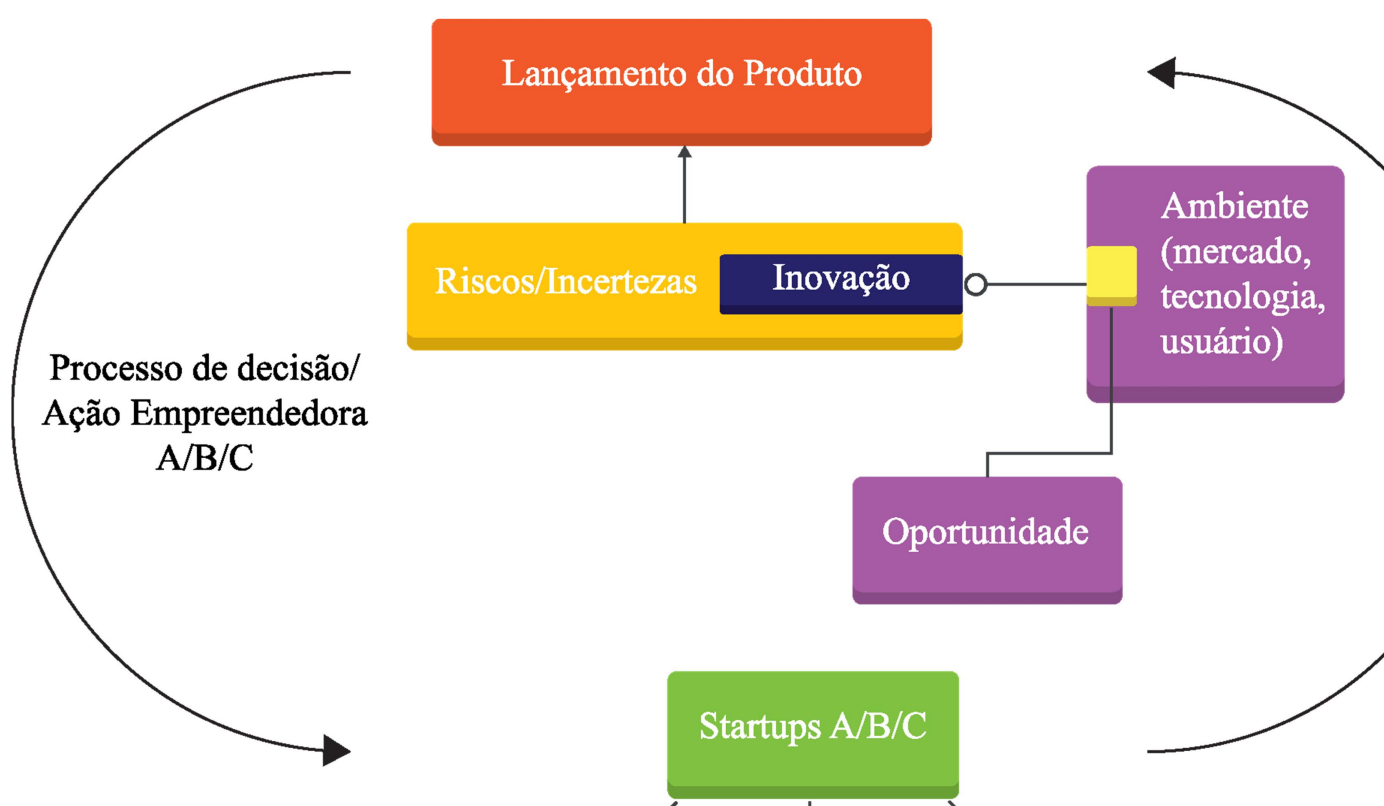
西 
riscos atrelados a essa inovação e os processos de decisão relacionados ao seu tratamento. Associados às características dessa interação, estão as percepções desse processo que podem ser diferentes de acordo com cada startup.

\subsubsection{Unidade de Análise e Tipo de Estudo de Casos: Casos Múltiplos}

De acordo com Yin (2010), a seleção da análise apropriada é uma consequência das questões de pesquisa primária. Quanto ao número de casos, os estudos de caso podem ser de caso único ou casos múltiplos. Segundo Godoy (1995b), quando o estudo envolve dois ou mais sujeitos, duas ou mais instituições, podemos falar de casos múltiplos.

O objetivo da utilização de casos múltiplos é possibilitar a comparação do desenvolvimento de produto em diferentes startups, identificando as semelhanças e diferenças entre os casos, procurando relacionar os contextos de cada uma delas. A unidade de análise considerada foi o processo de desenvolvimento de um novo produto.

\subsubsection{Escolha dos Casos}

Segundo Yin (2010) a escolha dos casos em um estudo de casos múltiplos deve seguir uma lógica semelhante a dos experimentos múltiplos, ou seja, a lógica da replicação. Nesse aspecto, cada caso deve procurar comprovar ou negar determinado aspecto da teoria que está sendo testada.

A escolha dos casos foi feita com base em uma dimensão considerada importante para os resultados da pesquisa como um todo. Essa dimensão foi o tipo do produto - New Ventures, Novas categorias, Novas plataformas e Novos produtos (DAVIS, 2002).

Esse fator foi considerado importante uma vez que cada tipo de produto possui pesos diferentes no cálculo do NPVR. Dessa forma, foi escolhido um caso para cada tipo de produto, seguindo o critério de:

New Ventures - são os "novos para o mundo", que representam o primeiro de seu tipo e necessitam da criação de um mercado totalmente novo - Caso Catarse.

Novas categorias - são "novos para a empresa" e incluem novas linhas de produtos que têm como alvo um mercado estabelecido em que a empresa não compete atualmente - Caso MercadoPago.

Novas plataformas - frequentemente são adições às linhas de produtos existentes, embora os próprios produtos possam ser bastante inovadores - Caso Betalabs. 
Novos produtos - são derivados de melhorias e revisões de produtos existentes, incluindo reduções de custos - Caso GuiaBolso.

Após essa seleção, foi feito contato com as empresas que ofereceram disponibilidade de tempo do fundador ou diretor para entrevistas semiestruturadas e abertura de documentação relativa ao assunto estudado. Pela facilidade de realização da pesquisa foram escolhidas empresas cujos escritórios estivessem na cidade de São Paulo. Foi enviado um email especificando os objetivos da pesquisa, os resultados esperados e o comprometimento necessário da empresa pesquisada.

\subsubsection{Coleta de Dados}

De acordo com Yin (2010), seis fontes de evidência podem ser utilizadas para a coleta de dados em um estudo de casos: documentação, registros de arquivos, entrevistas (abertas, fechadas e levantamentos), observação direta, observação participante e artefatos físicos. Nesse estudo, foram utilizadas entrevistas semiestruturadas (gravadas e transcritas), realizadas com os principais participantes dos processos de decisão de desenvolvimento - sócio ou diretor executivo, e também a análise de documentos e registros e a observação direta.

\subsubsection{O Roteiro para a Entrevista}

O roteiro para as entrevistas foi elaborado a partir das proposições iniciais, do modelo de pesquisa e das teorias apresentadas no levantamento bibliográfico. Foi realizado um estudo piloto, ou seja, a aplicação desse instrumento de pesquisa no contexto de duas startups diferentes dos casos apresentados. O objetivo do teste foi avaliar aspectos funcionais, tais como apropriação, ordenação, clareza das questões, de modo a corrigir eventuais desvios, antes da aplicação definitiva. O questionário encontra-se no Apêndice I.

\subsubsection{Etapas da pesquisa}

As etapas da pesquisa seguiram os passos sugeridos por Yin (2010) para o desenvolvimento de estudo de caso, representadas pela Figura 9: 


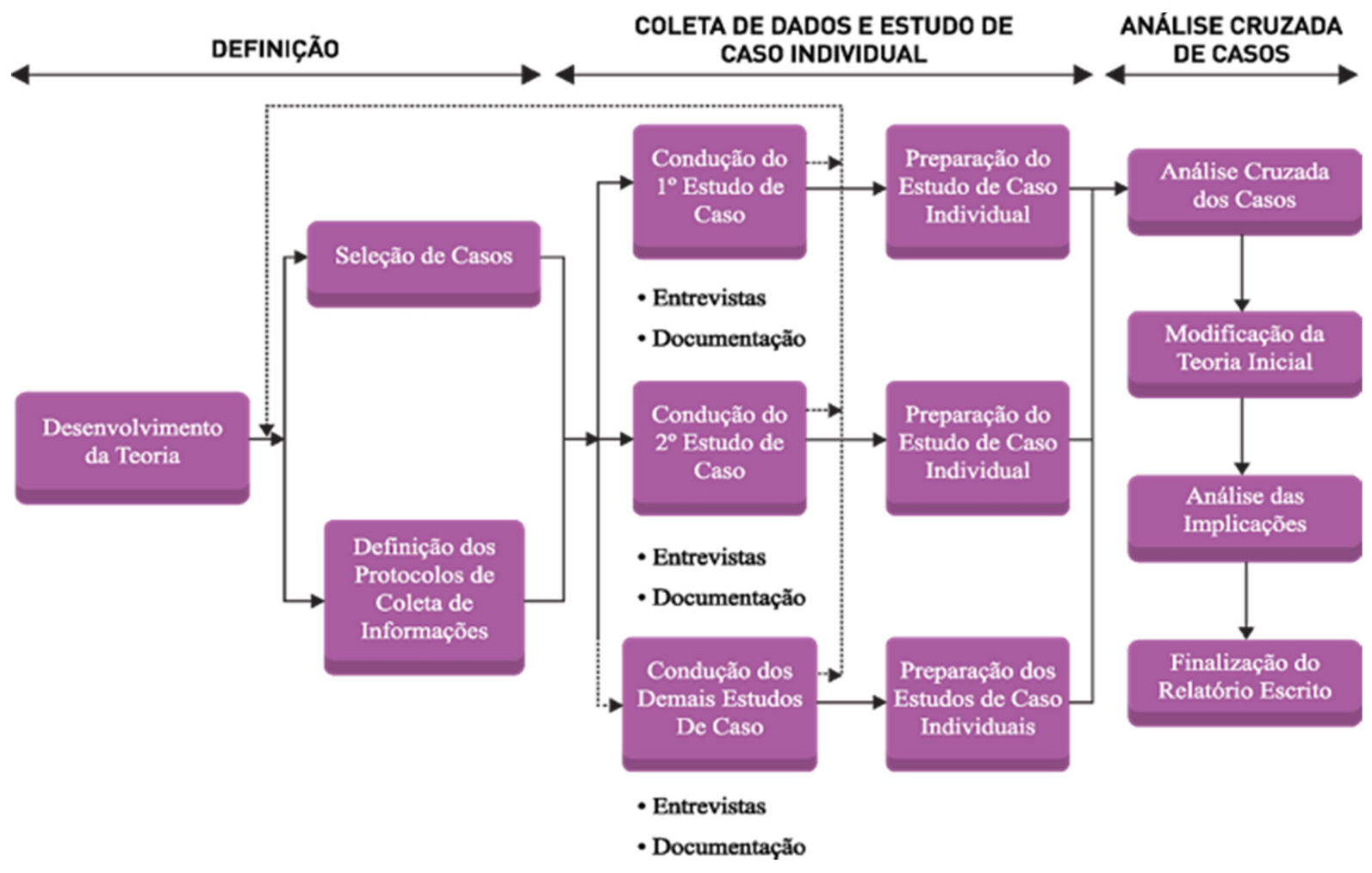

Figura 9 - Etapas da pesquisa

Fonte: Adaptado de Yin (2010)

A primeira fase da pesquisa foi elaborada a partir da revisão de artigos publicados em periódicos científicos, livros, teses e dissertações. Por meio dessa revisão foi possível desenhar um referencial teórico que contribuiu para a reflexão sobre os seguintes tópicos: startups, oportunidade, inovação, incerteza, ação empreendedora, plano e modelo de negócio e teoria do NPVR. Nesta fase, observou-se que apesar da existência de teorias complementares, não existia um consenso sobre um modelo de gestão de riscos para o desenvolvimento de novos produtos em startups. Identificou-se, assim, uma oportunidade de pesquisa.

Posteriormente, iniciou-se a etapa da coleta dos dados realizada por meio de entrevistas com fundadores ou diretores de empresas de tecnologia. Essas entrevistas foram pautadas em um roteiro que procurou explorar os tópicos descritos na matriz validação (Tabela 10): 
Tabela 10 - Matriz Validação

Matriz Validação

Objetivos

específicos

Base Conceitual
(Conceitos, Classificações, Relações e Modelos)

Conceitos abordados: Oportunidade e Inovação.

Identificar a oportunidade do negócio

Identificar os riscos nesse contexto

Conceitos abordados: Riscos Estratégicos, Teoria NPVR, Maturity Level in Enterprise Risk Management.

Conceitos abordados: Teoria NPVR.

Análise e avaliação

dentificar os tratamentos

Conceitos abordados: técnicas para respostas aos riscos,Selecionismo, Business Model Generation, Efetivação, Aprendizado por tentativa e erro, Lean Startup, Plano de
Perguntas

$1.1,4.1$

A,J

$4.3,5.1$

$\mathrm{L}, \mathrm{N}$

ecorrente das Respostas

Suportada pela Base Conceitual

negócios.

$1.3,2.2,2.3,3.1,3.2$

$4.2,4.4$

$1.2,2.1,2.4$ 


\section{1) Avaliação da Oportunidade}

1.1) Como nasceu a empresa? Qual oportunidade foi explorada?

A) Espera-se identificar a oportunidade de negócio e o estágio do desenvolvimento do mercado e da tecnologia no lançamento do negócio.

1.2) Foi escrito um plano de negócios antes do desenvolvimento da tecnologia? Foi utilizada alguma técnica de planejamento?

B) Analisar se foi seguida a lógica da efetivação ou ocorreu planejamento do negócio.

1.3) Diante da seguinte classificação:

New Ventures - são os "novos para o mundo", que representam o primeiro de seu tipo e necessitam da criação de um mercado totalmente novo - por exemplo, MP3 players.

Novas categorias - são "novos para a empresa" e incluem novas linhas de produtos, que têm como alvo um mercado estabelecido em que a empresa não compete atualmente.

Novas plataformas - frequentemente são adições às linhas de produtos existentes, embora os próprios produtos possam ser bastante inovadores.

Novos produtos - são derivados de melhorias e revisões de produtos existentes, incluindo reduções de custos.

Em qual categoria se enquadra o produto lançado?

C) O objetivo foi de selecionar o tipo de empreendimento para o cálculo do risco segundo a abordagem NPVR.

\section{2) Avaliação do Mercado}

2.1) Quais foram os mercados inicialmente identificados para o produto?

D) O objetivo foi de compreender se ocorreu um planejamento do posicionamento da empresa.

2.2) Todos os elementos da cadeia de valor exigido para se alcançar seus clientes potenciais, como capacidades da força de vendas, canais de distribuição, capacidades de fabricação e suporte ao cliente existiam internamente na empresa no lançamento? Foram construídas parcerias?

E) O objetivo é entender o grau de risco na cadeia de valor do negócio no lançamento.

2.3) A empresa já possuía presença no segmento mercado? Se sim, era líder?

F) O objetivo foi de entender o grau de risco de segmento de mercado.

2.4) Quais foram os canais desenhados para se aproximar do mercado-alvo?

G) Observar se os empreendedores aplicaram a estratégia de selecionismo, a lógica da efetivação ou um plano de negócio. 


\section{3) Avaliação do Usuário}

3.1) Os primeiros clientes possuíam conhecimento sobre a proposta de valor/design da inovação? O que o foi feito para aumentar o conhecimento do cliente sobre isso?

H) Identificar como os empreendedores gerenciaram as incertezas sobre os produtos. Esta pergunta procura mensurar o grau de especificação.

3.2) Quem definiu os atributos do produto? Houve uma pesquisa com o usuário antecipadamente?

I) Objetivo de identificar o grau de interação do produto.

\section{4) Tecnologia e recursos}

4.1) Qual era o estágio do desenvolvimento da tecnologia no lançamento do produto?

J) Objetivo de identificar o estágio do desenvolvimento da tecnologia atrelado ao risco da inovação.

4.2) A tecnologia já existia no mercado ou era um novo conceito?

K) Objetivo de mensurar o risco da inovação.

4.3) Quais foram as incertezas que surgiram durante o desenvolvimento do produto?

L) O objetivo foi de identificar quais incertezas influenciaram o desenvolvimento do produto.

4.4) A equipe já possuía experiência em projetos semelhantes? Diante das necessidades iniciais, pode-se considerar que a equipe era completa?

M) Objetivo de mensurar o risco de recursos.

\section{5) Avaliação geral do risco}

5.1) Fazendo uma análise a posteriori quais riscos você enxerga que a startup estava submetida no lançamento do produto?

N) O objetivo foi de selecionar riscos não observados nas teorias apresentadas. Foi apresentada a seguinte tabela de apoio, para facilitar a análise do empreendedor: 
Tabela 11 - Riscos no ambiente de valor

\begin{tabular}{cc}
\hline & Riscos mais Importantes no Ambiente de Valor \\
\hline Agentes & Riscos mais Importantes \\
Organização & Estratégico, Operacionais, Ético e Imagem \\
Clientes & Sociais e Imagem \\
Fornecedores & Estratégico, Operacionais, Ético e Imagem \\
Concorrentes & Financeiro, Inovação, Tecnológico, Ético e Imagem \\
Distribuidores & Estratégico, Operacionais, Ético e Imagem \\
Governo & Econômico \\
Sociedade & Sustentabilidade Ambiental e Meio Ambiente Oliva \\
\hline
\end{tabular}

Fonte: Oliva (2015)

A etapa de coleta de dados ocorreu por meio de contato com os entrevistados para explicar os objetivos da pesquisa e posterior visita às empresas. A tabela a seguir apresenta as empresas selecionadas, o cargo do entrevistado, o código de referência do entrevistado, a duração e data da entrevista, os documentos cedidos pelas empresas e os códigos de referência desses documentos que foram utilizados na apresentação dos casos. 
Tabela 12 - Dados da etapa de entrevistas

\begin{tabular}{|c|c|c|c|c|}
\hline Empresa & Cargo do entrevistado & Código do Entrevistado & Duração da Entrevista & Data da entrevista \\
\hline Catarse & Fundador & E1Caso01 & $30 \mathrm{~min}$ & $15 / 02 / 2016$ \\
\hline GuiaBolso & Fundador & E2Caso02 & $40 \mathrm{~min}$ & $12 / 01 / 2016$ \\
\hline MercadoPago & Diretor Geral & E3Caso03 & $52 \mathrm{~min}$ & $13 / 01 / 2016$ \\
\hline Betalabs & Fundador & E4Caso04 & $57 \mathrm{~min}$ & $11 / 02 / 2016$ \\
\hline
\end{tabular}

Tabela 13 - Documentos da etapa de entrevistas

\begin{tabular}{ccc|c|c}
\hline Empresa & Catarse & GuiaBolso & MercadoPago & Betalabs \\
\hline Documento & $\begin{array}{c}\text { Apresentação institucional } \\
\text { da empresa. }\end{array}$ & $\begin{array}{c}\text { Apresentação institucional } \\
\text { da empresa. }\end{array}$ & $\begin{array}{c}\text { Apresentação institucional } \\
\text { da empresa. }\end{array}$ & $\begin{array}{c}\text { Apresentação institucional } \\
\text { da empresa. }\end{array}$ \\
Código do documento & D1Caso01 & D2Caso02 & D3Caso03 & D4Caso04 \\
\hline
\end{tabular}


Após a definição dos casos principais e da realização das entrevistas, iniciou-se a etapa de análise dos dados, por meio do framework desenvolvido nessa dissertação, apresentado a seguir.

\subsubsection{Modelo de análise e apresentação dos casos}

Os dados da primeira etapa de coleta de dados resultaram em aproximadamente 179 minutos de entrevistas, que foram transcritas e analisadas por meio do auxílio do software Atlas.ti ${ }^{\circledR}$, de acordo com o modelo de análise proposto por Miles, Huberman, \& Saldaña (2014), que segue as seguintes etapas: condensação, visualização e elaboração de conclusões. As entrevistas foram codificadas em primeiro e segundo nível por dois pesquisadores e os dados foram confrontados para a verificação de possíveis falhas, garantindo maior confiabilidade aos resultados.

No Atlas.ti ${ }^{\circledR}$ os documentos primários (entrevistas) foram analisados por meio de códigos que se originaram dedutivamente ou indutivamente (emergentes do texto). Além disso, utilizou-se da ferramenta de citações, criadas por meio da seleção de segmentos do texto pelo pesquisador. O segundo ciclo de codificação analisou a lista inicial de códigos, observando sua relação com a estrutura teórica da dissertação. Neste ponto foram também propostas famílias (conjunto de códigos relacionados) que permitiram atribuir significado aos dados coletados.

As Famílias e Códigos podem ser verificados na Tabela 14: 
Tabela 14 - Codificacão

\begin{tabular}{|c|c|}
\hline Famílias & Códigos \\
\hline $\begin{array}{l}\text { Ações empreendedoras sobre } \\
\text { incerteza }\end{array}$ & Business plan, Aprendizado por tentativa-e-erro, Lean start-up, Selecionismo, Efetivação. \\
\hline Business Plan & Business plan, Business plan por projeto. \\
\hline Canvas & Canais (Canvas), Proposição de valor (Canvas). \\
\hline Características de start-up & Flexibilidade, Não autossustentável, Alta reatividade, Rápida Evolução. \\
\hline Comunicação & A importância da comunicação (marketing online), Controle de atividades, Comunicação interna, Networking. \\
\hline Maturity Level in Enterprise & Maturity Level in Enterprise Risk Management, Técnica para respostas aos riscos. \\
\hline Risk Management & \\
\hline Produto & Oportunidade, Inovação, Amadurecimento do produto, Ciclo de vida do produto, Benchmarking. \\
\hline Risco de Mercado & Avaliação da cadeia de valor, Avaliação segmento de mercado, A importância do tamanho do mercado. \\
\hline Risco de usuário & Avaliação da especificação, Avaliação da interação, Falta de informações sobre o consumidor. \\
\hline Risco técnico & Avaliação da inovação, Avaliação de recursos. \\
\hline Startup & $\begin{array}{l}\text { Flexibilidade, Incerteza, Ter somente um produto, Não autossustentável, Alta reatividade, Rápida Evolução, Falta de recursos, Organização. } \\
\text { completa, Equipe pequena, Pouca experiência de trabalho, Equipe com baixa experiência, Pressão do tempo. }\end{array}$ \\
\hline Teoria do NPVR & $\begin{array}{l}\text { Novas categorias (NPVR), Avaliação segmento de mercado, Avaliação da especificação, Avaliação da interação, Avaliação da inovação, } \\
\text { Avaliação de recursos, Novos produtos (NPVR), Nova plataforma (NPVR), New Venture (NPVR). }\end{array}$ \\
\hline
\end{tabular}


Após a etapa de codificação, foi criado um modelo que suportou a apresentação de cada caso. Esse modelo foi construído em complemento à abordagem inicial dessa pesquisa, englobando as seguintes fases consideradas importantes para a exibição dos casos:
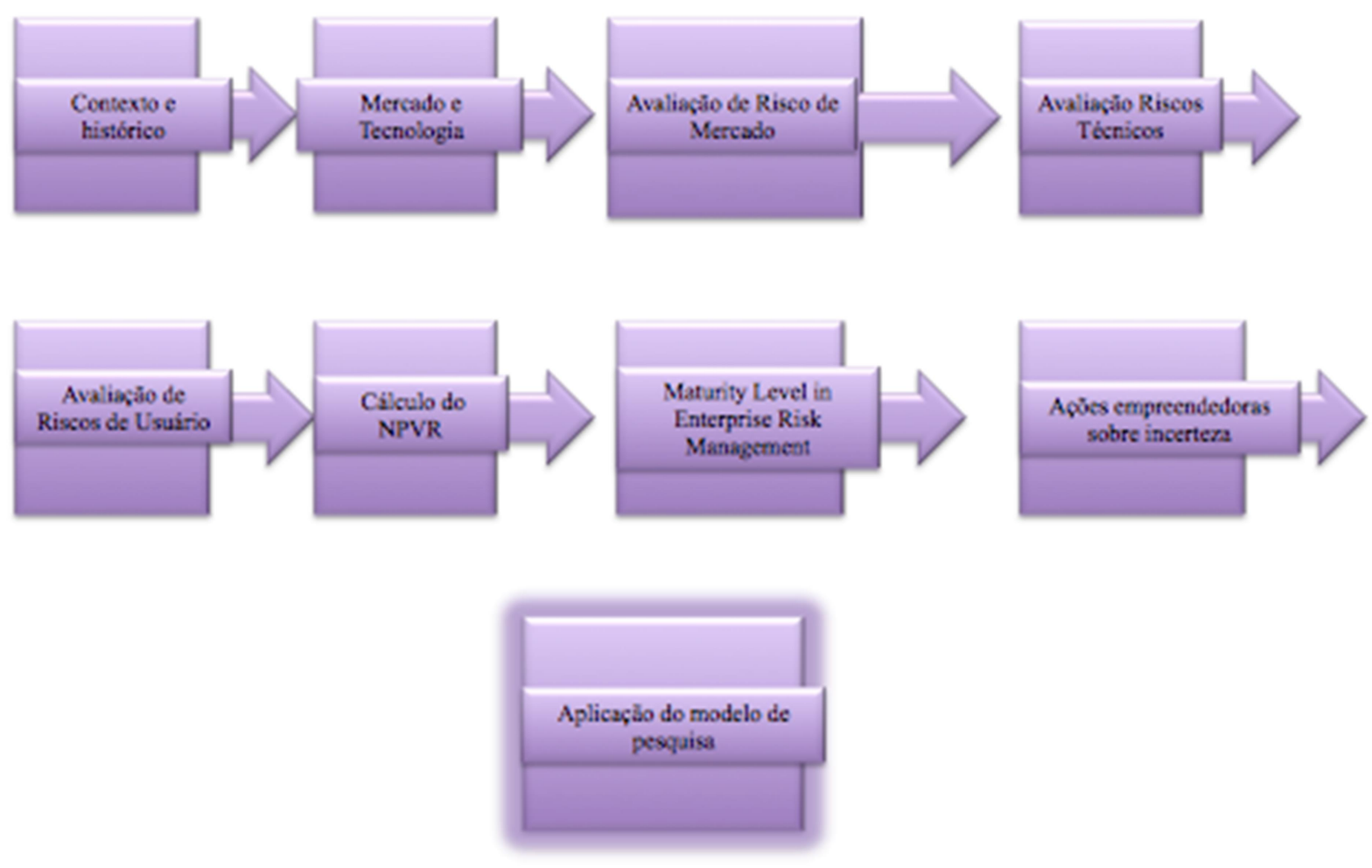

Figura 10 - Modelo de apresentação dos casos

1) Contexto e histórico - caracterização do ambiente no qual a empresa estava inserida, a sua linha do tempo, o perfil dos agentes envolvidos na gestão de risco e a oportunidade do negócio.

2) Mercado e tecnologia - consistem em elementos importantes, porque interferem no cálculo do risco da empresa por meio da abordagem do NPVR, proposta por Davis (2002).

3) Gestão de Riscos no caso - o objetivo desse tópico foi de avaliar a gestão de risco de cada empresa analisada, considerando a teoria do NPVR (DAVIS, 2002) que engloba a avaliação de risco de mercado, a avaliação dos riscos técnicos, a avaliação do riscos de usuário e o cálculo do NPVR. Ademais, a fim de complementar a análise, os casos foram avaliados por meio da Maturity Level in Enterprise Risk Management (Oliva, 2015).

4) Ações empreendedoras sobre incerteza - apresentados os principais riscos a que as startups estavam expostas, a sua mensuração e o contexto em que estavam inseridos. Nesse 
item foram avaliadas também as ações empreendedoras para mitigá-los, ou seja, quais foram as decisões que as empresas tomaram com a finalidade de diminuir suas exposições a esses riscos.

5) Aplicação do modelo de pesquisa sugerido - nesse tópico, foram analisados os dados a respeito das startups, de acordo com o modelo proposto dedutivamente pelo autor da pesquisa. Esse modelo foi criado a partir da revisão da literatura e por intermédio da análise dos dados coletados que foram condensados por meio da codificação de primeiro e segundo nível, tendo como referência para a codificação os aspectos propostos de maneira dedutiva.

Assim, a partir da combinação de aspectos dedutivos e indutivos, os dados foram analisados, descritos e exibidos por meio de tabelas e descrições textuais. Por fim, foi gerado o modelo descrito a seguir que auxiliou a etapa de análise e exibição dos dados.

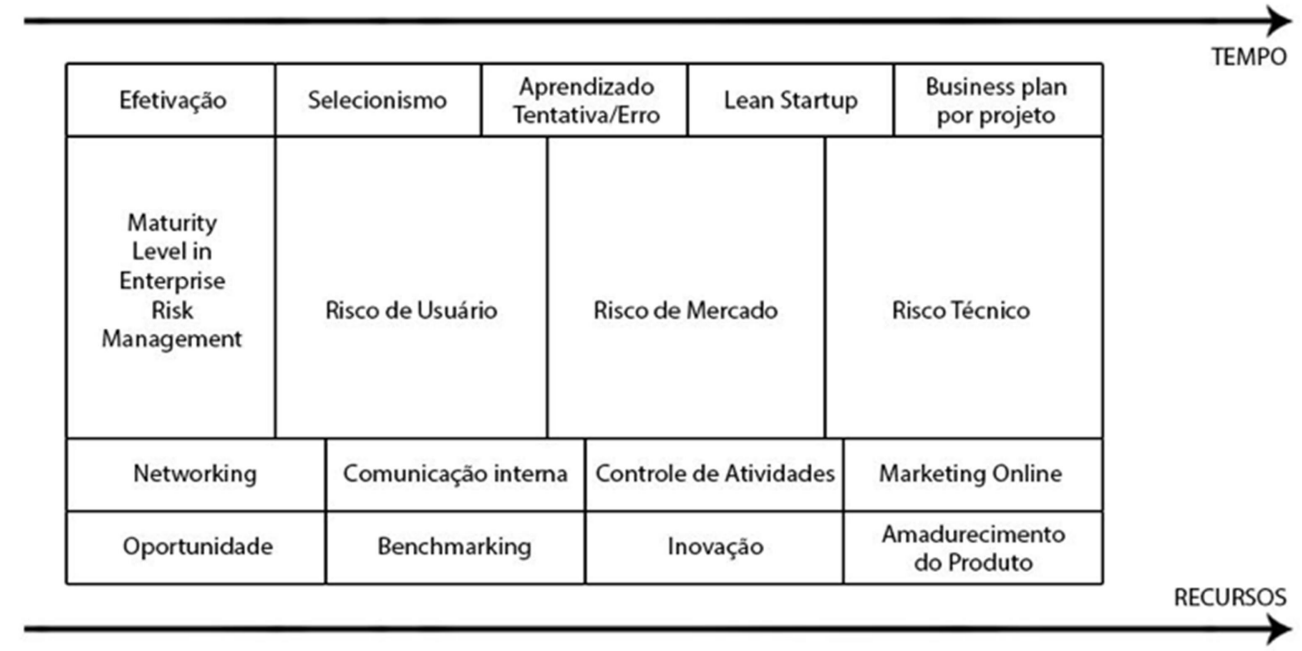

Figura 11 - Risk Management Matrix

Cada item da Risk management matrix, composta por elementos dedutivos oriundos principalmente de Davis (2002); Oliva (2015); Oliva et al. (2014); Blank e Dorf (2012); Jorion (2009); COSO (2007); Kambil e Mahidhar (2005) e por elementos indutivos emergentes da pesquisa, foi inserido de acordo com uma ordem definida pelo autor. Essa ordem levou em consideração os fatores tempo e recursos como delimitantes de um lançamento e desenvolvimento de uma nova tecnologia. A linha inferior da matriz descreve aspectos relacionados ao produto. Esses aspectos evoluem da esquerda para a direita e estão correlacionados com o tempo. Quanto mais maduro é um produto, mais aspectos da direita são observados. 
A segunda linha se relaciona com comunicação. Da mesma maneira que o produto, também tem uma evolução da esquerda para a direita. A linha central é a análise de risco, que considera a visão NPVR e a Maturity Level in Enterprise Risk Management e a superior demonstra as ações empreendedoras sobre incerteza. Mais uma vez, a evolução ocorre da esquerda para a direita, e possui ligação com o tempo e com recursos que a empresa possui. Quanto mais a empresa apresentar características do extremo direito, menor tendem a ser os riscos a ela associados. A Risk management matrix foi aplicada em todos os casos estudados para avaliar os elementos relacionados com o desenvolvimento de uma nova tecnologia.

Por fim, além da análise individual dos casos, Miles, Huberman e Saldaña (2014) apontam que a confiabilidade de uma pesquisa pode ser avaliada por meio de uma série de táticas, como a triangulação e member checking (que consiste na revisão pelos entrevistados dos casos quando finalizados), que também foram estratégias utilizadas na presente pesquisa com a finalidade de aumentar a qualidade dos casos analisados que são apresentados a seguir. 


\section{APRESENTAÇÃO E DISCUSSÃO DOS RESULTADOS}

Nesse capítulo são apresentados os dados coletados, seguido de análise e discussões. Em cada caso são apresentados o contexto e histórico do negócio, em seguida a caracterização do mercado e da tecnologia; a análise de riscos considerando a abordagem NPVR (Davis, 2002) e a Maturity Level in Enterprise Risk Management (Oliva, 2015); as principais ações da empresa nesse ambiente de incerteza de desenvolvimento e lançamento de uma tecnologia e por fim a aplicação do modelo de pesquisa - Risk management matrix.

\subsection{CASO CATARSE}

O caso Catarse demonstra-se representativo principalmente devido ao modelo de negócio proposto que era inédito no Brasil. Além disso, a empresa adotou práticas administrativas pouco convencionais, focadas na prática, priorizando o testar rápido e a aprendizagem tanto no desenvolvimento do produto como na gestão da empresa, o que aumentou o risco do projeto, mas acelerou o seu lançamento. Com relação ao desenvolvimento do produto, destacou-se a adoção do processo de benchmarking e também o pouco capital intensivo exigido para realizar o primeiro lançamento. Dos quatro estudados foi o que apresentou o maior risco e, mesmo assim, o Catarse conseguiu se manter líder de mercado após cinco anos de operação. Embora existissem diversos fatores responsáveis por isso, pode-se citar que nesse caso visualizasse alguns benefícios do pioneirismo, como o potencial de reconhecimento da marca atrelado ao modelo (crowdfunding) e o tempo de mercado que permitiu o refinamento de processos e aperfeiçoamento do serviço.

\subsubsection{Contexto e histórico}

De acordo com documentos cedidos pela empresa (D1Caso1), o Catarse foi fundado em 2011, sendo a primeira plataforma de financiamento coletivo (crowdfunding) para projetos criativos no Brasil. A oportunidade do negócio foi encontrada pelos fundadores no mercado cultural, especificamente no oferecimento de uma alternativa de financiamento artístico paralela às leis de incentivo do governo. A proposta da empresa era a de ocupar uma falha dos sistemas tradicionais de financiamentos da produção criativa, atendendo a demanda reprimida de propostas que encontravam menos burocracia e riscos e mais agilidade e independência de 
financiamento por meio dessa modalidade. Segundo o entrevistado (E1Caso01), “[...] a questão era que havia pessoas com boas ideias que ficavam engavetadas por falta de dinheiro, e muitas vezes, por pouco dinheiro".

Foi nesse contexto que os sócios recém-formados (pouca experiência profissional) procuravam um programador para criar uma plataforma que reproduzisse o Kickstarter, site americano reconhecido por ser o principal nesse segmento (processo de benchmarking). Por meio das suas redes de contatos (processo de networking), foram apresentados a um desenvolvedor que tinha a intenção de criar um site com a mesma finalidade. Dessa união surgiu o blog Crowdfunding Brasil, que foi o primeiro canal de discussão de financiamento coletivo do país.

De acordo com o entrevistado (E1Caso01), o modelo de negócio de um site de crowdfunding foi viável na época devido ao pouco capital intensivo exigido, sendo o custo principal o de pessoal, ou seja, a manutenção da pequena equipe que, na época, era formada por um designer, um desenvolvedor, um analista e um administrador (todos sócios).

Por envolver um projeto inovador e de baixo risco financeiro, os empreendedores não investiram capital em análises de viabilidade de mercado e consequentemente a falta de informações sobre o consumidor dificultou a construção da primeira versão do site. Assim, apesar de ter mais de cinco mil pessoas interessadas no lançamento, logo em sua primeira semana, a plataforma teve problemas como, por exemplo, com o sistema de pagamento que não aceitava boleto bancário.

Apesar de apresentar dificuldades comuns aos primeiros anos de uma startup (como a ausência de controle financeiro e estrutura horizontal associada com trabalho remoto), em cinco anos de atuação, o Catarse operacionalizou cerca de 38 milhões de reais de mais de 2.300 projetos financiados, e contava com aproximadamente 260 mil apoiadores.

\subsubsection{Negócio}

Nesse tópico são apresentadas a caracterização do mercado e da tecnologia. Essas características são relevantes por que consistem em pontos que serão avaliados no cálculo do risco da empresa por meio da abordagem do NPVR, proposta por Davis (2002). 


\subsubsection{Mercado e Tecnologia}

Os sites de crowdfunding são mais recentes no Brasil do que nos mercados europeus e americanos, sendo que os projetos no país têm um foco maior em ações culturais e beneficentes e ainda encontram barreira na insegurança jurídica causada pela ausência de legislação específica. A maioria das arrecadações no Brasil é voltada para projetos artísticos, seguido pelos de empreendedorismo e iniciativas de cunho social (SETTI; CRUZ, 2011), sendo que até 2014 foram arrecadados mais de 55 milhões de dólares na região da América Latina por intermédio desse modelo (MASSOLUTION, 2015).

Com relação à tecnologia, no caso do Catarse, não foi verificada uma barreira grande, visto que a proposta era de um marketplace simples e baseado em recompensas, sendo que todo colaborador tinha direito a uma de acordo com critérios definidos pelo dono do projeto. O funcionamento de uma campanha é descrito a seguir:

\section{Como funciona o Catarse?}

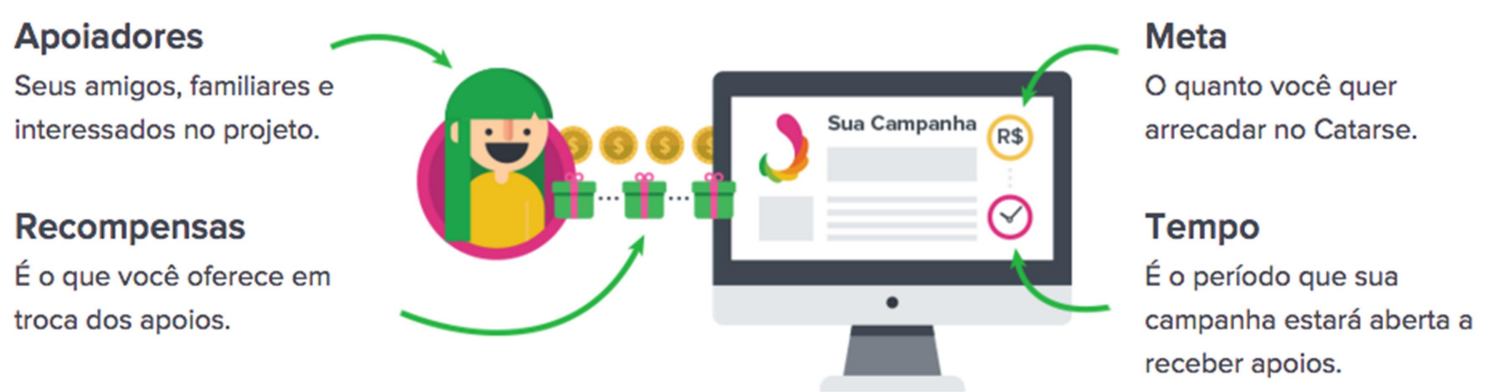

Figura 12 - Fluxograma de apresentação do modelo de funcionamento do site Catarse Fonte: Catarse (2016)

As recompensas, por sua vez, podem ser produtos, serviços ou formas simbólicas e criativas de agradecer ao engajamento dos colaboradores. Apesar de simples, uma dificuldade desse sistema era que existia um prazo para que a meta de arrecadação fosse alcançada e caso isso não ocorresse o dinheiro era estornado para os colaboradores. No começo da operação isso representava um risco, porque esse processo era feito manualmente o que o tornava complexo. 
Essas características de tecnologia e mercado são importantes para a pesquisa, pois implicam diretamente na avaliação de risco técnico da abordagem NPVR que será apresentada a seguir.

\subsubsection{Análise de Riscos no caso estudado}

O objetivo desse tópico é de avaliar os riscos que foram observados no Catarse, considerando a abordagem NPVR (DAVIS, 2002) e a Maturity Level in Enterprise Risk Management (OLIVA, 2015).

Davis (2012) entende que New Ventures - são os produtos novos para o mundo, que representam o primeiro de seu tipo e por isso necessitam da criação de um mercado totalmente novo.

Pode-se considerar o Catarse como sendo um New Ventures, pois o modelo de negócio e o conceito era inédito no Brasil, tanto que não possuía concorrência. Apresentado esse contexto inicial da startup, a seguir será explicada a avaliação de risco de mercado, de usuário e de tecnologia, as três dimensões consideradas pela visão NPVR.

\subsubsection{Avaliação de Risco de Mercado}

A partir dos dados levantados e da contextualização das atividades da empresa, foi analisado o risco de mercado por meio da comparação do quadro abaixo com a entrevista com o fundador do Catarse (E1Caso01).

Tabela 15- Critérios para avaliação de riscos da cadeia de valor e segmento de mercado

\begin{tabular}{|c|c|c|}
\hline Pontuação & Avaliação da cadeia de valor & Avaliação do segmento de mercado \\
\hline Alta & $\begin{array}{l}\text { Todos os requisitos da cadeia de } \\
\text { valor existem internamente na } \\
\text { empresa }\end{array}$ & $\begin{array}{l}\text { Empresa é líder de mercado no } \\
\text { segmento de mercado-alvo }\end{array}$ \\
\hline Média & $\begin{array}{l}\text { Todos os requisitos da cadeia de } \\
\text { valor existentes, alguns por meio de } \\
\text { parceiros }\end{array}$ & $\begin{array}{l}\text { Empresa vende outros produtos para } \\
\text { clientes no segmento de mercado }\end{array}$ \\
\hline Baixa & $\begin{array}{c}\text { Algumas ou todas as necessidades da } \\
\text { cadeia de valor não estão presentes } \\
\text { dentro da empresa ou com parceiros } \\
\text { existentes }\end{array}$ & $\begin{array}{l}\text { Novo segmento de mercado, ou a } \\
\text { empresa não tem presença no } \\
\text { segmento de mercado-alvo }\end{array}$ \\
\hline
\end{tabular}

Fonte: Davis (2002) 
$\mathrm{O}$ risco de mercado engloba qualquer elemento da cadeia de valor exigido de um novo produto para que ele atinja seus clientes potenciais. A partir dessa definição, pode se concluir que a pontuação do Catarse era baixa (2), pois a única parceria no lançamento da plataforma foi com o meio de pagamento que era responsável por processar todas as operações financeiras, inclusive por viabilizar os estornos de campanhas malsucedidas, ocupando assim um papel central da cadeia de valor da empresa.

Com relação à avaliação segmento de mercado, o Catarse tinha pontuação baixa (1), porque o crowdfunding era inexistente, sendo um novo segmento de mercado.

Analisado os riscos de mercado, a seguir será apresentado os riscos técnicos do negócio, outro fator da fórmula para cálculo do risco pela abordagem NPVR.

\subsubsection{Avaliação de Riscos Técnicos}

Riscos técnicos estão relacionados com o produto, bem como as capacidades de desenvolvimento da empresa. A pontuação obtida por estes fatores a partir da análise dos dados referentes ao Catarse está descrita a seguir:

Tabela 16 - Critérios para avaliação de riscos de inovação e recursos

\begin{tabular}{|c|c|c|}
\hline Pontuação & Avaliação da Inovação & Avaliação de Recursos \\
\hline Alta & $\begin{array}{l}\text { Utilização incremental de tecnologia bem } \\
\text { entendida }\end{array}$ & $\begin{array}{l}\text { Equipe de desenvolvimento com } \\
\text { experiência em projeto semelhante }\end{array}$ \\
\hline Média & $\begin{array}{l}\text { Nova tecnologia, protótipos desenvolvidos e } \\
\text { testados }\end{array}$ & $\begin{array}{c}\text { Nova equipe de desenvolvedores } \\
\text { com alguma experiência em } \\
\text { projetos semelhantes }\end{array}$ \\
\hline Baixa & $\begin{array}{l}\text { Nova tecnologia, fase de prova de conceito } \\
\text { com teste limitado }\end{array}$ & $\begin{array}{l}\text { Equipe incompleta e limitada } \\
\text { experiência em projetos } \\
\text { semelhantes }\end{array}$ \\
\hline
\end{tabular}

Fonte: Davis (2002)

É possível considerar, a partir dos dados levantados, a pontuação da inovação como baixa (2), pois a plataforma de lançamento estava em fase de prova de conceito e com teste limitado. De acordo com o entrevistado, o sistema era muito simples e sequer tinha integração com o meio de pagamento. Além disso, o primeiro teste foi limitado a cinco projetos, segundo (E1Caso01): “[...] eu queria só testar pequeno”.

Com relação à avaliação de recursos, a pontuação foi considerada média (3), pois apesar da equipe ser suficiente para o desenvolvimento do negócio, não havia um integrante 
com um histórico profissional relacionado com crowdfunding.

Complementando a avaliação tecnológica, no próximo item foi analisado o risco de usuário, que se divide em capacidade de interação e especificação.

\subsubsection{Avaliação de Riscos de Usuário}

Enquanto o risco de mercado determina a capacidade da empresa para vender e dar suporte ao produto, e o risco técnico determina sua capacidade para construir o produto, o risco do usuário determina a probabilidade de que a empresa esteja desenvolvendo o produto certo (Davis, 2002). Avaliação de risco do usuário se concentra nos seguintes fatores:

Tabela 17 - Critérios para avaliação de riscos de interação e especificação

\begin{tabular}{c|c|c}
\hline Pontuação & Avaliação da Interação & Avaliação da Especificação \\
\hline Alta & $\begin{array}{c}\text { Pesquisa com o usuário primário } \\
\text { realizada ou planejada antes do } \\
\text { desenvolvimento }\end{array}$ & $\begin{array}{c}\text { Extensão de design de produto e } \\
\text { especificação de desempenho } \\
\text { existentes }\end{array}$ \\
Média & $\begin{array}{c}\text { Pesquisa com o usuário não } \\
\text { realizada, mas pesquisa com um } \\
\text { produto secundário realiza }\end{array}$ & $\begin{array}{c}\text { Nova especificação de design e } \\
\text { desempenho no segmento de } \\
\text { mercado existente }\end{array}$ \\
Baixa & $\begin{array}{c}\text { Pesquisa com usuário não } \\
\text { realizada, atributos do usuário } \\
\text { atribuídos por equipe interna }\end{array}$ & $\begin{array}{c}\text { Novo design e especificação de } \\
\text { desempenho no segmento do } \\
\text { Novo Mercado }\end{array}$ \\
\hline
\end{tabular}

Fonte: Davis (2002)

Com relação à avaliação da interação, o Catarse teve pontuação baixa (1), porque não realizou uma pesquisa com o usuário primário antes do desenvolvimento da plataforma, conforme disse o entrevistado (E1Caso01) “[...] para colocar para rodar não teve um processo de pesquisa com os usuários, a gente se preocupava mais com o modelo ser funcional e por isso não tínhamos um perfil ideal de clientes". E1Caso01 justificou também a ausência de pesquisa devido ao baixo risco da operação: “[...] a gente não quis testar isso antes e não estava se importando muito, porque para colocar o site no ar não tivemos muito custo".

Em relação à especificação, o Catarse teve pontuação baixa (2), pois era um novo design para um segmento novo de mercado, o que gerava uma barreira de educação do usuário sobre o conceito desse modelo.

Apresentados os principais riscos e a sua distribuição no Catarse, no próximo item será apresentado o cálculo do NPVR, que utiliza as informações apresentadas para mensurar o quão exposto estava a empresa aos riscos de mercado, usuário e de tecnologia no momento do 
lançamento do produto.

\subsubsection{Cálculo do NPVR}

A partir dos dados coletados e apresentados posteriormente, o NPVR é calculado da seguinte forma:

$\mathrm{NPVR}=((\mathrm{aM}+\mathrm{bM}+\mathrm{cT}+\mathrm{dT}+\mathrm{eU}+\mathrm{fU}) / 10) \times$ Valor Presente Líquido

Considerando o Catarse como um New Ventures, de modo que os fatores de ponderação correspondentes a $\mathrm{M}=0.45, \mathrm{~T}=0.1$ e $\mathrm{U}=0.45$.

$\mathrm{NPVR}=((\mathrm{a} 0.45+\mathrm{b} 0.45+\mathrm{c} 0.1+\mathrm{d} 0.1+\mathrm{e} 0.45+\mathrm{f} 0.45) / 10) \times$ Valor Presente Líquido

Onde a, b, c, d, e, f são as avaliações da cadeia de valor, do segmento de mercado, inovação, recursos, capacidades de interação e de especificação.

Por fim, com objetivo sintetizar os riscos explicados anteriormente e facilitar a visualização de sua distribuição, a tabela 18 foi construída.

Tabela 18 - Resumo da avaliação dos riscos do Catarse

\begin{tabular}{c|c|c}
\hline Avaliação & Pontuação & Risco relacionado \\
\hline Cadeia de valor & 2 & Mercado \\
Segmento de mercado & 1 & Mercado \\
Inovação & 2 & Técnico \\
Recursos & 3 & Técnico \\
Interação & 1 & Usuário \\
Especificação & 2 & Usuário
\end{tabular}

Fonte: Davis (2002)

Aplicando a fórmula do NPVR:

$$
\begin{aligned}
& \text { NPVR }=((2 * 0.45+1 * 0.45+2 * 0.1+3 * 0.1+1 * 0.45+2 * 0.45) / 10) \times \text { VPL } \\
& \text { NPVR }=32 \% \text { VPL }
\end{aligned}
$$

Portanto o NPVR é de $32 \%$ do VPL original, indicando que $68 \%$ do valor VPL projetado estava em risco. Como o NPVR está integrado ao processo de decisão, este nível de risco indica que esse processo poderia ser aprimorado. Nesse caso em específico, o fato de o "fracasso" envolver baixo risco financeiro, foi importante para que as decisões fossem tomadas com uma análise menos profunda, o que aumentou o risco do projeto, mas acelerou o seu lançamento. 
A abordagem do NPVR (DAVIS, 2002) permite identificar e analisar relevantes riscos em dimensões chave no desenvolvimento das startups. No entanto, com o intuito de complementar e amplificar a dimensão dos riscos no fenômeno estudado, foram considerados aqueles propostos na abordagem da Maturity Level in Enterprise Risk Management, aos quais o Catarse estava submetido no seu lançamento, apresentadas e ilustrada a seguir.

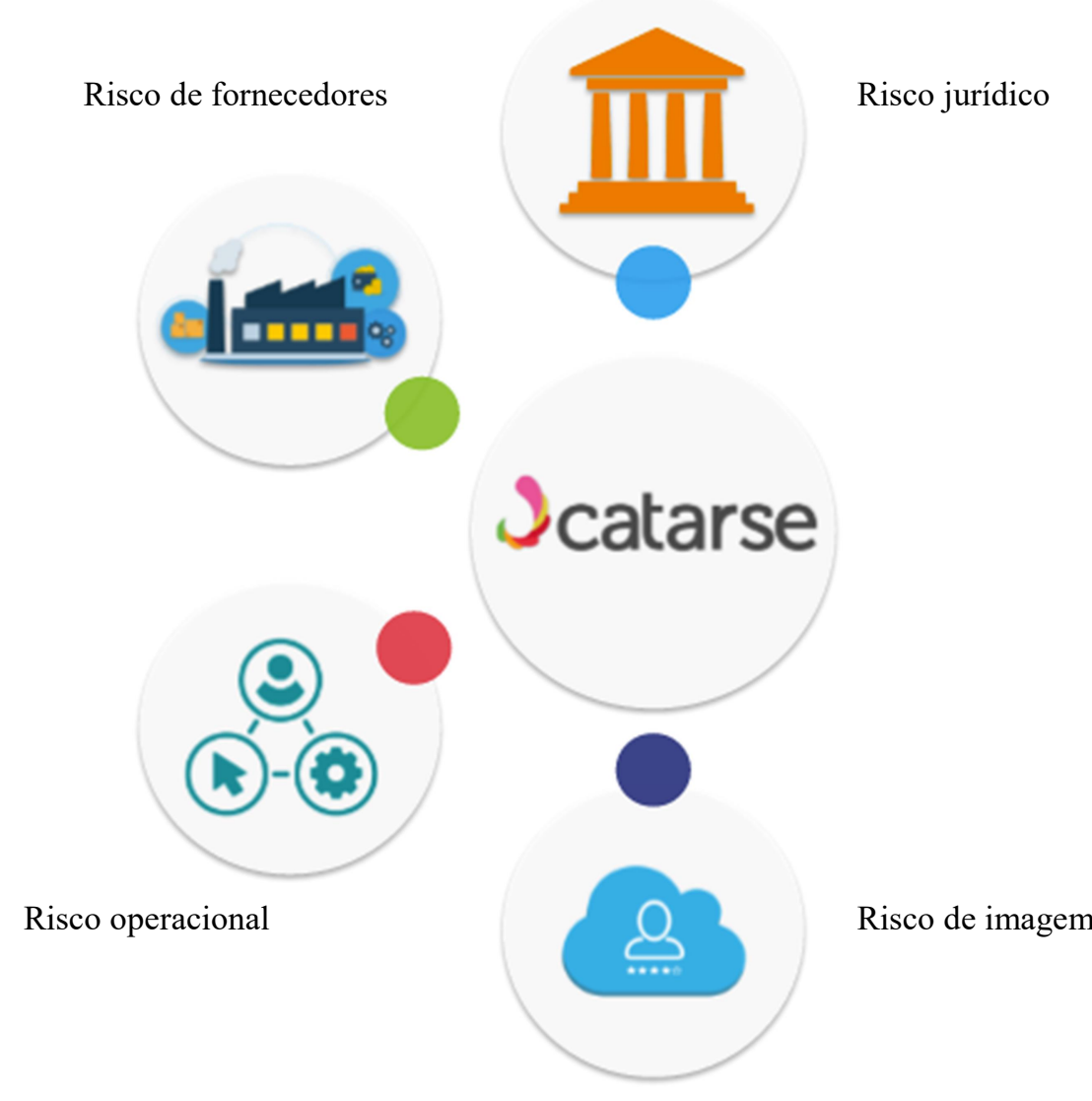

Figura 13 - Representação dos riscos do caso Catarse

Com relação aos riscos abordados por essa segunda visão, o Catarse estava sujeito aos riscos de "atraso na execução do projeto financiado", o que poderia gerar um problema de imagem para a empresa. De acordo com o entrevistado (E1Caso01), ocorreram situações em que após a arrecadação ter sido bem-sucedida, acontecer problemas com o beneficiário. Como exemplo, foi citado um caso em que membros de uma banda musical arrecadaram a meta e atrasaram o CD que prometeram. Outro risco relacionado com imagem, foram as campanhas que possuíam algum posicionamento político. Além disso, existia o risco de violação de direito autoral, que poderia ocasionar processos para grupos que tentavam financiar projetos que infringiam esse tipo de lei.

Além deles, sobre riscos operacionais foi citado o de controle dos fluxos financeiros 
da empresa que, no começo, era feito em uma planilha do software Microsoft Excel, ocasionando um risco, pois existia uma base de dados de segurança que poderia ser exposto ou perdido.

Outro ponto crítico era a dependência de somente um meio de pagamento (fornecedores), pois não existia uma alternativa viável no mercado para substituí-lo, visto que o sistema de pagamento escolhido foi a única empresa que aceitou ser parceira e trabalhar com as singularidades do modelo de crowdfunding.

Por fim, o problema jurídico e contábil devido à ausência na legislação brasileira de uma norma para regulamentar a declaração fiscal do dinheiro provindo de uma campanha de crowdfunding, bem como de uma definição legal sobre a isenção de impostos das recompensas.

Nota-se que todas as categorias de riscos levantadas podem representar maior ou menor ameaça ao negócio. O que vai determinar ou influenciar o seu impacto sobre o empreendimento é o modo como se responde aos riscos.

Nesse sentido, o Catarse promoveu no começo da empresa um rígido processo de curadoria para evitar a entrada de projetos com alto risco de insucesso. Ao mesmo tempo, para captar os melhores projetos, investiu no crescimento da rede de financiadores. E para viabilizar as campanhas, o Catarse investiu também em estratégias para apoiar o dono do projeto, como guias para apresentação de campanha e outras ações de orientação como a da ilustração abaixo:

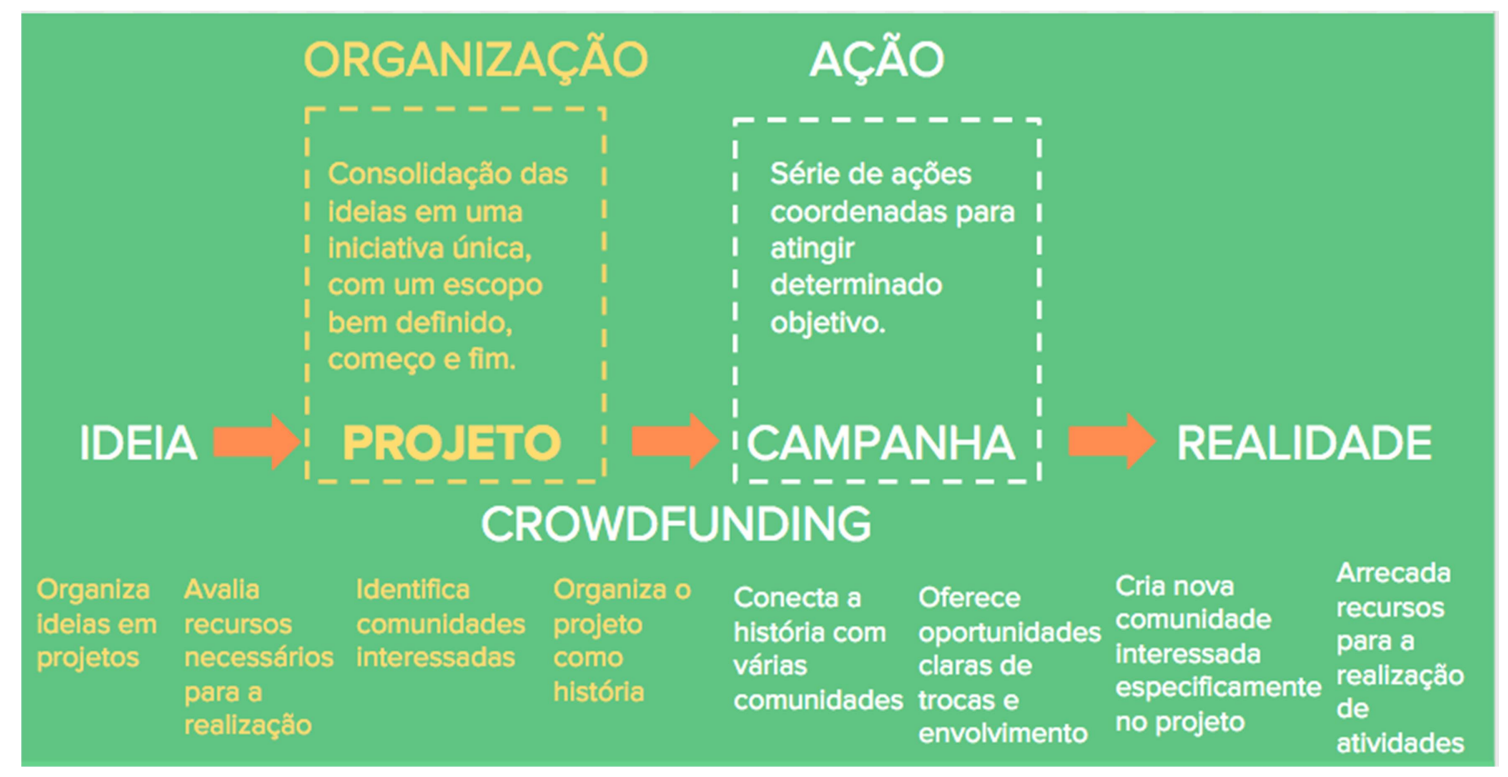

Figura 14 - Exemplo de modelo para orientação de campanha Fonte: Catarse (2016) 
Nesse quadro, a empresa apresenta todos os passos que devem ser seguidos para viabilizar um projeto. Além disso, são oferecidos também diversos vídeos e documentos sobre o funcionamento do crowdfunding, exemplos de campanhas de sucesso e planos de marketing para alcançar o público-alvo.

Apresentados os principais riscos aos quais o Catarse estava exposto, a sua mensuração e o contexto em que estavam inseridos, no próximo item são avaliadas as ações empreendedoras para mitigá-los, ou seja, quais foram as decisões que a empresa tomou com a finalidade de diminuir a sua exposição a esses riscos.

\subsubsection{Ações empreendedoras sobre incerteza}

Esse tópico aborda as principais ações da empresa no ambiente de incerteza de lançamento e desenvolvimento de uma tecnologia. No Catarse, foi observado que a maioria das ações não foram delineadas antes do lançamento do produto, e na entrevista evidenciou-se que o processo foi muito mais prático do que metodológico, priorizando o testar rápido e a aprendizagem tanto no desenvolvimento do produto como na administração do negócio. Como exemplos dessa constatação é possível destacar:

- Não houve um estudo do cliente potencial no desenvolvimento do produto, ausência considerada, à época da coleta de dados, como crítica pelo entrevistado (E1Caso01);

- A parte financeira foi estruturada somente após cinco anos de empresa.

Ou seja, os problemas, em sua maioria, eram resolvidos à medida que apareciam, não existindo um processo prévio para mitigá-los. Nota-se também a presença de efetivação na tomada de decisão na formação da equipe, pois esse procedimento foi realizado de maneira informal, sem investimento financeiro e planejamento, ficando nítido que os sócios selecionaram um conjunto de meios para verificar o que era possível ser feito a partir deles.

Também foi observada a aplicação da filosofia do Lean Start-up no desenvolvimento do produto que, no começo, era simples e foi sendo remodelado de acordo com o feedback dos usuários. Como exemplo, pode-se citar a ausência de boleto bancário no sistema de pagamento que precisou ser inserido na primeira semana após o lançamento.

Como esse processo de comunicação com o usuário demonstrou resultados positivos, a empresa decidiu construir um fórum destinado ao feedback dos clientes que guiaram as modificações da plataforma. De acordo com o entrevistado (E1Caso01): "Não adiantava nada eu colocar uma novidade, se eu não soubesse como é que aquilo efetivamente iria impactar o dia a dia das pessoas". 
Por fim, como o Catarse não conduziu os processos estratégicos de maneira mais tradicional, não se constatou nesse caso a adoção de um plano de negócio. Segundo o entrevistado, os sócios tinham somente uma folha, que traduzia o modelo de marketplace: “A gente não teve um processo estruturado para crescer" (E1Caso01). Essa ausência de planejamento causou alguns problemas de gestão futuros, como dificuldades financeiras para custear o crescimento da empresa.

Em relação ao acompanhamento de execução das atividades, observou-se que no início do Catarse o trabalho era remoto, o que ocasionava dificuldade de controle e diminuição da agilidade de tomada de decisão.

Apresentadas as ações empreendedoras sobre incerteza, o próximo tópico foi destinado a analisar o caso pelo quadro proposto por essa dissertação.

\subsubsection{Aplicação do modelo de pesquisa no caso Catarse}

Nesse tópico são apresentados os dados a respeito do Catarse de acordo com o modelo proposto dedutivamente. Os dados coletados foram condensados por meio de codificação de primeiro e segundo nível, tendo como referência para a codificação os aspectos propostos de maneira dedutiva. Buscou-se, entretanto, reconhecer e classificar dados que não estavam dentro dos códigos estabelecidos previamente por meio do modelo da pesquisa.

Assim, a partir da combinação de aspectos dedutivos e indutivos os dados foram analisados, descritos e exibidos por meio de tabelas e descrições textuais. Por fim, foi gerado um modelo a fim de auxiliar futuras startups no desenvolvimento de novas tecnologias no mercado brasileiro apresentado a seguir. 


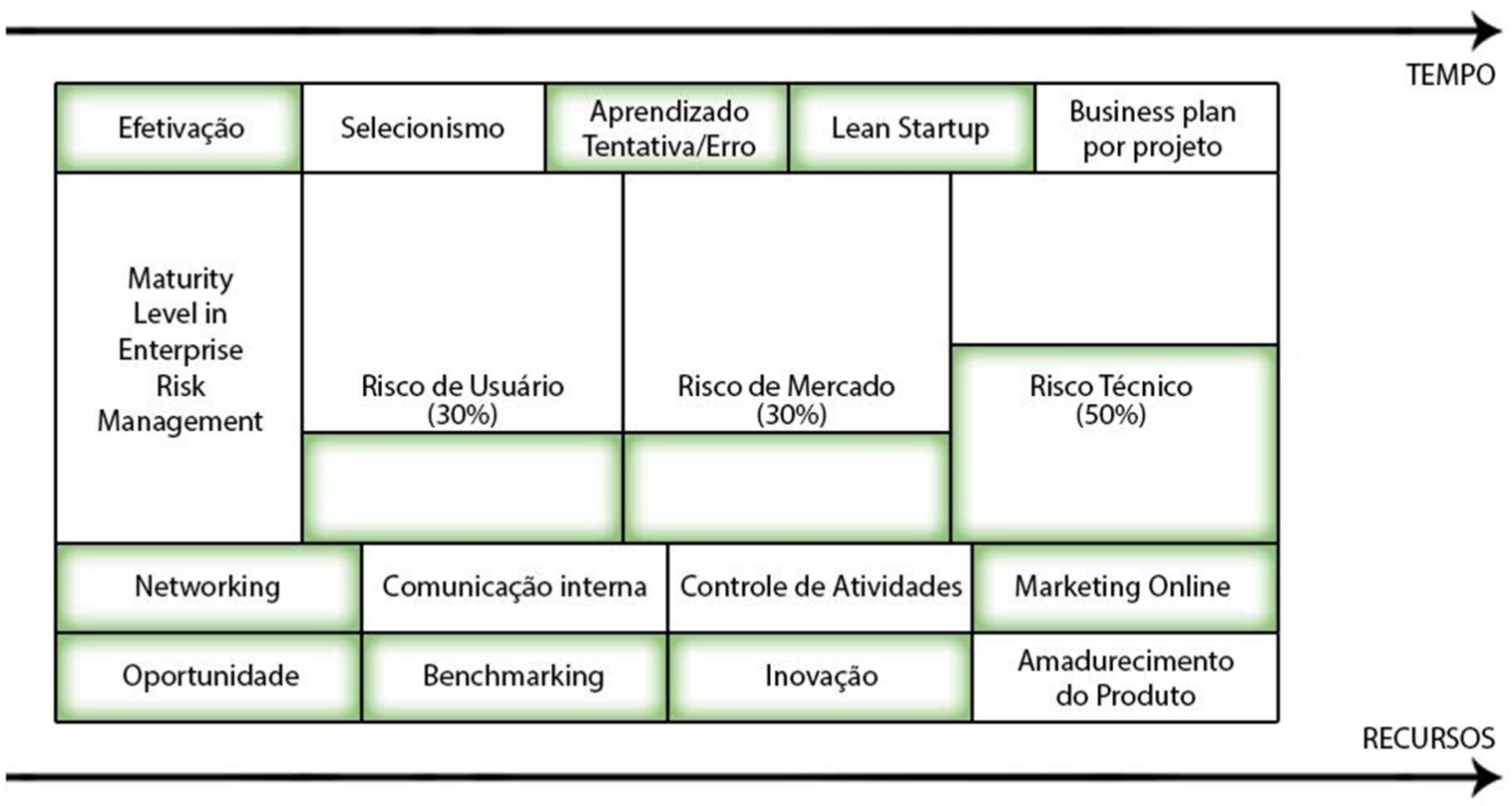

Figura 15 - Risk Management Matrix - Catarse

As células da matriz circundadas em verde representam as características presentes no Catarse. Observa-se que os elementos mais relacionados às fases iniciais de uma startup (em que recurso é um fator limitante) são observados. Efetivação, por exemplo, nas ações empreendedoras e networking com relação à comunicação foram importantes fatores citados.

A filosofia do Lean Startup (RIES, 2011), baseada na aprendizagem validada por meio de feedback dos clientes de forma rápida e frequente foi adotada como estratégia de melhoria contínua do site. Além dela, o benchmarking com as soluções desenvolvidas no exterior foi explorado e essas ações em conjunto ajudaram a viabilizar o produto, mesmo com um risco alto.

Outro ponto importante na gestão de projetos e não observado é o desenvolvimento de business plan. Por estar ausente, houve dificuldades na administração do negócio, que idealmente deveria ocorrer por meio de planejamento de cenários futuros alternativos e definição de objetivos específicos e metas, juntamente com o cálculo dos recursos necessários para atingi-las. Ao compreender melhor o negócio e o mercado, o Catarse poderia ter planejado a forma de operar e ampliar os resultados de longo prazo.

A ausência de um plano de negócios também afetou decisões de investimento durante o ciclo de vida da empresa, pois em um mercado de financiamento competitivo, todos os credores potenciais exigem acesso às declarações financeiras juntamente com um plano atualizado.

Com relação à comunicação, que desempenha um papel fundamental na manutenção 
de uma empresa, não foi observado um sistema adequado, em que os participantes conseguissem se comunicar de forma consistente sobre o estágio dos projetos da empresa. Considerando que a comunicação regular permite que os funcionários trabalhem de maneira mais produtiva, esse foi um risco para a startup.

Esses fatores em conjunto demonstraram que o Catarse possuía diversas lacunas no seu lançamento, que aumentaram o seu risco global. Com o amadurecimento da empresa, algumas dessas incertezas foram sendo superadas, como por exemplo, o risco de o produto não ser aceito pelo mercado.

Esse caso é representativo, pois dos quatro estudados foi o que apresentou o maior risco e mesmo assim a empresa conseguiu se manter líder de mercado após cinco anos de operação. Embora existam diversos fatores responsáveis por isso, pode-se citar que nessa startup visualizasse alguns benefícios do pioneirismo, como o potencial de reconhecimento da marca atrelado ao modelo proposto (crowdfunding) e o tempo de mercado que permitiu o refinamento de processos e aperfeiçoamento do serviço. 


\subsection{CASO GUIABOLSO}

No caso do GuiaBolso, um ponto observado com maior intensidade com relação aos demais casos foi o uso de networking para o desenvolvimento da empresa, desde a construção da sociedade as parcerias estratégicas. Apesar de poucos anos no mercado, é relevante também o número de usuários que somavam mais de 1,8 milhão em fevereiro de 2016. A empresa apresentava algumas caraterísticas de startups como o fato de ainda não possuir fluxo de caixa, mas pelo seu potencial já havia recebido o aporte de mais de 22 milhões de reais de fundos de investimento até a data da entrevista. Outro ponto importante do caso, foi a questão do benchmarking que esteve presente desde a concepção do produto até a sua prototipagem.

\subsubsection{Contexto e histórico}

De acordo com documentos fornecidos pela empresa (D1Caso02), o aplicativo GuiaBolso foi lançado em abril de 2014, sendo o primeiro sistema de controle financeiro automático do Brasil. Seu programa permitia a conexão com contas de banco, baixando automaticamente todas as informações de gastos e rendas do usuário, sem a necessidade de inserção de dados manuais. A evolução da empresa é apresentada a seguir pela sua linha do tempo:

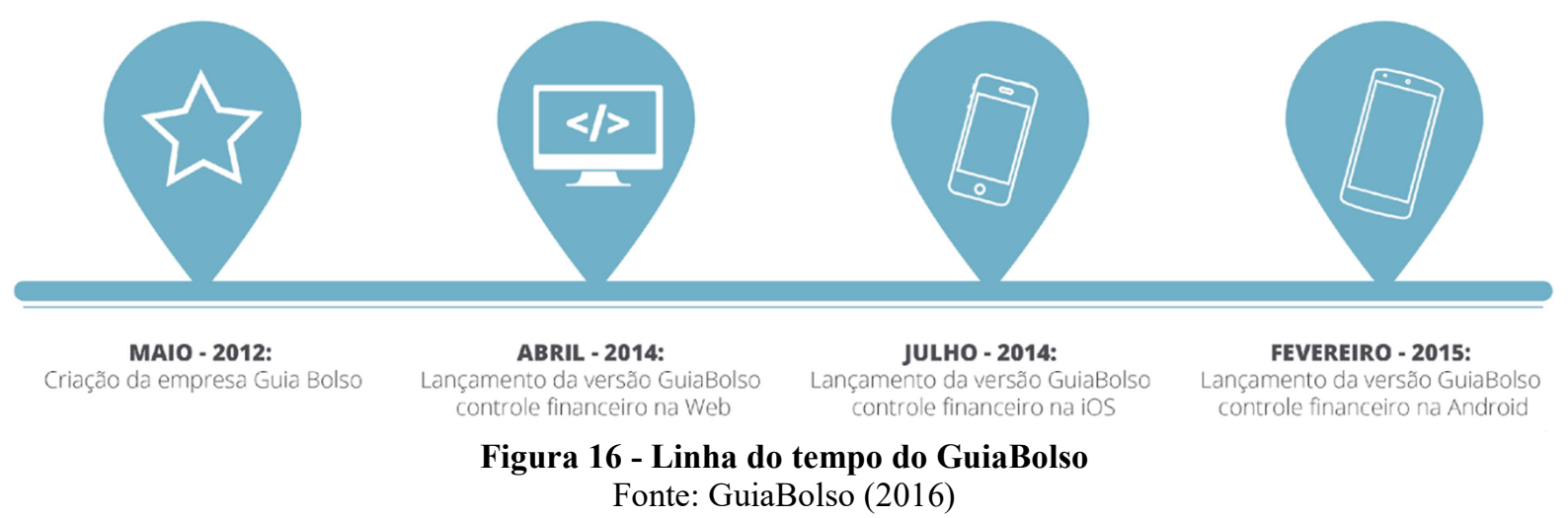

O primeiro lançamento foi um site (web), em 2012, que realizava consultorias financeiras, mas sem a possibilidade de leituras automáticas de contas, o que inviabiliza sua escalabilidade. Todavia, no lançamento da sua primeira versão para smartphones, em julho de 2014, o GuiaBolso cresceu e em 2015, somava mais de 1,8 milhão de usuários que apresentavam, em média, uma melhoria de $14 \%$ na sua saúde financeira, após um mês de uso do aplicativo. 
$\mathrm{Na}$ entrevista com o fundador da empresa (E1Caso02), percebeu-se que o GuiaBolso, que tem menos de quatro anos de mercado, ainda apresentava caraterísticas de startups (listadas nesse estudo no item Startups), tais como: a flexibilidade na tomada de decisão; ter somente um produto no portfólio e a rápida evolução da ferramenta. Outras características de startups que estavam presentes no caso são: a organização completa (representada pela constante presença dos sócios em todos os processos da empresa) e a não autossustentabilidade (por não possuir fluxo de caixa). Embora não fosse rentável, o GuiaBolso já tinha recebido o aporte de mais de 22 milhões de reais de fundos de investimento até fevereiro de 2016, uma demonstração do potencial do negócio.

\subsubsection{Negócio}

Nesse tópico é apresentada a caracterização do mercado e da tecnologia. Essas características são relevantes por que consistem em pontos que serão avaliados no cálculo do risco da empresa por meio da abordagem do NPVR, proposta por Davis (2002).

\subsubsection{Mercado}

O GuiaBolso foi fundado em um momento de crescimento econômico no Brasil que ampliou a classe média no país. De acordo com o primeiro relatório Novas Vozes da Classe Média (2012), estima-se que, em 2012, 53\% da população brasileira, o equivalente a 104 milhões de pessoas pertencia à classe média, comparados com os 38\% em 2002.

Nesse mesmo intervalo de tempo, segundo o IBGE (2013), o contingente de pessoas procurando trabalho teve redução de 2,6 milhões para 1,3 milhões e o poder de compra aumentou em $29,6 \%$.

Esse cenário positivo, entretanto, foi acompanhado por índices negativos, como o aumento da dívida da população mais pobre e da inflação. De acordo com o Relatório de Inclusão Financeira (2015), a população de menor renda, com até três salários mínimos, foi o grupo mais representativo em número de tomadores de crédito. Do total de 56 milhões de tomadores de crédito em 2014, 34 milhões estava nessa faixa, o que equivale a $20 \%$ da população adulta. A representatividade desse segmento era um risco quando se analisava o comprometimento de renda e de inadimplência principalmente com as dívidas de cartão de 
crédito, uma modalidade de pagamento usada por 52 milhões de brasileiros (SPCBRASIL, 2015).

Dentre esses brasileiros, $96 \%$ afirmavam não ter conhecimento sobre a taxa de juros mensal quando optavam por pagar o mínimo da fatura, sendo que em 2015, a taxa do cartão de crédito chegou a cerca de 300\% ao ano (SPCBRASIL, 2015).

Nesse cenário, o GuiaBolso foi fundado com a proposta principal de auxiliar os brasileiros que tiveram acesso à crédito mais recentemente. De acordo com o entrevistado (E1Caso02), a empresa tinha como objetivo ajudar essa nova geração de consumidor a controlar suas finanças e entender os produtos ofertados pelos bancos. Segundo previsões internas do GuiaBolso o mercado estimado era de vinte milhões de contas bancárias até 2017.

Apresentado o panorama do mercado, no próximo item será apresentado o processo de construção da tecnologia que também é importante para a avaliação dos riscos do empreendimento.

\subsubsection{Tecnologia}

Em relação à tecnologia, nesse caso dois pontos se destacam. O primeiro é o benchmarking que esteve presente desde a concepção do produto até a sua prototipagem. Com essa estratégia, o GuiaBolso foi capaz de identificar uma oportunidade local e ajustar um modelo internacional ao mercado brasileiro, apesar das diferenças culturais, legais e econômicas entres os países.

Com relação ao risco, esse processo aprimorou o desenvolvimento do produto a partir da comparação com empresas bem-sucedidas no exterior, por meio do aprendizado com os erros e acertos de seus antecessores, reduzindo assim as suas próprias necessidades de investimento. De acordo com o entrevistado, a empresa teve contato direto com os grandes players mundiais como o Mint, Level Money e o Moneytree.

Além disso, por ter sido a pioneira nessa proposta de valor no Brasil, o GuiaBolso demonstrou uma estratégia eficaz em marketing e tecnologia que ampliou o reconhecimento da marca e o acesso aos dados dos clientes por meio do seu sistema que permitia a conexão com contas de banco, baixando automaticamente todas as informações de gastos e rendas do usuário, sem a necessidade de lançamentos manuais. Esse fator se tornou mais relevante para o contexto do GuiaBolso, porque quanto mais informações dos usuários, maiores seriam as chances de sucesso dos futuros modelos de monetização da empresa (no caso dela seguir o exemplo do Mint que monetiza por meio de recomendações de serviços financeiros). 
Por outro lado, por ser a first mover (a primeira empresa a apresentar esse modelo no mercado nacional), a startup se submeteu a alguns riscos como, por exemplo, a aprovação do conceito do negócio pelos bancos (que estão inseridos em uma indústria tradicional e fortemente regulamentada), a construção da infraestrutura de segurança dos dados disponibilizados pelos usuários e a educação dos clientes sobre os benefícios do aplicativo.

Além do benchmarking, o segundo fator presente no desenvolvimento do produto foi o design centrado no usuário, ou seja, a empresa valorizava a interação com o produto e investiu em uma interface intuitiva do aplicativo, com o intuito de diminuir a curva do aprendizado e aumentar a taxa de conversão. De acordo com o entrevistado, no lançamento do aplicativo as métricas da empresa tiveram uma evolução positiva, devido a melhoria na experiência do usuário, visto que o primeiro site do GuiaBolso ainda dependia de inserção manual dos dados o que diminuía o engajamento. Por meio dessa constatação e com pesquisas com os clientes, a empresa rapidamente mudou a sua tecnologia, realizando mais de um lançamento no período de dois anos, com o objetivo de criar um produto que melhor atendesse às necessidades do mercado.

Essas características de tecnologia são importantes para a pesquisa, pois implicam diretamente na avaliação de risco técnico da abordagem NPVR que será apresentada a seguir.

\subsubsection{Análise de Riscos no caso estudado}

O objetivo desse tópico é de avaliar os riscos que foram observados no GuiaBolso, considerando a abordagem NPVR (DAVIS, 2002) e a Maturity Level in Enterprise Risk Management (OLIVA, 2015).

Davis (2002) entende que "Novos produtos" são derivados de melhorias e revisões de produtos existentes. Pode-se considerar o aplicativo do GuiaBolso como sendo um novo produto, pois teve origem a partir da antiga versão do site da empresa que era uma espécie de um consultor em que os usuários preenchiam manualmente as suas informações financeiras.

De acordo com o entrevistado o aplicativo não foi a ideia inicial da empresa. Todavia, depois do lançamento do site, percebeu-se que os usuários não sabiam como responder as perguntas sobre suas finanças, o que o tornava inviável. A estratégia então foi alterada (pivotagem) e após realizar os primeiros acordos com os bancos, a versão inicial do aplicativo foi produzida e os retornos foram positivos. Com esse resultado, a empresa decidiu desativar o site e investiu somente no aplicativo. 
Apresentado esse contexto inicial da startup à época, a seguir explica-se a avaliação de risco de mercado, de usuário e de tecnologia, as três dimensões consideradas pela visão NPVR.

\subsubsection{Avaliação de Risco de Mercado}

A partir dos dados levantados e da contextualização das atividades da empresa, foi analisado o risco de mercado por meio da comparação do quadro abaixo com a entrevista com o fundador do GuiaBolso (E1Caso02).

Tabela 19 - Critérios para avaliação de riscos da cadeia a de valor e segmento de mercado

\begin{tabular}{|c|c|c|}
\hline Pontuação & Avaliação da cadeia de valor & Avaliação do segmento de mercado \\
\hline Alta & $\begin{array}{l}\text { Todos os requisitos da cadeia de } \\
\text { valor existem internamente na } \\
\text { empresa }\end{array}$ & $\begin{array}{l}\text { Empresa é líder de mercado no } \\
\text { segmento de mercado-alvo }\end{array}$ \\
\hline Média & $\begin{array}{l}\text { Todos os requisitos da cadeia de } \\
\text { valor existentes, alguns por meio de } \\
\text { parceiros }\end{array}$ & $\begin{array}{l}\text { Empresa vende outros produtos para } \\
\text { clientes no segmento de mercado }\end{array}$ \\
\hline Baixa & $\begin{array}{c}\text { Algumas ou todas as necessidades da } \\
\text { cadeia de valor não estão presentes } \\
\text { dentro da empresa ou com parceiros } \\
\text { existentes }\end{array}$ & $\begin{array}{l}\text { Novo segmento de mercado, ou a } \\
\text { empresa não tem presença no } \\
\text { segmento de mercado-alvo }\end{array}$ \\
\hline
\end{tabular}

Fonte: Davis (2002)

O risco de mercado engloba qualquer elemento da cadeia de valor exigido de um novo produto para que ele atinja seus clientes potenciais. A partir dessa definição, pode se concluir que a pontuação foi média/alta (4), pois de acordo com o entrevistado, nos seus primeiros meses de atuação o GuiaBolso teve acesso a rede Endeavor e procurou trazer advisors importantes para o desenvolvimento do negócio como, por exemplo, o primeiro investidor do Mint, uma plataforma americana similar ao GuiaBolso, e o ex-presidente do Banco Santander. Além disso, para o desenvolvimento do produto, a empresa estabeleceu parcerias com a Kellogg School of Management e com Harvard para trabalhar com questões relativas ao comportamento do consumidor na plataforma.

Alguns bancos também eram parceiros e a empresa tinha relacionamento com Google que fornecia informações para a melhoria do produto disponibilizado na Play Store, a loja virtual de aplicativos do Google.

Por fim, com relação a avaliação de segmento de mercado, o GuiaBolso tinha 
pontuação baixa (2), pois o segmento de mercado era novo. Apesar disso, é importante relatar que o aplicativo já chegou a liderar a lista de downloads da Apple Store, a loja virtual de aplicativos da Apple.

Analisado os riscos de mercado, a seguir serão apresentados os riscos técnicos do negócio, outro fator da fórmula para cálculo do risco pela abordagem NPVR.

\subsubsection{Avaliação de Riscos Técnicos}

Riscos técnicos estão relacionados com o produto, bem como as capacidades de desenvolvimento da empresa. A pontuação obtida por estes fatores a partir da análise dos dados referentes ao GuiaBolso é resumida a seguir:

Tabela 20 - Critérios para avaliação de riscos de inovação e recursos

\begin{tabular}{|c|c|c|}
\hline Pontuação & Avaliação da Inovação & Avaliação de Recursos \\
\hline Alta & $\begin{array}{l}\text { Utilização incremental de tecnologia bem } \\
\text { entendida }\end{array}$ & $\begin{array}{l}\text { Equipe de desenvolvimento com } \\
\text { experiência em projeto semelhante }\end{array}$ \\
\hline Média & $\begin{array}{l}\text { Nova tecnologia, protótipos desenvolvidos e } \\
\text { testados }\end{array}$ & $\begin{array}{c}\text { Nova equipe de desenvolvedores } \\
\text { com alguma experiência em } \\
\text { projetos semelhantes }\end{array}$ \\
\hline Baixa & $\begin{array}{l}\text { Nova tecnologia, fase de prova de conceito } \\
\text { com teste limitado }\end{array}$ & $\begin{array}{l}\text { Equipe incompleta e limitada } \\
\text { experiência em projetos } \\
\text { semelhantes }\end{array}$ \\
\hline
\end{tabular}

Fonte: Davis (2002)

$\mathrm{Na}$ análise dos dados coletados a pontuação da inovação foi considerada como média (3), pois se tratava de uma nova tecnologia com protótipos desenvolvidos e testados. De acordo com o entrevistado, somente os early adopter (usuários mais adeptos às novas tecnologias) tinham conhecimento da proposta de valor da empresa e o conceito do aplicativo era inexistente.

Com relação à avaliação de recursos, a pontuação era baixa (2), pois a equipe era incompleta e com experiência limitada em projetos parecidos. Segundo o entrevistado, na construção do aplicativo não havia um especialista com conhecimento avançado sobre conexão com bancos, pois a tecnologia era recente. Sobre a gestão do produto, não existia dentro da equipe pessoas com experiência em projetos de software, sendo a responsável destacada para isso uma profissional de outra especialidade. Todavia, um ponto considerado positivo para a gestão do risco foi que para a segurança do aplicativo, a empresa alocou um 
professor da universidade de Stanford, autoridade no assunto.

Complementando a avaliação tecnológica, no próximo item foi analisado o risco de usuário que se divide em capacidade de interação e especificação.

\subsubsection{Avaliação de Riscos de Usuário}

Enquanto o risco de mercado determina a capacidade da empresa para vender e dar suporte ao produto, e o risco técnico determina sua capacidade para construir o produto, o risco do usuário determina a probabilidade de que a empresa esteja desenvolvendo o produto certo (DAVIS, 2002). Avaliação de risco do usuário se concentra nos seguintes fatores:

Tabela 21 - Critérios para avaliação de riscos de interação e especificação

\begin{tabular}{c|c|c}
\hline Pontuação & Avaliação da Interação & Avaliação da Especificação \\
\hline Alta & $\begin{array}{c}\text { Pesquisa com o usuário primário } \\
\text { realizada ou planejada antes do } \\
\text { desenvolvimento }\end{array}$ & $\begin{array}{c}\text { Extensão de design de produto e } \\
\text { especificação de desempenho } \\
\text { existentes }\end{array}$ \\
Média & $\begin{array}{c}\text { Pesquisa com o usuário não } \\
\text { realizada, mas pesquisa com um } \\
\text { produto secundário realiza }\end{array}$ & $\begin{array}{c}\text { Nova especificação de design e } \\
\text { desempenho no segmento de } \\
\text { mercado existente }\end{array}$ \\
Baixa & $\begin{array}{c}\text { Pesquisa com usuário não } \\
\text { realizada, atributos do usuário } \\
\text { atribuídos por equipe interna }\end{array}$ & $\begin{array}{c}\text { Novo design e especificação de } \\
\text { desempenho no segmento do } \\
\text { Novo Mercado }\end{array}$ \\
\hline
\end{tabular}

Fonte: Davis (2002)

Com relação à avaliação da interação, o GuiaBolso teve pontuação alta (5), pois a empresa procurou entender, principalmente por meio do benchmarking, quais eram as funcionalidades mais valorizadas pelos usuários antes de iniciar o desenvolvimento da tecnologia. Além disso, por meio da versão web do consultor financeiro, foram realizadas mais de 40 mil consultorias e essa experiência permitiu entender melhor o consumidor.

Logo após o lançamento da primeira versão do aplicativo, segundo o entrevistado (E1Caso02), a empresa também fez testes com foco na usabilidade. Para isso, existia dentro da equipe uma pesquisadora que estudava o desempenho do aplicativo e foram firmadas parcerias com professores de universidades que realizaram experimentos com os usuários.

Em relação à especificação, o GuiaBolso teve pontuação baixa (2), pois foi o primeiro em um novo mercado e a versão do aplicativo, apesar do benchmarking com companhias estrangeiras, introduziu um novo design para o mercado brasileiro.

Apresentados os principais riscos e a sua distribuição, no próximo item será 
apresentado o cálculo do NPVR, que utiliza as informações apresentadas para mensurar o quão exposto estava a empresa aos riscos de mercado, de usuário e de tecnologia no momento do lançamento do produto.

\subsubsection{Cálculo do NPVR}

A partir dos dados coletados pelo modelo apresentado posteriormente, o NPVR é calculado da seguinte forma:

$$
\mathrm{NPVR}=((\mathrm{aM}+\mathrm{bM}+\mathrm{cT}+\mathrm{dT}+\mathrm{eU}+\mathrm{fU}) / 10) \times \text { Valor Presente Líquido }
$$

Considerando o GuiaBolso como um Novo Produto Derivado, de modo que os fatores de ponderação correspondentes a $\mathrm{M}=0.3, \mathrm{~T}=0.6$ e $\mathrm{U}=0.1$ :

$$
\text { NPVR }=((\mathrm{a} 0.4+\mathrm{b} 0.4+\mathrm{c} 0.2+\mathrm{d} 0.2+\mathrm{e} 0.4+\mathrm{f} 0.4) / 10) \times \text { Valor Presente Líquido }
$$

Onde a, b, c, d, e, f são as avaliações da cadeia de valor, do segmento de mercado, inovação, recursos, capacidades de interação e de especificação.

Por fim, com objetivo sintetizar os riscos explicados anteriormente e facilitar a visualização de sua distribuição, a tabela 22 foi construída.

Tabela 22 - Resumo da avaliação dos riscos do GuiaBolso

\begin{tabular}{c|c|c}
\hline Avaliação & Pontuação & Risco relacionado \\
\hline Cadeia de valor & 4 & Mercado \\
Segmento de mercado & 2 & Mercado \\
Inovação & 3 & Técnico \\
Recursos & 2 & Técnico \\
Interação & 5 & Usuário \\
Especificação & 2 & Usuário \\
\hline
\end{tabular}

Aplicando a fórmula do NPVR:

$\mathrm{NPVR}=((4 * 0.3+2 * 0.3+3 * 0.6+2 * 0.6+5 * 0.1+2 * 0.1) / 10) \times \mathrm{VPL}$

$\mathrm{NPVR}=55 \% \mathrm{VPL}$ 
Portanto o NPVR era de $55 \%$ do VPL original, indicando que $45 \%$ do valor VPL projetado estava em risco. Como o NPVR está integrado ao processo de decisão, este nível de risco indica que poderiam ser tomadas medidas a fim de diminuir a exposição do negócio, principalmente com relação à avaliação de recursos. Os demais riscos associados com menor pontuação - segmento de mercado e especificação - são consequências particulares do mercado e do pioneirismo da empresa, sendo mais difícil gerenciá-los.

A abordagem do NPVR (DAVIS, 2002) permite identificar e analisar relevantes riscos em dimensões chave no desenvolvimento das startups. Com o intuito de complementar e amplificar a dimensão dos riscos no fenômeno estudado, no entanto, foram considerados aqueles propostos na abordagem da Maturity Level in Enterprise Risk Management (OLIVA, 2015), aos quais o GuiaBolso estava submetido no seu lançamento.

Nesse quesito, o entrevistado relatou que a questão de segurança do aplicativo não era um fator de risco e sim um requisito para a empresa poder atuar, ou seja, sem isso o modelo de negócio seria falho.

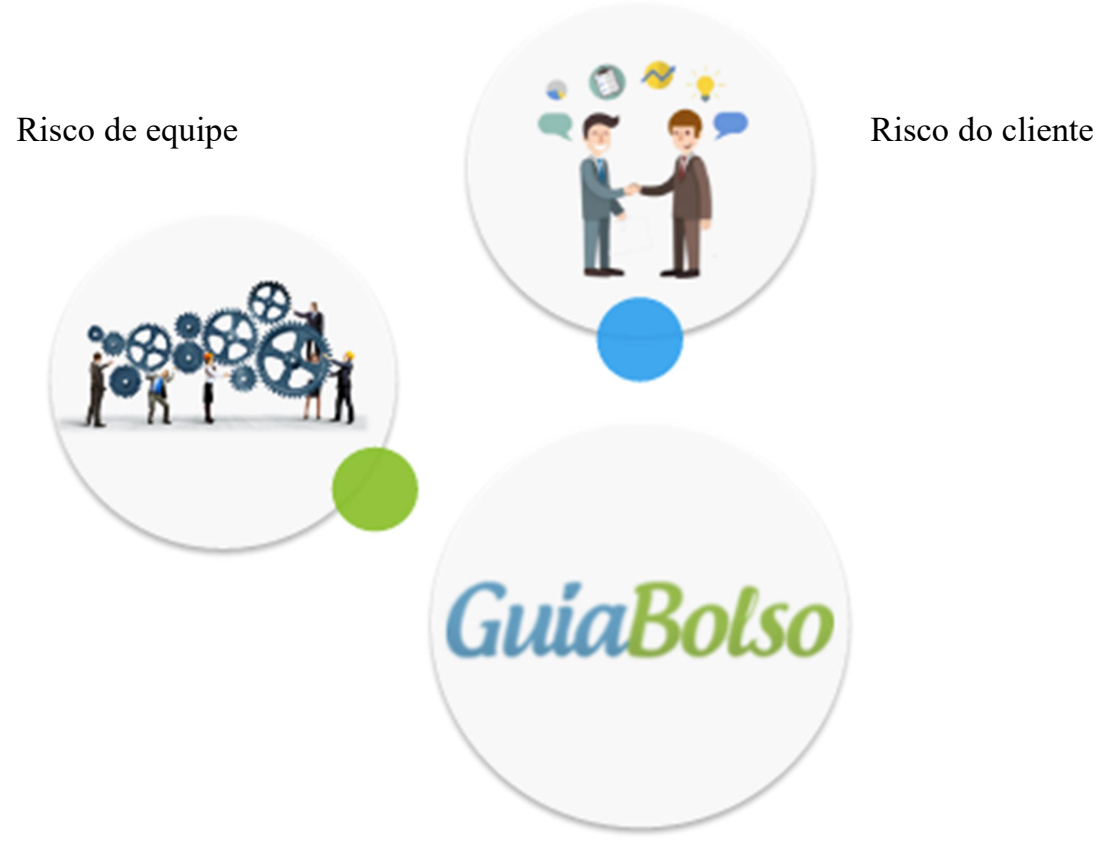

Figura 17 - Representação dos riscos do caso GuiaBolso

Dos demais riscos propostos pela teoria, o entrevistado somente reforçou o fator de equipe e o de adoção da tecnologia pelo usuário, ou seja, havia o risco de desenvolvimento de um aplicativo sem valor para o cliente final.

Apresentados os principais riscos aos quais o GuiaBolso estava exposto, a sua mensuração e o contexto em que estavam inseridos, no próximo item serão avaliadas as ações 
empreendedoras para mitigá-los, ou seja, quais foram as decisões que a empresa tomou com a finalidade de diminuir a sua exposição a esses riscos.

\subsubsection{Ações empreendedoras sobre incerteza}

Este tópico aborda as principais ações da empresa nesse ambiente de incerteza do lançamento e desenvolvimento de uma tecnologia. No GuiaBolso foi observada a aplicação de todas as ações empreendedoras mapeadas nesse estudo, desde a efetivação ao business plan por projeto. No começo, por exemplo, não havia na equipe alguém com experiência em desenvolvimento de produto e a contratação de uma gestora do setor de eletrodomésticos para conduzir esse processo, demonstrou a seleção de meios disponíveis para viabilizar o negócio (efetivação). Ao mesmo tempo, o GuiaBolso executava ensaios paralelos para definir a melhor abordagem ex post (selecionismo), como foi, por exemplo, o lançamento do site simultaneamente à construção do aplicativo.

Ainda na fase do site, de acordo com o fundador (E1Caso02), a empresa demonstrou aprender por tentativa-e-erro: “[...] as pessoas não tinham ideia de como responder as perguntas do consultor financeiro, por mais teoricamente simples que fossem". A filosofia do lean start-up também esteve presente por intermédio das constantes interações com os usuários. E por fim, foi implementação também business plan por projeto, por meio de planejamentos trimestrais que eram divididos em atividades semanais em um modelo taylor made, metodologia que se baseia na adaptação dos projetos de forma mais eficiente às diferentes necessidades dos clientes.

Apresentadas as principais ações para lidar com a incerteza, a seguir será analisado o caso GuiaBolso por meio do modelo de análise de risco proposto por essa pesquisa.

\subsubsection{Aplicação do modelo de pesquisa sugerido no caso GuiaBolso}

Nesse tópico são analisados os dados a respeito do GuiaBolso de acordo com o modelo proposto dedutivamente. Os dados coletados foram condensados através de codificação de primeiro e segundo nível, tendo como referência para a codificação os aspectos propostos de maneira dedutiva. Buscou-se, entretanto, reconhecer e classificar dados que não estavam dentro dos códigos estabelecidos previamente por meio do modelo da pesquisa.

Assim, a partir da combinação de aspectos dedutivos e indutivos, os dados foram 
analisados, descritos e exibidos por meio de tabelas e descrições textuais. Por fim, foi gerado um modelo a fim de auxiliar futuras startups no desenvolvimento de novas tecnologias no mercado brasileiro, apresentado a seguir.

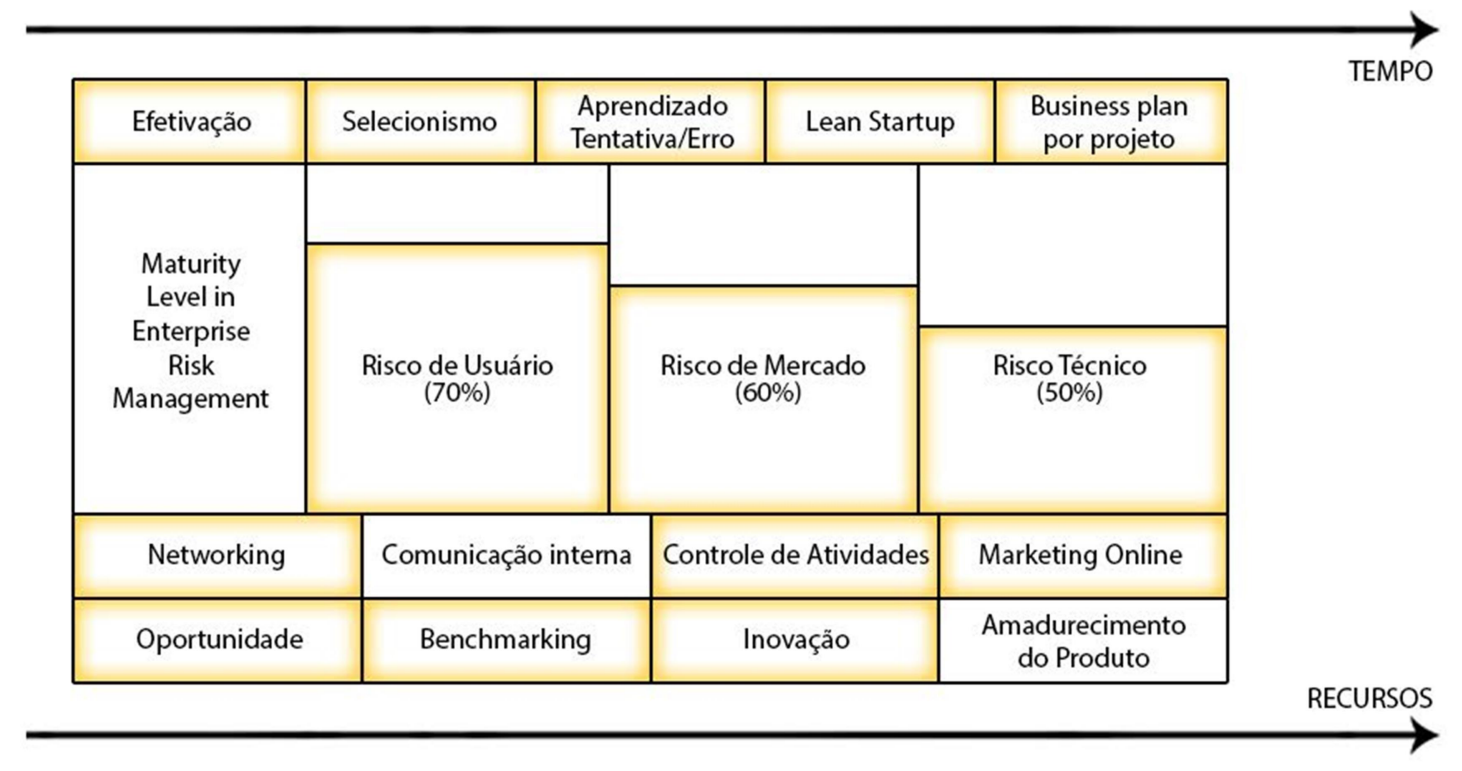

Figura 18 - Risk Management Matrix - GuiaBolso

As células da matriz circundadas em amarelo representam as características presentes no GuiaBolso. Observa-se que desde a sua fundação o networking foi importante, como descreveu o entrevistado que conheceu o seu sócio em um antigo emprego. Após a criação do negócio, o networking foi importante também na construção de parcerias como as feitas com Harvard, para o desenvolvimento do produto e com a Rede Endeavor, que proporcionou acesso aos primeiros advisors.

Em relação aos elementos ausentes, observou-se que na comunicação interna não foi citado a utilização de um software específico (no momento do lançamento do aplicativo em 2014) e produto ainda estava amadurecendo, visto que a empresa estudava meios para monetizá-lo.

Esses fatores em conjunto demonstraram que o GuiaBolso já era mais maduro que uma startup nascente, mas ainda enfrentava incertezas que aumentaram o risco global do negócio. Com o amadurecimento da empresa, algumas dessas incertezas foram sendo superadas, como por exemplo, o risco de o produto não ser aceito pelo mercado, todavia, ainda existiam desafios como a implementação do modelo de monetização, a manutenção do relacionamento positivo com os bancos e a expansão da sua base de usuários. 


\subsection{CASO MERCADOPAGO}

O MercadoPago demonstra-se um caso diferenciado das startups em geral, uma vez que teve origem em 2004 no MercadoLivre, maior marketplace online brasileiro, no momento em que a empresa expandia seu negócio principal de forma a viabilizar além do ato de comprar o ato de pagar em sua plataforma. Dessa forma, algumas características comuns às startups (descritas no referencial teórico no item Startups) não foram observadas. Todavia, o ambiente de incerteza, a geração de uma inovação a partir de uma oportunidade, a aplicação dos modelos de aprendizado por tentativa-e-erro e lean startup foram percebidos. Como destaque, verificou-se a construção de plano de negócios por projeto, de maneira a definir objetivos específicos para os gestores e acompanhar sua implementação, e a importância da comunicação na gestão do negócio.

\subsubsection{Contexto e histórico}

O MercadoPago é a maior plataforma de pagamento pela internet da América Latina. Foi fundado no ecossistema do MercadoLivre e possui cerca de 158 milhões de usuários (D1Caso03). Em 2016, se destacava no portfólio do MercadoLivre e representava um quinto do faturamento do conglomerado (ROMER, 2016).

De acordo com informações disponibilizadas à pesquisa pela empresa (D1Caso03), o MercadoLivre foi fundado em 1999, e era líder em comércio eletrônico na América Latina, estando presente em 16 países. A empresa apresentava um ecossistema que viabilizava a compra, venda, pagamento, entrega, publicidade e gestão de vendas online. Esse conjunto de unidades de negócio é um fato importante, pois de acordo com a abordagem NPVR (Davis, 2002), por meio desse modelo o MercadoPago apresentou maior viabilidade de mercado, por possuir melhores condições para atender seus clientes potenciais. Essa evolução da empresa é apresentada pela ilustração a seguir: 


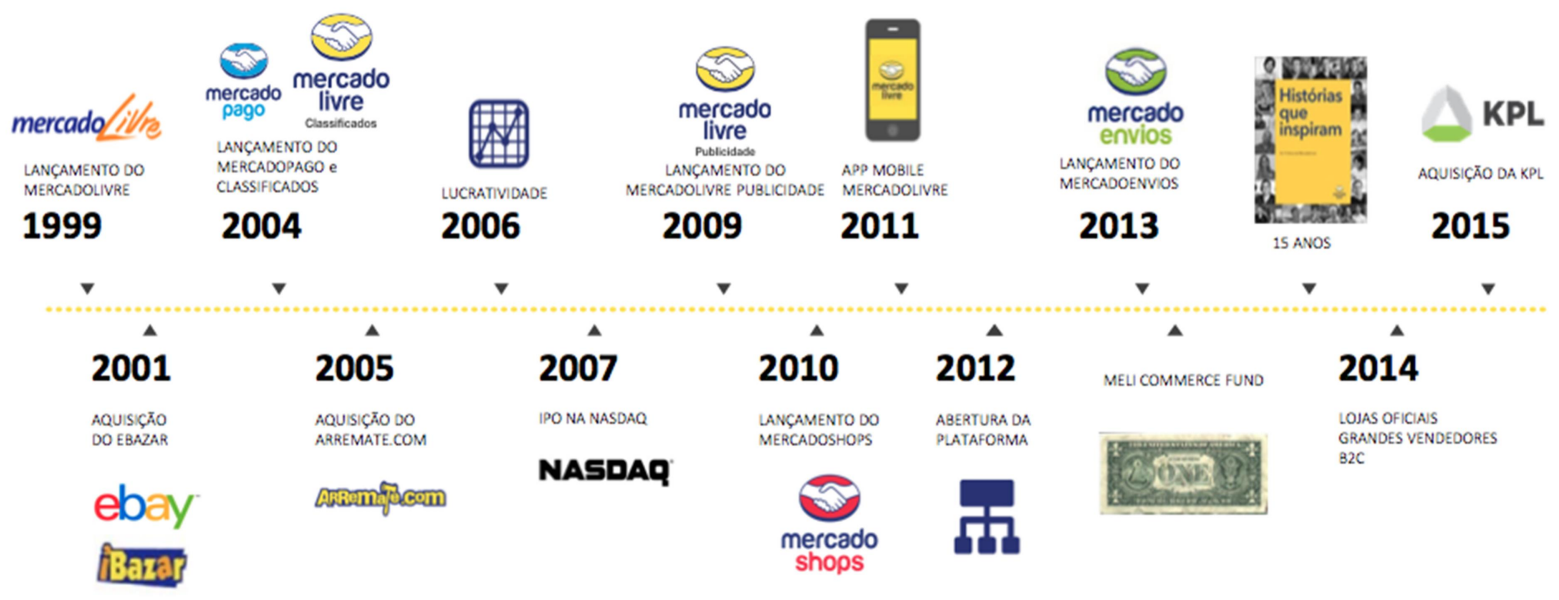

Figura 19 - Linha do tempo do MercadoLivre Fonte: MercadoPago (2015)

Nesse contexto, o MercadoPago foi fundado em uma fase de crescimento do número de consumidores adeptos ao comércio eletrônico que fez emergir a necessidade de ferramentas para tornar segura a intermediação comercial online. Nesse cenário, os provedores de serviços de pagamento começaram a oferecer um sistema que verificava a idoneidade do pedido, o que permitiu a criação de um meio mais confiável nas transações. A partir do resultado positivo do lançamento da sua primeira versão em 2004 no Brasil, México, Argentina, Colômbia, Chile e Venezuela, o MercadoPago investiu também em novas soluções a fim de atender às demandas do mercado.

Esse processo de amadurecimento foi explicado pelo entrevistado (E1Caso03). De acordo com ele, o MercadoPago, no início de sua operação, por meio da custódia das transações, viabilizou o pagamento online, permitindo ao comprador ter maior segurança, visto que o dinheiro somente era transferido ao vendedor no momento que a entrega fosse confirmada. Esse foi o primeiro objetivo da solução. Com a evolução do mercado, a demanda por parcelamento dos pagamentos em até 12 vezes (com acréscimo) foi atendida em 2007, quando o MercadoPago ofereceu essa opção. Em 2010, a empresa começou a disponibilizar a ferramenta para vendedores fora do MercadoLivre, ou seja, um e-commerce de sapatos, por exemplo, poderia ter o sistema de pagamento dentro do seu site, mas com login ainda sendo feito pelo MercadoPago em sua modalidade de checkout de re-direcionamento (carteira digital na web). Essa atualização foi uma das principais responsáveis pelo crescimento do negócio. Em 2014, entretanto, essa tecnologia não era mais aderente ao vendedor que desejavam o checkout invisível, em que o cliente final não precisava realizar mais esse login e digitava apenas as informações do cartão de crédito. E mais recentemente, a empresa inseriu no 
mercado o Mobile POS, que oferece soluções de pagamento para compras feitas em lojas físicas no Brasil. Segundo o diretor (E1Caso03): “[...] o tempo todo estamos melhorando o produto, lançando novas features, mas sempre resolvendo o problema da nossa base de clientes, eles nos dizem quais são as suas necessidades e a gente resolve”.

Essa evolução apresenta uma estreita ligação com a teoria do Lean Startup (Ries, 2011), pois nota-se que a validação do aprendizado com o cliente é constante e que o ciclo de vida de cada produto é rápido e contínuo. Além disso, essa metodologia define "valor" somente para o que gera benefício para cliente e para a empresa (que precisava demonstrar resultados a seus acionistas de forma trimestral), considerando qualquer adição à tecnologia fora desse contexto como desperdício.

\subsubsection{Negócio}

Nesse tópico é apresentada a caracterização do mercado e da tecnologia. Essas características são relevantes por que consistem em pontos que serão avaliados no cálculo do risco da empresa por meio da abordagem do NPVR, proposta por Davis (2002).

\subsubsection{Mercado}

As mudanças rápidas em diversos setores da economia devido aos avanços da tecnologia e da globalização promovem um cenário de risco e instabilidade para muitas empresas. Isso se reflete em aspectos financeiros e estratégicos, como por exemplo, na volatilidade das margens operacionais e na liderança de mercado, que passou a ser um estado e não uma característica permanente.

Essa incerteza representa um agravante na elaboração da estratégia, pois as abordagens tradicionais assumiam um ambiente de negócios relativamente mais previsível. Com as constantes mudanças no comportamento do consumidor, as empresas precisam ser ágeis tanto na gestão do produto como nos modelos de negócios e processos, a fim de entender rapidamente os sinais do ambiente externo, decodificá-los e formularem planos de ação. Dentro desse contexto, essa gestão cautelosa foi observada no caso MercadoPago que realizava, por exemplo, periódicas pesquisas de mercado para entender as próximas tendências do setor de pagamentos online dentro e fora do Brasil. 
Em 2014, por exemplo, um estudo realizado pelo MercadoPago previu que os consumidores esperam ter opções de pagamentos personalizadas, por meio reconhecimento digital e de retina (ÉPOCA NEGÓCIOS, 2014).

De acordo com o entrevistado (E1Caso03), os empresários precisam entender que qualquer produto com mais de seis meses na internet é ultrapassado e, além disso, ouvir o cliente constantemente é uma regra para se manter no mercado, pois o amadurecimento do conhecimento do cliente com relação à internet e principalmente ao e-commerce se encontra em curva exponencial.

Nesse cenário, conclui-se que uma abordagem centrada no cliente é importante para a empresa conseguir responder às mudanças do comportamento do consumidor e conhecer novas expectativas sobre seu serviço. Especificamente para essa pesquisa, esse ponto é relevante, porque influencia diretamente na avaliação de interação da abordagem NPVR.

\subsubsection{Tecnologia}

Em relação à tecnologia, o MercadoPago apresentou-se como sendo uma organização ágil, experimental e colaborativa. De acordo com o diretor (E1Caso03), o primeiro benefício do MercadoPago para o vendedor foi a captura do impulso de compra, que promoveu um aumento na quantidade de vendas, e o segundo, foi o recebimento do valor da venda livre de risco, pois o MercadoPago garantia a transação. Para o comprador, era a garantia de receber o produto ou o dinheiro de volta. Esse foi o primeiro benefício, o trust (confiança entre as partes da transação), e em um segundo momento o maior benefício se transformou no parcelamento em até doze vezes. Ou seja, a empresa evoluiu rapidamente de acordo com as demandas de seus clientes e procurou experimentar novas soluções para validá-las e integrá-las com as demais ferramentas do ecossistema do MercadoLivre.

Percebe-se que ao invés de tentar se igualar ou superar a concorrência, o MercadoPago investiu na inovação, com ênfase no valor percebido pelo cliente, o que incentivava os gestores para ir além de melhorias incrementais, focando investimento em novas formas de negócios. Por exemplo, das empresas de pagamento com atuação no Brasil, o MercadoPago era a única inserida em um ecossistema de e-commerce, que abrangia desde o marketplace até a entrega do produto.

Nesse processo de inovação destacou-se, por meio das falas do entrevistado (E1Caso03) e dos documentos fornecidos pela companhia (D1Caso03), que na empresa o 
fator "funcionário qualificado" era valorizado e que ela se concentrava em apoiar seus empregados a melhorar suas habilidades por meio de treinamento interno.

Em relação ao desenvolvimento da tecnologia, observou-se a prática de um modelo ágil de gestão que enfatiza a adaptabilidade de curto prazo e implicava no fato da companhia ser capaz de responder com rapidez e eficácia às mudanças de requisitos, promovendo assim o amadurecimento de forma exponencial do produto.

O processo de desenvolvimento foi voltado para a introdução de um fluxo de produtos a um ritmo constante. Nota-se também que a maioria dos novos produtos não foram projetados a partir do zero, mas evoluíram dentro da cadeia de valor.

Essas características de tecnologia são importantes para a pesquisa, pois implicam diretamente na avaliação de risco técnico da abordagem NPVR que será apresentado a seguir.

\subsubsection{Análise de Riscos no caso estudado}

O objetivo desse tópico é de avaliar os riscos que foram observados no Mercado Pago, considerando a abordagem NPVR (Davis, 2002) e a Maturity Level in Enterprise Risk Management (Oliva, 2015).

Davis (2002) entende que "Novas categorias" são produtos "novos para a empresa" e incluem novas linhas de produtos, que têm como alvo um mercado estabelecido em que a empresa não compete atualmente. Pode-se considerar o MercadoPago como sendo uma nova categoria, pois sua origem está atrelada ao MercadoLivre, e para o MercadoLivre o oferecimento de um sistema de pagamento era um novo serviço, em um mercado com concorrência pequena, mas existente.

De acordo com o entrevistado (E1Caso03), o MercadoLivre é um marketplace onde compradores e vendedores anunciam os seus produtos. No ano de 2004, os clientes desse marketplace já se encontravam para realizar as trocas de cada venda, só que havia outros problemas para serem resolvidos, como por exemplo, a segurança do pagamento dessa operação. O MercadoPago veio então fazer parte do ecossistema do MercadoLivre, para resolver esse problema dos compradores e vendedores. Exposto esse contexto, a seguir será apresentada a avaliação de risco de mercado, de usuário e de tecnologia, as três dimensões consideradas pela visão NPVR. 


\subsubsection{Avaliação de Risco de Mercado}

A partir dos dados levantados e da contextualização das atividades da empresa, foi analisado o risco de mercado por meio da comparação do quadro abaixo com a entrevista com o diretor geral do MercadoPago (E1Caso03).

Tabela 23 - Critérios para avaliação de riscos da cadeia de valor e segmento de mercado

\begin{tabular}{|c|c|c|}
\hline Pontuação & Avaliação da cadeia de valor & Avaliação do segmento de mercado \\
\hline Alta & $\begin{array}{l}\text { Todos os requisitos da cadeia de valor } \\
\text { existem internamente na empresa }\end{array}$ & $\begin{array}{c}\text { Empresa é líder de mercado no segmento } \\
\text { de mercado-alvo }\end{array}$ \\
\hline Média & $\begin{array}{l}\text { Todos os requisitos da cadeia de valor } \\
\text { existentes, alguns por meio de parceiros }\end{array}$ & $\begin{array}{l}\text { Empresa vende outros produtos para } \\
\text { clientes no segmento de mercado }\end{array}$ \\
\hline Baixa & $\begin{array}{l}\text { Algumas ou todas as necessidades da } \\
\text { cadeia de valor não estão presentes } \\
\text { dentro da empresa ou com parceiros } \\
\text { existentes }\end{array}$ & $\begin{array}{c}\text { Novo segmento de mercado, ou a } \\
\text { empresa não tem presença no segmento } \\
\text { de mercado-alvo }\end{array}$ \\
\hline
\end{tabular}

Fonte: Davis (2002)

O risco de mercado engloba qualquer elemento da cadeia de valor exigido de um novo produto para que atinja seus clientes potenciais. A partir dessa definição, pode se concluir que a pontuação do MercadoPago foi alta (4), pois apesar do conglomerado atual não existir em 2004, com a evolução da empresa o MercadoPago se tornou parte do ecossistema do MercadoLivre, representado pela ilustração a seguir: 


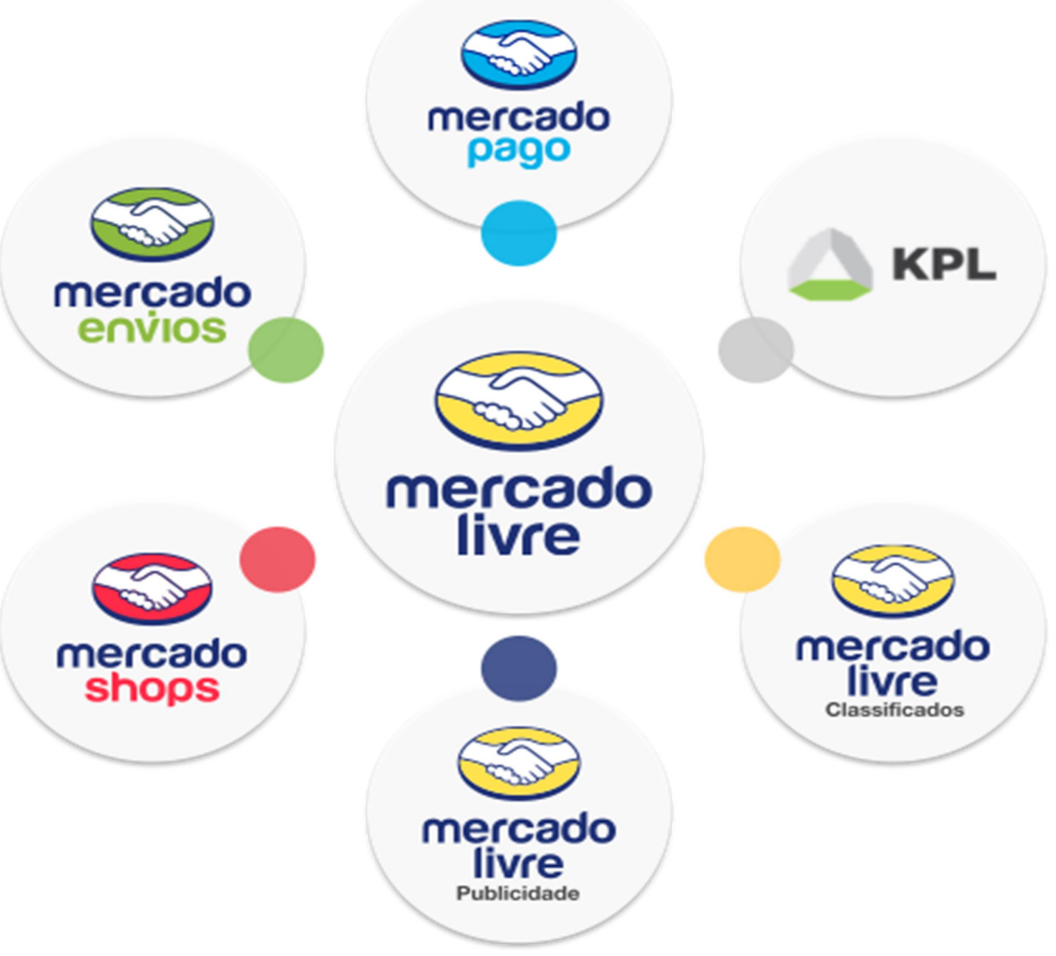

Figura 20 - Ecossistema MercadoPago

Fonte: MercadoLivre (2016)

De acordo com (E1Caso03), o MercadoLivre era um marketplace onde compradores e vendedores podiam se encontrar e fazer transações. Além disso, existiam outras unidades de negócios como o MercadoEnvios, que viabilizava aos vendedores trabalharem em volumetrias crescentes de tabelas públicas dos Correios; o MercadoAds, que era a ferramenta de publicidade e links patrocinados dentro do MercadoLivre; e mais recentemente a unidade de gestão de E-commerce, chamada KPL, para gerir todo o back office das operações de $e$ Commerce.

Esse modelo de integração vertical gerou oportunidades para obtenção de economias de escala, escopo, maior controle sobre a cadeia de valor e sobre os preços finais dos serviços. Observa-se que existiam sinergias entre estas unidades, e como as opções do mercado ainda não eram eficientes ao ponto de prover transações com preço de livre concorrência, o benefício da integração vertical se tornava ainda maior.

O fato de o MercadoLivre ter controle do seu ecossistema também construiu uma barreira maior à entrada de concorrentes, ampliando assim a competitividade e rentabilidade, pois devido à sua integração verticalmente, maiores seriam os recursos financeiros e administrativos exigidos de um competidor.

Além disso, com esse formato a empresa criou uma experiência de usuário mais 
uniforme que compelia os consumidores a investir em toda a sua linha de produtos. Esses fatores foram importantes, porque interferiram na avaliação da cadeia de valor da abordagem NPVR.

Ainda com relação à cadeia de valor, o MercadoPago desenvolveu parcerias com empresas que possuíam ativos e competências complementares ao seu negócio. Segundo (E1Caso03), o MercadoPago era um revendedor de transações por meio das bandeiras de cartões Visa, Master e dos boletos fornecidos pelos bancos, sendo essenciais a construção de parcerias com esses distribuidores. Além disso, para evitar risco de indisponibilidade, a empresa tinha mais do que um parceiro para qualquer iniciativa. A dependência de parceiros nesse requisito foi o fator principal para a avaliação da cadeia de valor ser quatro ao invés de cinco.

Por fim, com relação a avaliação segmento de mercado, o MercadoPago teve pontuação alta (5), porque o MercadoLivre era líder no segmento de mercado-alvo na época. "Em termos de e-commerce o Mercado Livre não era único, mas em termos de marketplace não só era líder como era o único em 2004” (E1Caso03).

Analisado os riscos de mercado, a seguir será apresentado os riscos técnicos do negócio, outro fator da fórmula para cálculo do risco pela abordagem NPVR.

\subsubsection{Avaliação de Riscos Técnicos}

Riscos técnicos estão relacionados com o produto, bem como as capacidades de desenvolvimento da empresa. A pontuação obtida por estes fatores a partir da análise dos dados referentes ao MercadoPago está resumida na tabela seguinte:

Tabela 24 - Critérios para avaliação de riscos de inovação e recursos

\begin{tabular}{|c|c|c|}
\hline Pontuação & Avaliação da Inovação & Avaliação de Recursos \\
\hline Alta & $\begin{array}{l}\text { Utilização incremental de tecnologia bem } \\
\text { entendida }\end{array}$ & $\begin{array}{l}\text { Equipe de desenvolvimento com } \\
\text { experiência em projeto semelhante }\end{array}$ \\
\hline Média & $\begin{array}{l}\text { Nova tecnologia, protótipos desenvolvidos e } \\
\text { testados }\end{array}$ & $\begin{array}{l}\text { Nova equipe de desenvolvedores } \\
\text { com alguma experiência em projetos } \\
\text { semelhantes }\end{array}$ \\
\hline Baixa & $\begin{array}{l}\text { Nova tecnologia, fase de prova de conceito com } \\
\text { teste limitado }\end{array}$ & $\begin{array}{l}\text { Equipe incompleta e limitada } \\
\text { experiência em projetos semelhantes }\end{array}$ \\
\hline
\end{tabular}

Fonte: Davis (2002) 
A partir da análise dos dados coletados, pode-se considerar a pontuação da inovação como média (3), pois se tratava de uma nova tecnologia, mas com protótipos desenvolvidos e testados, como pode ser observado pelo fato de que, à época, era um novo conceito. $\mathrm{O}$ entrevistado (E1Caso03) entende que para o Brasil, no ano de 2004, a concepção de carteira digital era inexplorada.

Com relação à avaliação de recursos, a pontuação foi média/alta (4), porque a equipe era completa, nova e com experiência em projetos de tecnologia da informação. $O$ entrevistado (E1Caso03), explicou que não existiam especialistas em pagamento online no Brasil e por isso formaram o time internamente, visto que o MercadoPago foi um dos pioneiros.

Complementando a avaliação tecnológica, no próximo item foi analisado o risco de usuário, uma das categorias propostas dedutivamente para analisar o risco nesse tipo de negócio. O risco de usuário está relacionado a dois elementos principais, a capacidade de interação e especificação.

\subsubsection{Avaliação de Riscos de Usuário}

Enquanto o risco de mercado determina a capacidade da empresa para vender e dar suporte ao produto, e risco técnico determina sua capacidade para construir o produto, o risco do usuário determina a probabilidade de que a empresa esteja desenvolvendo o produto certo (Davis, 2002). Avaliação de risco do usuário se concentra nos seguintes fatores:

Tabela 25 - Critérios para avaliação de riscos de interação e especificação

\begin{tabular}{c|c|c}
\hline Pontuação & Avaliação da Interação & Avaliação da Especificação \\
\hline Alta & $\begin{array}{c}\text { Pesquisa com o usuário primário } \\
\text { realizada ou planejada antes do } \\
\text { desenvolvimento }\end{array}$ & $\begin{array}{c}\text { Extensão de design de produto e } \\
\text { especificação de desempenho } \\
\text { existentes }\end{array}$ \\
Média & $\begin{array}{c}\text { Pesquisa com o usuário não } \\
\text { realizada, mas pesquisa com um } \\
\text { produto secundário realiza }\end{array}$ & $\begin{array}{c}\text { Nova especificação de design e } \\
\text { desempenho no segmento de } \\
\text { mercado existente }\end{array}$ \\
Baixa & $\begin{array}{c}\text { Pesquisa com usuário não } \\
\text { realizada, atributos do usuário } \\
\text { atribuídos por equipe interna }\end{array}$ & $\begin{array}{c}\text { Novo design e especificação de } \\
\text { desempenho no segmento do } \\
\text { Novo Mercado }\end{array}$ \\
\hline
\end{tabular}

Fonte: Davis (2002)

Com relação à avaliação da interação, o MercadoPago teve pontuação alta (5), porque procurou entender o usuário em todas as fases do desenvolvimento do produto. E1Caso03 
explicou que sempre eram realizadas pesquisas com os compradores e vendedores (para entender as suas necessidades) e estudo comparativo com outras empresas, principalmente as do Vale do Silício. Ou seja, os produtos eram aprimorados não com base em suposições e instintos, mas por meio de testes e comunicação direta com o usuário. Esta abordagem centrada no cliente era acompanhada por uma política de foco no valor percebido e na rápida avaliação da interação com o produto.

Dessa maneira, o lançamento de novas features tinha como objetivo a resolução de problemas, evitando desperdício de tempo e recursos com investimento que não geravam valor. Segundo o diretor (E1Caso03), não existia um mecanismo ideal para entender os clientes, mas era preciso ter atenção constante para que o produto amadurecesse na mesma velocidade em que as necessidades dos consumidores emergissem, sendo que uma pesquisa de seis meses sobre os hábitos de consumo era considerada desatualizada.

Esse modelo de gestão reduziu o risco do MercadoPago em seu estágio inicial, por meio da prototipagem rápida e testes reais $\mathrm{A} / \mathrm{B}$ (que consistem em dividir o tráfego de uma determinada página em duas versões para medir qual é a que apresenta maior taxa de conversão) que geravam aprendizagem contínua. A filosofia era de orientar a concepção do desenvolvimento pelas necessidades provindas de várias interações e feedback dos usuários, que permitiam melhorar um conceito ou produto em ciclos curtos.

Em relação à especificação, o MercadoPago tinha pontuação média (3), porque apresentou um novo design para um segmento de mercado já existente, mas novo no Brasil, como confirmou o entrevistado (E1Caso03): [...] o conceito de pagar pela internet, em 2004, não era exatamente uma inovação, mas era um conceito novo para o brasileiro médio." $\mathrm{Ou}$ seja, a disponibilização de dados financeiros pela internet não era hábito e representava um desafio para a empresa, uma barreira de confiança.

Por se tratar de uma inovação disruptiva, sua adoção envolvia um nível alto de incerteza, pois a empresa poderia realizar o lançamento prematuramente e sofrer prejuízos devido à resistência dos usuários na adoção da tecnologia e a falta de entendimento do produto.

Apresentados os principais riscos e a sua distribuição no MercadoPago, no próximo item é apresentado o cálculo do NPVR, que utiliza os dados analisados para mensurar o quão exposto estava a empresa aos riscos de mercado, usuário e de tecnologia no momento do lançamento do produto. 


\subsubsection{Cálculo do NPVR}

A partir dos dados coletados pelo modelo apresentado posteriormente, o NPVR é calculado da seguinte forma:

$$
\mathrm{NPVR}=((\mathrm{aM}+\mathrm{bM}+\mathrm{cT}+\mathrm{dT}+\mathrm{eU}+\mathrm{fU}) / 10) \times \text { Valor Presente Líquido }
$$

Considerando o MercadoPago como uma nova categoria, de modo que os fatores de ponderação correspondentes a $\mathrm{M}=0.4, \mathrm{~T}=0.2$ e $\mathrm{U}=0.4$.

$\mathrm{NPVR}=((\mathrm{a} 0.4+\mathrm{b} 0.4+\mathrm{c} 0.2+\mathrm{d} 0.2+\mathrm{e} 0.4+\mathrm{f} 0.4) / 10) \times$ Valor Presente Líquido

Onde a, b, c, d, e, f são as avaliações da cadeia de valor, do segmento de mercado, inovação, recursos, capacidades de interação e de especificação.

Por fim, com objetivo sintetizar os riscos explicados anteriormente e facilitar a visualização de sua distribuição, a tabela 26 foi construída.

Tabela 26 - Resumo da avaliação dos riscos do MercadoPago

\begin{tabular}{c|c|c}
\hline Avaliação & Pontuação & Risco relacionado \\
\hline Cadeia de valor & 4 & Mercado \\
Segmento de mercado & 5 & Mercado \\
Inovação & 3 & Técnico \\
Recursos & 4 & Técnico \\
Interação & 5 & Usuário \\
Especificação & 3 & Usuário \\
\hline
\end{tabular}

Aplicando a fórmula do NPVR:

$\mathrm{NPVR}=((4 * 0.4+5 * 0.4+3 * 0.2+4 * 0.2+5 * 0.4+3 * 0.4) / 10) \times \mathrm{VPL}$

$\mathrm{NPVR}=82 \% \mathrm{VPL}$

Portanto o NPVR é de $82 \%$ do VPL original, indicando que $18 \%$ do valor VPL projetado estava em risco. Como o NPVR está integrado ao processo de decisão, este nível de risco indica que foi feito um trabalho que diminuiu os níveis de incerteza e facilitou a consolidação da proposta de valor.

Nota-se que a detecção precoce dos riscos é importante, porque é geralmente mais fácil, menos dispendioso e menos prejudicial alterar um plano antes da sua execução. Isso é possível por meio da integração da gestão de risco aos processos chaves do negócio ao invés de considerá-la como uma atividade secundária que será aplicada no decorrer do 
desenvolvimento do produto. Essa integração ajuda na análise de decisões de investimento, bem como na identificação de oportunidades para reduzir incerteza e melhorar a economia do projeto. As organizações podem concentrar-se assim na incerteza de forma holística, em vez de apenas identificar e medir os riscos individualmente, reduzindo o potencial de sofrer efeitos negativos sobre os lucros.

Por fim, com o intuito de complementar e amplificar a dimensão dos riscos no fenômeno estudado, foram considerados aqueles propostos na abordagem da Maturity Level in Enterprise Risk Management (Oliva, 2015), aos quais o MercadoPago estava submetido em 2004, quando foi lançado.

Considerando essa visão, o MercadoPago estava sujeito, à época, aos riscos de imagem, operacional, ético, tecnológico e de segurança.

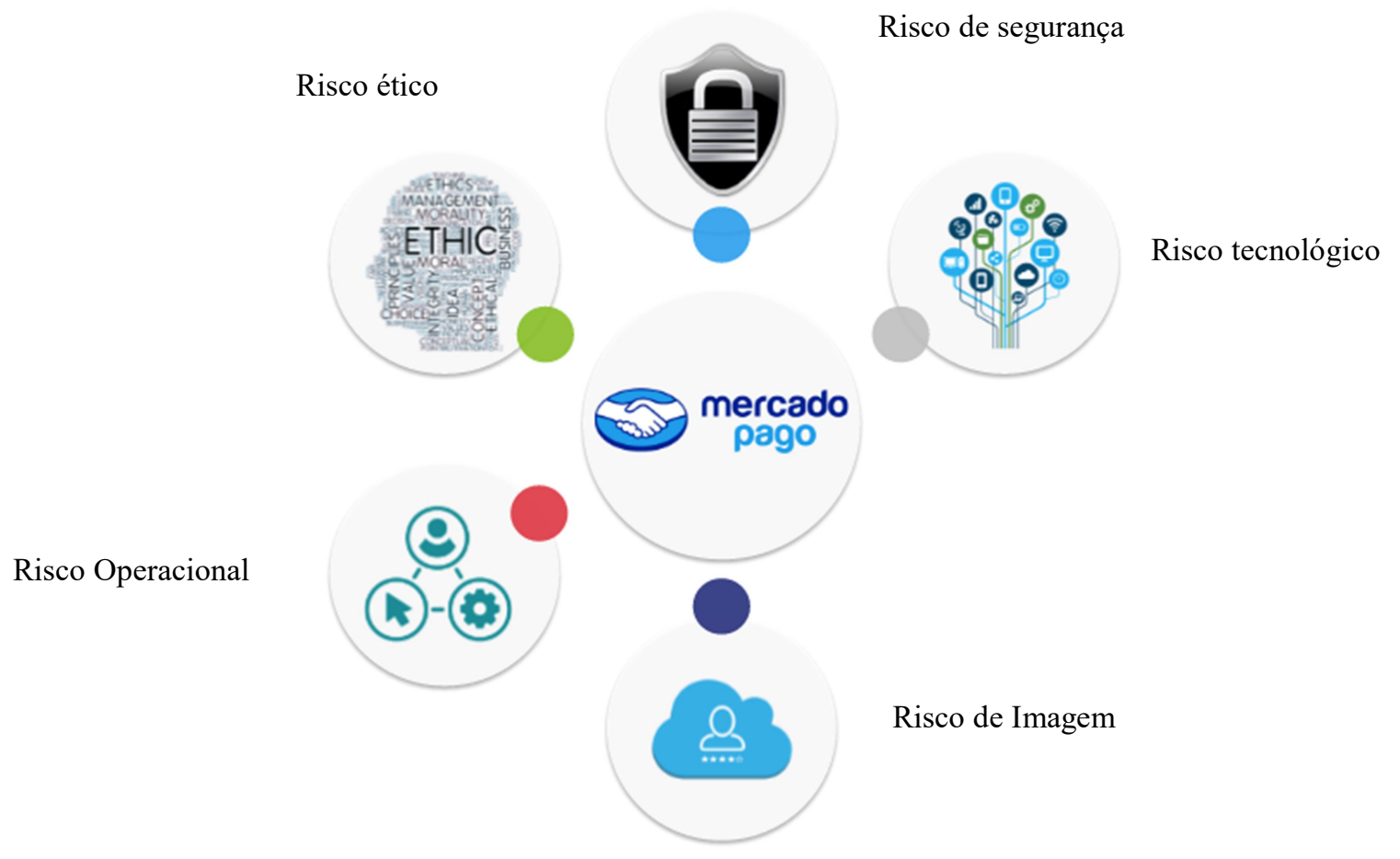

Figura 21 - Representação dos riscos do caso MercadoPago

De acordo com o entrevistado (E1Caso03), a empresa não podia se envolver em um escândalo na mídia, porque colocaria em risco a credibilidade da marca e a confiança no processamento das operações. Além disso, um erro operacional poderia resultar em prejuízos de milhões de dólares em poucos segundos, devido às inúmeras transações realizadas. A questão ética também era um ponto de atenção, porque envolvia o risco de imagem da marca. Os erros tecnológicos, por sua vez, poderiam inviabilizar a empresa no mercado, como 
explicou (E1Caso03): "Se errássemos um bit na quantidade de transações por segundo, pensando numa ação de vendas anual como a Black Friday, por exemplo, o cliente deixava o site do nosso vendedor e ia para o do concorrente.” E por fim a questão da segurança, pois como lidavam com transações financeiras, além das regras impostas pelo próprio MercadoPago, a companhia respondia às leis do governo e regulamentações do mercado financeiro nacional e normas de empresas listadas na Nasdaq bem como da Mastercard e Visa, e para estar qualificada para tal teve que realizar investimentos em infraestrutura, como na filmagem de todos os ambientes e armazenamento dos vídeos em servidores estrangeiros por regulamentação da Payment Card Industry Security Standards Council (PCI-SSC).

Apresentados os principais riscos aos quais o MercadoPago estava exposto, a sua mensuração e o contexto em que estavam inseridos, no próximo item são avaliadas as ações empreendedoras para mitigá-los, ou seja, quais foram as decisões que a empresa tomou com a finalidade de diminuir a sua exposição a esses riscos.

\subsubsection{Ações empreendedoras sobre incerteza}

Esse tópico aborda as principais ações da empresa nesse ambiente de incerteza do desenvolvimento e lançamento de uma tecnologia.

O MercadoPago, diferentemente das outras empresas analisadas nesse estudo, possuía uma estrutura organizacional madura por ter sido criado dentro do MercadoLivre. Desde o seu lançamento, a empresa demonstrou gestão profissional, o que permitia o planejamento de ações e previsão de receita de maneira mais consistente. A companhia apresentou organização na melhoria de processos de produtividade para se posicionar em um mercado que se tornaria competitivo. Um aspecto importante observado também foi que a informalidade, comum nos primeiros anos de uma startup, não foi relatada, mesmo sendo a empresa pequena no seu começo, contando com apenas dois funcionários na estrutura do MercadoLivre.

Durante as primeiras fases do desenvolvimento do produto, todavia, foi observada a adoção da metodologia de aprendizagem por tentativa-e-erro, visto que a empresa trabalhava em um ambiente de incerteza: “[...] era desafiador, havia muito medo, então, sim, tínhamos que quebrar essa barreira de confiança e explicar porque era seguro" (E1Caso03).

Para contornar essa situação, o MercadoPago procurou por meio de testes contínuos provar cada uma de suas hipóteses iniciais, em busca de um modelo de negócios escalável e rentável. "A gente desenvolveu tudo com erros e acertos e o tempo todo melhorando esse grande software MercadoPago" (E1Caso03). 
Em paralelo ao "aprendizado por tentativa-e-erro", verificou-se a aplicação do Lean Startup como filosofia para o desenvolvimento do produto, fato que permitiu uma melhor gestão de riscos da inovação. No MercadoPago a validação da ferramenta foi colocada no centro da construção do negócio, sendo as decisões tomadas, na maioria das vezes, com base em testes de hipóteses. De acordo com (E1Caso03), a empresa apresentava uma ideia e questionava os clientes via testes $\mathrm{A} / \mathrm{B}$ sobre a viabilidade de implementá-la ou atendia uma demanda emergente dos próprios cliente, sendo que somente nessas duas situações aprimorava o produto. Ou seja, para o MercadoPago nenhum lançamento foi feito apenas por ser inovador, mas sempre com foco no valor percebido e na sustentabilidade econômica e financeira de cada empreitada. Esse processo promoveu um amadurecimento do produto que o tornou viável apesar das constantes e rápidas mudanças tecnológicas.

Com relação à gestão da empresa, foi observada a construção de plano de negócios por projeto, de maneira a definir objetivos específicos para os gestores e acompanhamento da sua implementação. Nesse contexto, o fator comunicação foi ressaltado na entrevista. De acordo com (E1Caso03), para cada projeto sempre era feito um plano de negócio. Todas as decisões de investimento tinham seu próprio plano macro de um ano que era dividido em micro atividades diárias de modo que durante doze meses cada funcionário sabia qual era a sua meta.

Em termos de ferramenta de acompanhamento dos projetos, a empresa usava o Microstrategy (TM) e o SAP $\left({ }^{\mathrm{TM}}\right)$, tanto para projetar um ano para frente ou três anos para frente, quanto para medir mês a mês ou dia a dia. Do ponto de vista de comunicação, para que os funcionários soubessem os estágios de cada projeto foi utilizado o Sales Force e mais recentemente o Facebook at work.

A comunicação e gestão de atividades foram importantes para esse caso, pois por terem sido implementadas corretamente promoveram compromisso de toda a organização com resultados de longo prazo, por meio da otimização das entregas, redução de custos, melhoria da produtividade e contorno dos riscos.

Apresentadas as principais ações para lidar com a incerteza, a seguir será analisado o caso MercadoPago por meio do modelo proposto por essa pesquisa. 


\subsubsection{Aplicação do modelo de pesquisa sugerido no caso MercadoPago}

Neste tópico, foram analisados os dados a respeito do MercadoPago, de acordo com a Risk management matrix, composta por elementos dedutivos oriundos principalmente de Davis (2002); Oliva (2015); Oliva et al. (2014); Blank e Dorf (2012); Jorion (2009); COSO (2007); Kambil e Mahidhar (2005) e por elementos indutivos emergentes da pesquisa. As células da matriz apresentada a seguir circundadas em laranja representam as características presentes no MercadoPago.

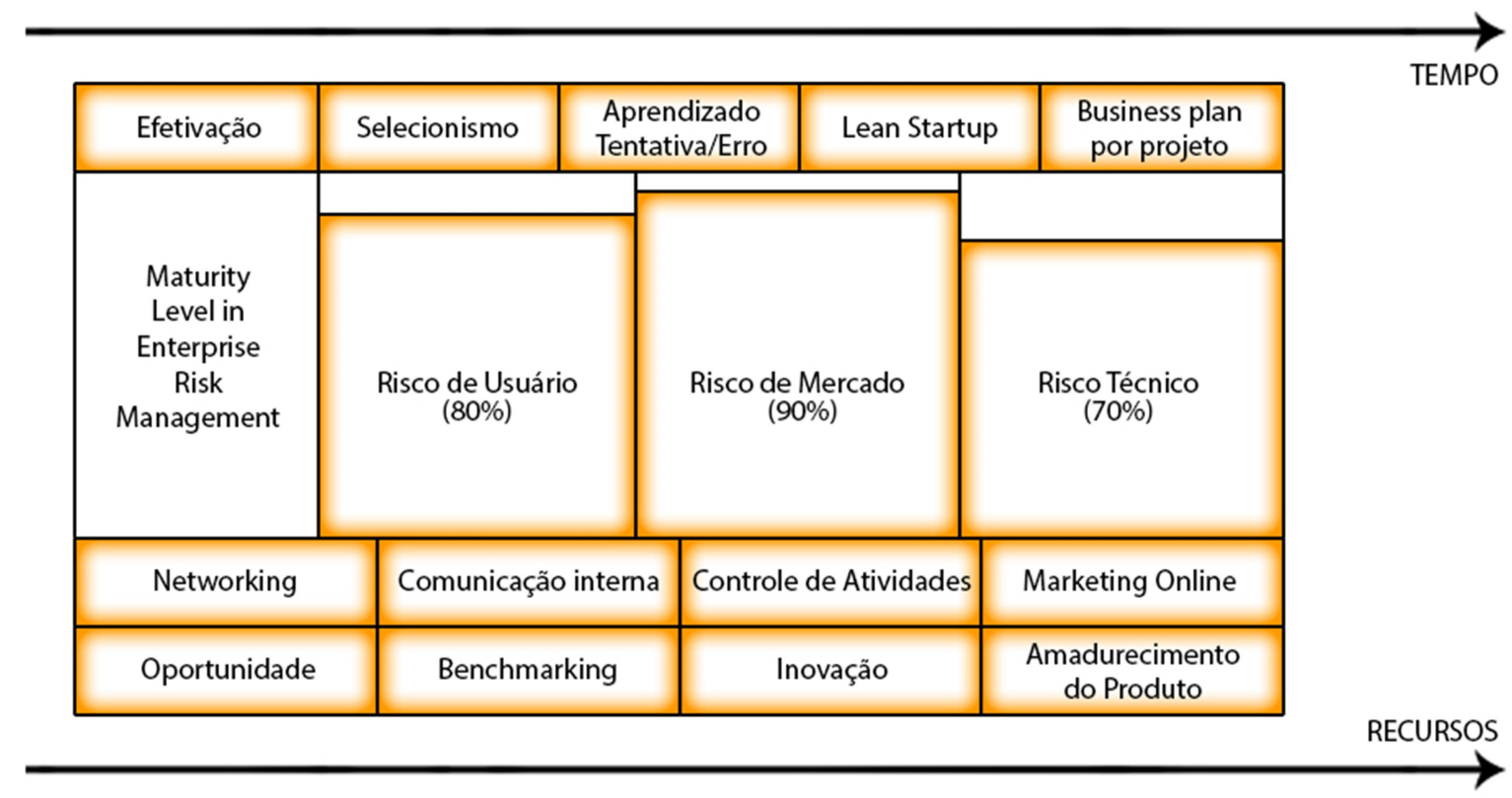

Figura 22 - Risk Management Matrix - MercadoPago

Considera-se importante ressaltar que no caso MercadoPago, que alguns elementos mais relacionados às fases iniciais de uma startup, em que recurso é um fator limitante foram também observados. Efetivação e selecionismo, por exemplo, nas ações empreendedoras e networking com relação à comunicação foram citados. No MercadoPago, a figura do dono era presente, ou seja, desde a sua criação além do nome da empresa o papel do fundador foi relevante na construção de parcerias e prospecção de clientes.

A filosofia do Lean Startup (Ries, 2011) foi mencionada em diversas partes da entrevista e pode-se atentar também para a utilização de métodos ágeis, que foram percebidos quando a empresa adotou a filosofia de teste rápido com o cliente, centrado na melhoria contínua e com o escopo flexível, priorizando um desenvolvimento com ciclos mais curtos. 
Além disso, observa-se que o MercadoPago já passou por todas as fases do desenvolvimento do produto. Esse processo iniciou-se com a identificação da oportunidade, o benchmarking com as soluções desenvolvidas no exterior, o desenvolvimento da inovação e o seu amadurecimento. Esses dois últimos itens foram expostos pelo entrevistado: “O Mercado Pago tem um software campeão no Brasil, que ninguém tem. E se alguém for tentar construir vai demorar treze anos. Levamos treze anos para chegar onde nós estamos hoje" (E1Caso03).

Todos esses fatores em conjunto viabilizaram o produto e demonstram que a implementação de uma estratégica de gestão de riscos, baseada na abordagem teórica apresentada, pode torná-los mais compreensíveis, mensuráveis e controláveis. 


\subsection{CASO BETALABS}

A Betalabs desenvolveu um produto complementar ao seu sistema de e-commerce (uma nova plataforma segundo a abordagem NPVR) e por isso foi selecionada para essa dissertação. Como pontos principais desse caso, pode-se citar a cultura da empresa fortemente conectada aos sócios (organização completa), o modelo de gestão de recursos humanos que valorizava novos profissionais e o desenvolvimento de um produto por meio do aprendizado junto ao cliente. O caso demonstrou que apesar do sistema ERP (Enterprise Resource Planning) ser classificado como uma nova categoria e, além disso, tratar-se de um bem complementar com a finalidade de gerar uma vantagem competitiva por meio do seu efeito multiplicador sobre as vendas do produto primário, existiam riscos que não podiam ser ignorados para viabilizá-lo no mercado.

\subsubsection{Contexto e histórico}

A Betalabs é uma startup que oferta plataformas de e-commerce e sistemas de gestão (ERP) online customizados. A unidade de análise desse estudo foi a solução ERP Cloud da empresa, que era uma suíte flexível de funcionalidades especializadas para a indústria e serviços, com a função de integrar os setores de uma empresa (como planejamento, compras, estoques, vendas, marketing, finanças e recursos humanos), permitindo a comunicação entre eles. Esse sistema é representado pela Figura 23.

De acordo com informações disponibilizadas pela empresa (D1Caso04), o ERP na nuvem tinha como principais benefícios para o cliente a redução de custo com contração e manutenção de serviços, além de diminuição de gastos com equipe e prestadores de serviço de TI. 


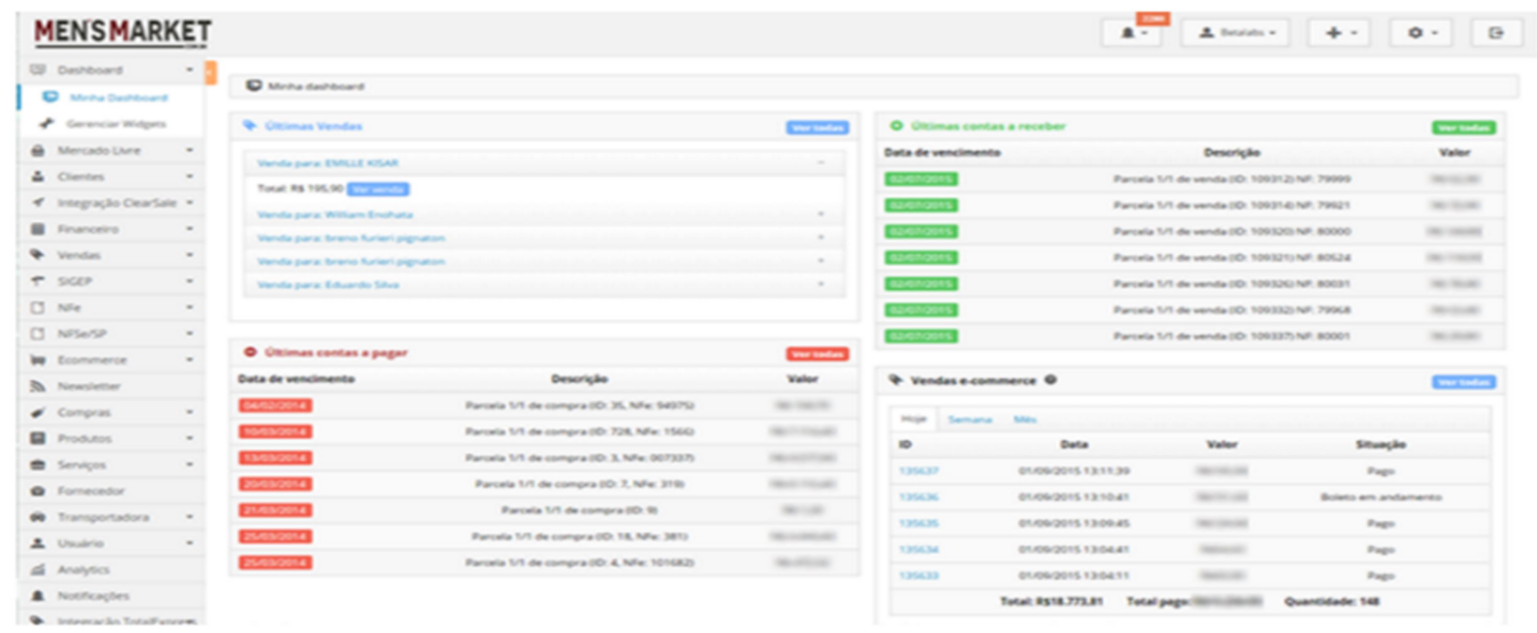

Figura 23 - Representação do sistema ERP ofertado pela Betalabs Fonte: Betalabs (2016)

Segundo o entrevistado (E1Caso04) a empresa identificou a oportunidade do negócio quando construía sistemas sob medida, visto que nos seus primeiros anos de atuação atendia clientes de diversos tipos de mercados por meio de construção de sites personalizados (modelo software house). Com esse primeiro modelo de negócio, foi-se observado em muitos casos, que os clientes necessitavam também de um sistema ERP, porque a maioria deles trabalham com lojas virtuais, onde era necessária a integração entre o setor financeiro, o cadastro de produtos e estoque, por exemplo. Dessa maneira, os sócios consideraram oportuna a construção de um sistema ERP híbrido (uma parte do código padrão e outra que podia ser customizada).

Com essa integração, a Betalabs conseguiu atender seus clientes de forma mais econômica, com maior velocidade e também apresentou uma diferenciação importante dos demais ERP, por meio da oferta de personalização que não era disponibilizada por empresas de grande porte do mercado.

Apesar de bons resultados financeiros, os primeiros anos da Betalabs demonstraram-se essencialmente incertos. O modelo customizado de ERP, embora fosse uma diferenciação, agregava o risco de erros na estimativa de custo e tempo de entrega. Como exemplo dessa incerteza, pode-se citar que a primeira versão estável do produto ficou disponível somente após três meses depois do primeiro lançamento.

Além disso, a empresa possuía uma equipe com pouca experiência profissional, pois todos os funcionários começaram como estagiários. Ademais, como o time era pequeno, o conhecimento ficava concentrado em poucas pessoas o que aumentava o risco de gestão de recursos humanos. Por fim, a Betalabs estava exposta à concorrência que promovia uma 
pressão constante pela inovação.

Para responder as demandas do mercado, a Betalabs utilizou dois métodos principais: o Benchmarking e o Lean Startup. De acordo com o entrevistado, no lançamento do serviço, as solicitações por novas funcionalidades eram diárias e era preciso conciliar o atendimento ao cliente como estudo de mercado para evitar se distanciar das tendências tecnológicas. Com relação ao Lean Startup, o entrevistado (E1Caso04) exemplifica:

\footnotetext{
Para alguns projetos de ERP existiam casos em que o fluxo mudava muito e em muitos deles havia um tempo de maturação do produto, e às vezes, o fluxo era tão inovador que nem a empresa e nem o cliente o dominavam, então o tempo de maturação era ainda maior, porque tanto a empresa quanto o cliente precisavam aprender juntos e o resultado disso era imprevisível no começo da relação (E1Caso04).
}

Outros dois pontos importantes desse caso, foi o fato da empresa ter uma cultura fortemente conectada com os sócios (organização completa), o que segundo o entrevistado facilitava a comunicação da estratégia, pois para cada setor do negócio existia um responsável (próximo aos sócios) com grau de decisão de gestão. O segundo ponto era que a empresa não era autossustentável, pois apesar de possuir um equilíbrio financeiro, ainda não apresentava uma receita recorrente que cobrisse o custo fixo, dependendo então de novas vendas para se manter.

\subsubsection{Negócio}

Nesse tópico é apresentada a caracterização do mercado e da tecnologia. Essas características são relevantes por que consistem em pontos que serão avaliados no cálculo do risco da empresa por meio da abordagem NPVR, proposta por Davis (2002).

\subsubsection{Mercado e tecnologia}

Os sistemas ERP (Enterprise Resource Planning) são módulos empresariais conectados a uma base central com a finalidade de apoiar as operações de uma empresa, tais como as de manufatura, suprimentos, finanças ou recursos humanos. Como principais características desses sistemas, pode-se citar que são pacotes comerciais de software que simulam e integram processos por meio da utilização de um banco de dados corporativo, disponibilizando informações quando necessário (SOUZA, 2000). 
O sistema ERP oferecido pela Betalabs foi baseado em cloud computing (servidor em nuvem) possuindo vantagens como a utilização do programa por meio do navegador da internet (sem a necessidade de instalações e de servidores utilizados por sistemas de ERP tradicionais), diminuindo assim o custo de aquisição, pois os custos fixos de investimentos em TI (tecnologia da informação) são transformados em variáveis.

Com relação ao mercado brasileiro de ERP, de acordo com a Pesquisa Anual de Uso de Tecnologia da Informação (2015), a maior parte dele estava dividido entre três empresas: TOTVs com $36 \%$, a SAP com $30 \%$ e a Oracle com 16\%. Apesar dessa concentração, existia um segmento (das pequenas empresas) disputado por novas companhias que criaram produtos mais acessíveis hospedados na nuvem. Uma amostra do potencial desse segmento foi o crescimento de $80 \%$ da Betalabs em 2015 .

Essas características de tecnologia e mercado foram importantes para a pesquisa, pois implicam diretamente na avaliação de risco técnico da abordagem NPVR que será apresentada a seguir.

\subsubsection{Análise de Riscos no caso estudado}

O objetivo desse tópico é de avaliar os riscos que foram observados na Betalabs, considerando a abordagem NPVR (DAVIS, 2002) e a Maturity Level in Enterprise Risk Management (OLIVA, 2015).

Davis (2002) entende que "Novas plataformas" são adições às linhas de produtos existentes, embora os próprios produtos possam ser bastante inovadores.

Pode-se considerar o sistema de ERP da Betalabs como sendo uma "nova plataforma", pois ao se analisar o seu modelo de venda, o produto principal era o sistema de e-commerce que representava $70 \%$ do faturamento, todavia quem contratava o e-commerce, usualmente, utilizava também o sistema ERP, ou seja, eram soluções agregadas, que utilizavam a mesma base tecnológica. 


\subsubsection{Avaliação de Risco de Mercado}

A partir dos dados levantados e da contextualização das atividades da empresa, foi analisado o risco de mercado por meio da comparação do quadro abaixo com a entrevista com o fundador da Betalabs (E1Caso04).

Tabela 27 - Critérios para avaliação de riscos da cadeia de valor e segmento de mercado

\begin{tabular}{c|c|c}
\hline Pontuação & Avaliação da cadeia de valor & Avaliação do segmento de mercado \\
\hline Alta & $\begin{array}{c}\text { Todos os requisitos da cadeia de } \\
\text { valor existem internamente na } \\
\text { empresa }\end{array}$ & $\begin{array}{c}\text { Empresa é líder de mercado no } \\
\text { segmento de mercado-alvo }\end{array}$ \\
Média & $\begin{array}{c}\text { Todos os requisitos da cadeia de } \\
\text { valor existentes, alguns por meio de } \\
\text { parceiros }\end{array}$ & $\begin{array}{c}\text { Empresa vende outros produtos para } \\
\text { clientes no segmento de mercado }\end{array}$ \\
Baixa & $\begin{array}{c}\text { Algumas ou todas as necessidades da } \\
\text { cadeia de valor não estão presentes } \\
\text { dentro da empresa ou com parceiros } \\
\text { existentes }\end{array}$ & $\begin{array}{c}\text { Novo segmento de mercado, ou a } \\
\text { empresa não tem presença no } \\
\text { segmento de mercado-alvo }\end{array}$ \\
\hline
\end{tabular}

Fonte: Davis (2002)

O risco de mercado engloba qualquer elemento da cadeia de valor exigido de um novo produto para que ele atinja seus clientes potenciais. A partir dessa definição, pode se concluir que a pontuação da Betalabs era baixa (2), pois quando lançou o serviço, a startup não possuía nenhum programa de parceiros e todo o processo para disponibilizar o produto no mercado foi realizado internamente, mas de forma incompleta. Todavia, os sócios possuíam uma cadeia de contatos que foi essencial para a empresa conseguir os primeiros clientes. Ao mesmo tempo, houve um investimento em assessoria de imprensa para divulgar os serviços nos meios de comunicação.

Com relação à avaliação segmento de mercado, a Betalabs apresentava pontuação média (3), pois não era líder no mercado, mas vendia outros produtos no mesmo segmento, apesar de ser pequena naquele momento.

Analisado os riscos de mercado, a seguir serão apresentados os riscos técnicos, outro fator da fórmula para cálculo do risco pela abordagem NPVR. 


\subsubsection{Avaliação de Riscos Técnicos}

Riscos técnicos estão relacionados com o produto, bem como as capacidades de desenvolvimento da empresa. A pontuação obtida por estes fatores a partir da análise dos dados referentes à Betalabs está resumida a seguir:

Tabela 28 - Critérios para avaliação de riscos de inovação e recursos

\begin{tabular}{|c|c|c|}
\hline Pontuação & Avaliação da Inovação & Avaliação de Recursos \\
\hline Alta & $\begin{array}{l}\text { Utilização incremental de tecnologia bem } \\
\text { entendida }\end{array}$ & $\begin{array}{l}\text { Equipe de desenvolvimento com } \\
\text { experiência em projeto semelhante }\end{array}$ \\
\hline Média & $\begin{array}{l}\text { Nova tecnologia, protótipos desenvolvidos e } \\
\text { testados }\end{array}$ & $\begin{array}{l}\text { Nova equipe de desenvolvedores } \\
\text { com alguma experiência em } \\
\text { projetos semelhantes }\end{array}$ \\
\hline Baixa & $\begin{array}{l}\text { Nova tecnologia, fase de prova de conceito } \\
\text { com teste limitado }\end{array}$ & $\begin{array}{l}\text { Equipe incompleta e limitada } \\
\text { experiência em projetos } \\
\text { semelhantes }\end{array}$ \\
\hline
\end{tabular}

Fonte: Davis (2002)

Pode-se considerar a pontuação da inovação como baixa (2), pois o sistema, quando lançado, estava em fase de prova de conceito e o teste foi realizado no próprio cliente. De acordo com o entrevistado, menos de $50 \%$ do produto estava pronto o que gerou atraso na entrega de requisitos básicos como geração de nota fiscal e controle de estoque. Entretanto, esse processo se deu com um cliente que aceitou o risco de trabalhar com um produto em fase de teste, tendo como benefício um preço menor do que o de mercado. Apesar do produto ter itens padrões, como autenticação e de controle financeiro, alguns requisitos eram muito específicos, o que dificultou a sua construção baseada somente em benchmarking.

Sobre a avaliação de recursos, a Betalabs priorizava a contratação de novos profissionais, para ter a oportunidade de moldá-los ao invés de treinar profissionais mais experientes que geralmente trazem hábitos e noções pré-concebidas de experiências profissionais anteriores. Além disso, segundo (E1Caso04), novos profissionais conseguiam facilmente se fundir à cultura da empresa e rapidamente construir as habilidades desejadas. Entretanto, de acordo com a abordagem NPVR, por possuir uma equipe nova com pouco conhecimento prévio em ERP a pontuação da empresa foi média (3).

Complementando a avaliação tecnológica, no próximo item foi analisado o risco de usuário, uma das categorias propostas dedutivamente para analisar o risco nesse tipo de negócio. O risco de usuário se divide em capacidade de interação e a especificação. 


\subsubsection{Avaliação de Riscos de Usuário}

Enquanto o risco de mercado determina a capacidade da empresa para vender e dar suporte ao produto, e o risco técnico determina sua capacidade para construir o produto, o risco do usuário determina a probabilidade de que a empresa esteja desenvolvendo o produto certo (DAVIS, 2002). Avaliação de risco do usuário se concentra nos seguintes fatores:

Tabela 29 - Critérios para avaliação de interação e especificação

\begin{tabular}{c|c|c}
\hline Pontuação & Avaliação da Interação & Avaliação da Especificação \\
\hline Alta & $\begin{array}{c}\text { Pesquisa com o usuário primário } \\
\text { realizada ou planejada antes do } \\
\text { desenvolvimento }\end{array}$ & $\begin{array}{c}\text { Extensão de design de produto e } \\
\text { especificação de desempenho } \\
\text { existentes }\end{array}$ \\
Média & $\begin{array}{c}\text { Pesquisa com o usuário não } \\
\text { realizada, mas pesquisa com um } \\
\text { produto secundário realiza }\end{array}$ & $\begin{array}{c}\text { Nova especificação de design e } \\
\text { desempenho no segmento de } \\
\text { mercado existente }\end{array}$ \\
Baixa & $\begin{array}{c}\text { Pesquisa com usuário não } \\
\text { realizada, atributos do usuário } \\
\text { atribuídos por equipe interna }\end{array}$ & $\begin{array}{c}\text { Novo design e especificação de } \\
\text { desempenho no segmento do } \\
\text { Novo Mercado }\end{array}$ \\
\hline
\end{tabular}

Fonte: Davis (2002)

Com relação à avaliação da interação, a Betalabs não realizou pesquisa com usuário, mas adotou um modelo de construção do produto em conjunto com o cliente. Além disso, a ideia de produzir um ERP escalável não foi gerada por meio de uma pesquisa que demonstrou uma oportunidade de mercado, mas por causa de uma necessidade observada internamente. Por esses fatores a pontuação foi média (3).

Com relação à avaliação da especificação, de acordo com o entrevistado, a maioria dos clientes que optaram por contratar o ERP eram pessoas mais familiarizadas com tecnologia, mas não necessariamente com ERP. "Eram pessoas que tinham uma predisposição a testar coisas diferentes e que queriam de fato um produto um pouco mais inovador, isso fez a diferença" (E1Caso04). Ou seja, clientes mais avessos à tecnologia e inovação não eram o público alvo naquele momento. Além do mais, por ter sido uma nova iniciativa dentro da empresa, não havia domínio sobre o funcionamento do sistema ERP e o aprendizado foi construído junto ao cliente e sem uma definição fechada de escopo. No entanto, se por um lado nenhuma pesquisa de mercado foi realizada, por outro, a empresa estudou os clientes já atendidos e conseguiu identificar quais poderiam ter mais aderência ao produto, e por meio desse processo percebeu que havia necessidades em comum. Tais necessidades delimitaram a estrutura do produto padrão. $\mathrm{O}$ fato de a tecnologia ERP ser conhecida no mercado diminuiu o 
risco de especificação, todavia o ERP na nuvem era novidade na época. Assim, por esse conjunto de fatores, pode-se considerar o risco como médio (3).

Apresentados os principais riscos e a sua distribuição na Betalabs, no próximo item será apresentado o cálculo do NPVR, que utiliza as informações apresentadas para mensurar o quão exposto estava a empresa aos riscos de mercado, usuário e de tecnologia no momento do lançamento do produto.

\subsubsection{Cálculo do NPVR}

A partir dos dados coletados pelo modelo apresentado posteriormente, o NPVR é calculado da seguinte forma:

$\mathrm{NPVR}=((\mathrm{aM}+\mathrm{bM}+\mathrm{cT}+\mathrm{dT}+\mathrm{eU}+\mathrm{fU}) / 10) \times$ Valor Presente Líquido

Considerando a Betalabs como uma nova plataforma, de modo que os fatores de ponderação correspondentes a $\mathrm{M}=0.35, \mathrm{~T}=0.35$ e $\mathrm{U}=0.3$ :

$\mathrm{NPVR}=((\mathrm{a} 0.35+\mathrm{b} 0.35+\mathrm{c} 0.35+\mathrm{d} 0.35+\mathrm{e} 0.3+\mathrm{f} 0.3) / 10) \times$ Valor Presente Líquido

Onde a, b, c, d, e, f são as avaliações da cadeia de valor, do segmento de mercado, inovação, recursos, capacidades de interação e de especificação.

Por fim, com objetivo sintetizar os riscos explicados anteriormente e facilitar a visualização de sua distribuição, a tabela 30 foi construída.

Tabela 30 - Resumo da avaliação dos riscos da Betalabs

\begin{tabular}{c|c|c}
\hline Avaliação & Pontuação & Risco relacionado \\
Cadeia de valor & 2 & Mercado \\
Segmento de mercado & 3 & Mercado \\
Inovação & 2 & Técnico \\
Recursos & 3 & Técnico \\
Interação & 3 & Usuário \\
Especificação & 3 & Usuário \\
\hline
\end{tabular}

Aplicando a fórmula do NPVR:

$\mathrm{NPVR}=((2 * 0.35+3 * 0.35+2 * 0.35+3 * 0.35+3 * 0.3+3 * 0.3) / 10) \times \mathrm{VPL}$

$\mathrm{NPVR}=55 \% \mathrm{VPL}$ 
Portanto o NPVR é de $55 \%$ do VPL original, indicando que $45 \%$ do valor VPL projetado estava em risco. Como o NPVR está integrado ao processo de decisão, este nível de risco indica que esse lançamento poderia ser aprimorado. No caso específico da Betalabs, existiam riscos provenientes de dentro da organização, que poderiam ser controlados ou evitados por meio de: construção de parcerias para dispor de todos os requisitos da cadeia de valor; testes com protótipos antes da introdução da tecnologia no mercado; investimento em equipe de desenvolvimento com experiência em projeto semelhante e pesquisa com o usuário primário antes do desenvolvimento.

Em relação à abordagem da Maturity Level in Enterprise Risk Management (OLIVA, 2015), o entrevistado citou como um dos riscos o de imagem, pois estavam produzindo um negócio inovador para a empresa e financiado pelo cliente, dessa forma se o produto final ficasse abaixo das expectativas poderiam ocorrer problemas.

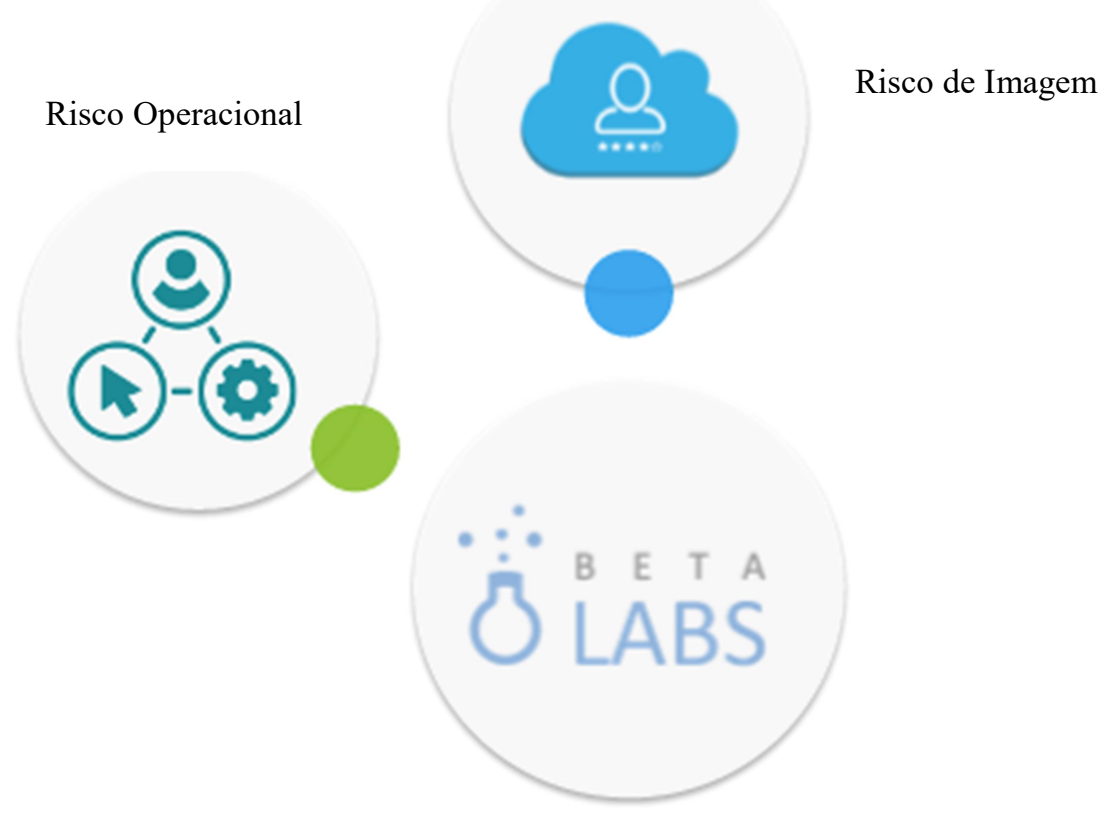

Figura 24 - Representação dos riscos do caso Betalabs

Além desse, foi mencionado o risco operacional, porque a Betalabs era pequena e tinha um número considerável de projetos sendo executados simultaneamente. Sobre esse último aspecto, a ação dos sócios para mitigá-lo foi de criar uma metodologia de precificação para equilibrar as margens com o tempo estimado de entrega de cada projeto, tendo como premissa que em alguns deles essa estimativa de tempo poderia estar errada no momento da assinatura do contrato com o cliente.

Apresentados os principais riscos aos quais a Betalabs estava exposta, a sua 
mensuração e o contexto em que estavam inseridos, no próximo item serão avaliadas as ações empreendedoras para mitigá-los.

\subsubsection{Ações empreendedoras sobre incerteza}

Esse tópico abordou as principais ações da empresa nesse ambiente de incerteza do lançamento e desenvolvimento de uma tecnologia.

A Betalabs apresentou no seu processo de desenvolvimento de produto um conjunto de ações para conseguir mitigar os riscos como, por exemplo, o aprendizado por tentativa-eerro, visto que no começo da operação o conhecimento sobre o sistema ERP era pequeno e foi sendo construído por meio de testes no cliente que levaram meses para viabilizar a primeira versão estável do produto.

Mesmo após ter essa versão validada, a empresa ainda se deparava com clientes que possuíam fluxos internos de informação muito diferentes, o que ampliou o tempo de maturação da ferramenta. Segundo o entrevistado (E1Caso04), esse era um dos pontos críticos da oferta de customização do ERP: “A customização tem sempre esse risco de demorar mais do que o cliente gostaria que demorasse, de custar mais do que a gente imaginava e a nossa vida é fazer a gestão disso". Apesar de a customização ser, à época da pesquisa, um diferencial, no começo foi difícil para a Betalabs transmitir essa proposta de valor para o cliente, porque muitos deles não entendiam o motivo de pagar um valor maior pelo serviço devido a esse diferencial.

$\mathrm{Na}$ etapa dos primeiros protótipos, a empresa utilizou-se também do benchmarking, procurando estudar as melhores ferramentas de ERP do mercado. Em paralelo, procurou atender às demandas dos seus clientes que em muitos casos pediam customizações não encontradas nos concorrentes.

A empresa apresentou também constantes evoluções do produto utilizando o método Lean Startup. A versão inicial do ERP, por exemplo, só possuía 50\% da tecnologia da versão estável do produto e essa evolução aconteceu por meio de constantes validações da ferramenta com o cliente.

Apresentadas as ações empreendedoras sobre incerteza, o próximo tópico foi destinado a analisar o caso pelo quadro proposto por essa dissertação. 


\subsubsection{Aplicação do modelo de pesquisa sugerido no caso Betalabs}

Nesse tópico, foram analisados os dados a respeito da Betalabs, de acordo com o modelo proposto dedutivamente pelo autor da pesquisa. Os dados coletados foram condensados por meio de codificação de primeiro e segundo nível, tendo como referência para a codificação os aspectos propostos de maneira dedutiva. Buscou-se, entretanto, reconhecer e classificar dados que não estavam dentro dos códigos estabelecidos previamente por meio do modelo da pesquisa.

Assim, a partir da combinação de aspectos dedutivos e indutivos os dados foram analisados e exibidos por meio de tabelas e descrições textuais. Por fim, foi gerado um modelo a fim de auxiliar futuras startups no lançamento de novas tecnologias no mercado brasileiro.

As células da matriz circundadas em vermelho representam as características presentes na Betalabs.

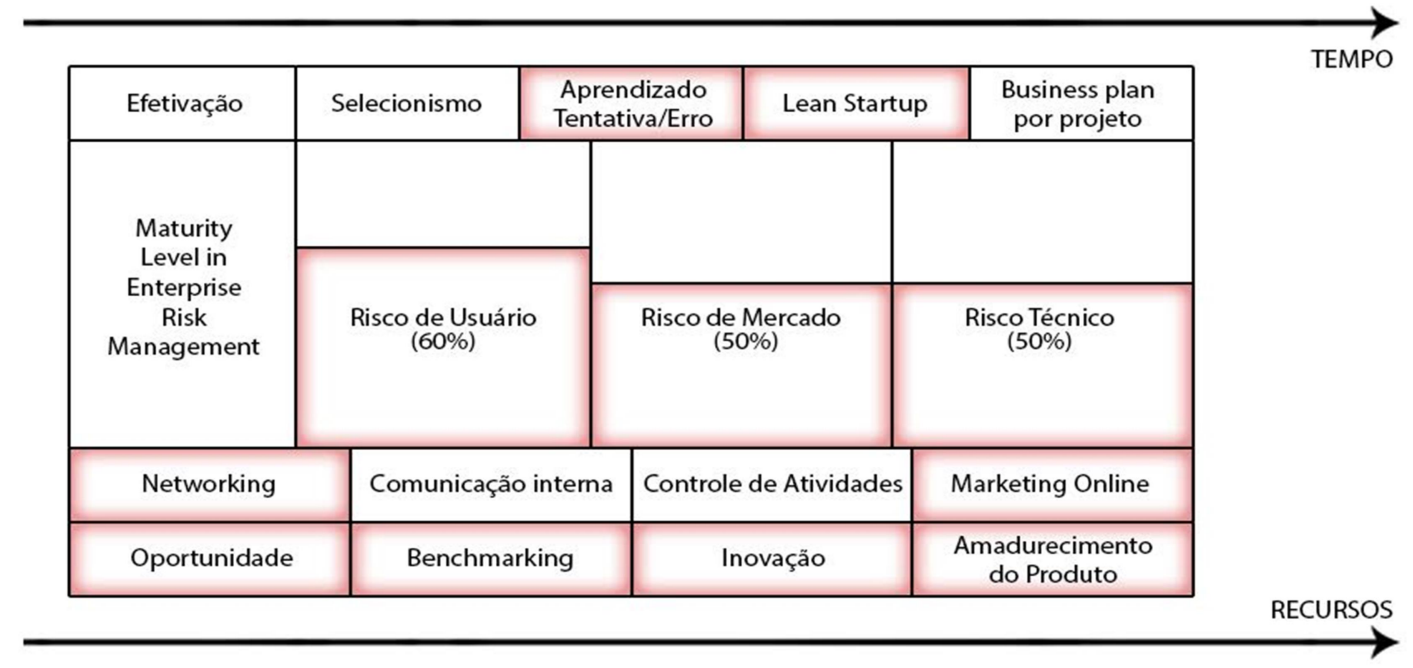

Figura 25 - Risk Management Matrix - Betalabs

No caso da Betalabs, dois pontos observados com intensidade foram o networking e a prática do Lean Startup, método centrado na melhoria contínua e no escopo flexível, priorizando um desenvolvimento com ciclos mais curtos.

Em relação aos elementos que poderiam ser aprimorados, pode-se citar a pequena rede de parceiros na cadeia de valor e a comunicação interna, pois não foi mencionada a utilização de um software específico para isso (no momento do lançamento do sistema ERP).

Esses fatores em conjunto demonstraram que a Betalabs já era mais madura que uma 
startup nascente, mas ainda enfrentava incertezas que aumentaram o risco global do negócio. Com o amadurecimento da empresa, algumas dessas incertezas foram sendo superadas, como por exemplo, o risco de o produto não ser aceito pelo mercado.

Conclui-se que esse caso é representativo, pois foi demonstrado que apesar do produto ser uma nova categoria e tratar-se assim de um bem complementar que foi desenvolvido com a finalidade de gerar uma vantagem competitiva através do seu efeito multiplicador sobre as vendas do produto primário, os riscos existiam e não podiam ser ignorados.

\subsection{Análise da experiência do empreendedor - Caso Polinize}

Pode-se considerar que se porventura o primeiro lançamento da Polinize (motivação para o desenvolvimento desse estudo) fosse analisado por meio da matriz apresentada, poderia ter obtido um melhor direcionamento, pois, naquele momento, não consultamos uma ferramenta que proporcionasse uma visão global dos riscos do negócio.

Como exemplos dos problemas da Polinize, pode-se citar a baixa experiência da equipe e a adoção de ações empreendedoras baseadas principalmente no selecionismo e na efetivação. Isso ocorreu desde a formação da equipe até mesmo na estratégia de produto. A empresa foi construída por meio de um processo de experimentação de várias ideias, sem um escopo definido e com um time formado por meio de networking dos sócios. Ocorreram problemas na gestão da comunicação, principalmente pelo fato do trabalho ter sido remoto e em cidades diferentes. O controle de atividades também era pouco desenvolvido e um sistema foi implementado para essa finalidade somente meses depois do lançamento. Marketing online também não foi considerado importante e essa decisão acarretou em problemas para viabilizar a solução no mercado. Ou seja, no lançamento, havia um time incompleto, um produto sem teste, um mercado pouco estudado e uma gestão de atividades com deficiências. Sobre o desenvolvimento do produto também ocorreu o processo de benchmarking, por meio do estudo de soluções que estavam se sobressaindo no mercado norte americano.

Apesar da condição negativa no momento do lançamento, a empresa conseguiu superar parte dessas dificuldades e foi possível estabelecer um canal com os primeiros usuários bem como um estudo da utilização da plataforma, que permitiu a sua evolução. Esse movimento está alinhado com a visão do Lean Startup e Aprendizado por tentativa-e-erro. Todavia, um plano de negócios para a empresa não chegou a ser construído no primeiro ano da operação, sendo escrito somente na fase de captação de investimentos. 
Com relação aos riscos da visão NPVR, a Polinize possuía um risco de mercado alto, pois não estabelecemos parcerias com elementos da cadeia de valor exigidos para atingir os clientes potenciais. Em todos os itens do NPVR possuíamos pontuação baixa, pois não realizamos pesquisa com usuário, não conhecíamos bem o modelo de negócio para viabilizar a empresa financeiramente e o design da proposta era novo no Brasil.

Considerando que algumas necessidades da cadeia de valor não estavam presentes dentro da empresa ou com parceiros existentes, que a Polinize não tinha presença no segmento de mercado-alvo, que o site era uma nova tecnologia em fase de prova de conceito com teste limitado, que a equipe era incompleta e com limitada experiência em projetos semelhantes, e que não foi realizada uma pesquisa com usuário, sendo também um novo design e especificação de desempenho no segmento do Novo Mercado, o risco do primeiro lançamento da Polinize (considerando-a como uma New Ventures) foi de:

$$
\text { NPVR }=((1 * 0.45+1 * 0.45+1 * 0.1+1 * 0.1+1 * 0.45+1 * 0.45) / 10) \times \text { Valor Presente }
$$

Líquido

NPVR $=20 \%$ VPL

Portanto o NPVR é de $20 \%$ do VPL original, indicando que $80 \%$ do valor VPL projetado estava em risco. De forma complementar, analisando a situação da empresa no momento do lançamento do produto por meio da Risk management matrix, tem-se a seguinte figura:

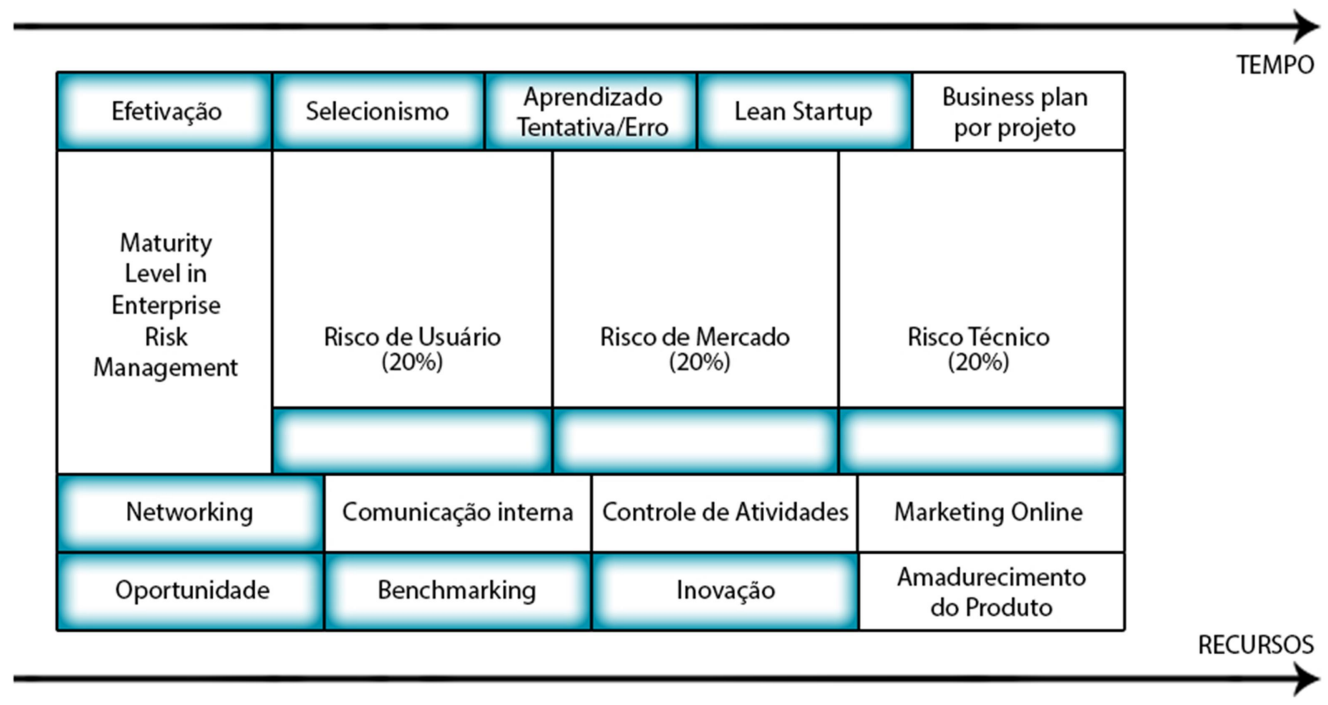

Figura 26 - Risk Management Matrix - Polinize

Mesmo envolvido em um cenário crítico como o descrito, resolvemos seguir com o projeto e nos ajustamos de acordo com as demandas que surgiram. O resultado foi que 
ocorreu desperdício de tempo e dinheiro, entretanto o aprendizado gerado nos permitiu ter uma avaliação como a que está sendo apresentada e pivotar a estratégia. A empresa conseguiu superar esse estágio, mas é nítido que se houvesse mais planejamento, uma equipe mais experiente, um investimento maior em processos e marketing e pesquisas do mercado e cliente, a viabilidade financeira do negócio seria mais rápida. 


\section{$5 \quad$ ANÁLISE E DISCUSSÃO DOS CASOS}

Este capítulo apresenta uma análise comparativa dos estudos de caso realizados nas quatro empresas que foram objeto da pesquisa. Os critérios de análise utilizados nos estudos de caso individualmente foram retomados e analisados de forma conjunta tendo por objetivo realizar a replicação lógica proposta no método de pesquisa e a consequente validação da abordagem estudada.

A análise ao longo dos casos pode se dar de mais de uma maneira. Neste estudo optou-se pela análise por variáveis (Miles et al, 2014), que possibilita o olhar transversal ao caso por meio das variáveis dedutivas e indutivas provenientes do estudo.

Comparando as empresas, pode-se observar que o Catarse se encontra na extremidade mais próxima a de uma startup que segue o modelo boostrapping, aquele que ocorre quando os sócios usam somente recursos próprios, sem apoio de fundos de investimento ou aceleradoras. Já o MercadoPago se posiciona no extremo oposto, pois se originou no MercadoLivre, uma empresa consolidada no mercado e com uma estrutura de capital e de recursos humanos amadurecida. A Betalabs pode ser considerada a segunda mais próxima do modelo de boostrapping, porque também não recebeu aportes de fundo de investimento, todavia, possuía um modelo de gestão mais organizado; e, por fim, o GuiaBolso aproxima-se do MercadoPago, por possuir também fundos de investimento e mentores que ajudaram a empresa a se profissionalizar de forma mais rápida, embora ainda não possuísse um modelo financeiro validado.

Para facilitar a visualização das características de comunicação e desenvolvimento de produto de cada empresa, os riscos observados e as ações empreendedoras tomadas, a seguir são apresentadas tabelas comparativas dos casos: 
A tabela 31 apresenta as características observadas no caso Catarse de forma resumida:

Tabela 31 - Pontuação do NPVR no caso 01 (Catarse)

\begin{tabular}{|c|c|c|c|}
\hline \multicolumn{4}{|r|}{ 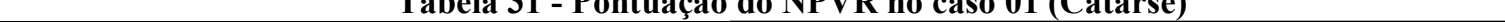 } \\
\hline Avaliação & Pontuação & $\begin{array}{c}\text { Risco } \\
\text { relacionado }\end{array}$ & Evidências \\
\hline $\begin{array}{l}\text { Cadeia de } \\
\text { valor }\end{array}$ & 2 & Mercado & $\begin{array}{l}\text { - A única parceria no lançamento da plataforma era o } \\
\text { de meio de pagamento para viabilizar a questão dos } \\
\text { estornos de pagamento. }\end{array}$ \\
\hline $\begin{array}{l}\text { Segmento de } \\
\text { mercado }\end{array}$ & 1 & Mercado & $\begin{array}{l}\text { - O crowdfunding era inexistente na época, sendo um } \\
\text { novo segmento de mercado. }\end{array}$ \\
\hline Inovação & 2 & Técnico & $\begin{array}{l}\text { - A plataforma de lançamento estava em fase de prova } \\
\text { de conceito e com teste limitado. }\end{array}$ \\
\hline Recursos & 3 & Técnico & $\begin{array}{l}\text { - Não havia um integrante com um histórico } \\
\text { profissional relacionado com crowdfunding. } \\
\text { - O time era suficiente para o desenvolvimento do } \\
\text { negócio. }\end{array}$ \\
\hline Interação & 1 & Usuário & $\begin{array}{l}\text { - Não ocorreu uma pesquisa com o usuário primário } \\
\text { antes do desenvolvimento da plataforma. }\end{array}$ \\
\hline Especificação & 2 & Usuário & $\begin{array}{l}\text { - Era um novo design para um segmento novo de } \\
\text { mercado. }\end{array}$ \\
\hline
\end{tabular}

A tabela 32 apresenta as características observadas no caso GuiaBolso de forma resumida:

Tabela 32 - Pontuação do NPVR no Caso 02 (GuiaBolso)

\begin{tabular}{|c|c|c|c|}
\hline Avaliação & Pontuação & $\begin{array}{c}\text { Risco } \\
\text { relacionado }\end{array}$ & Evidências \\
\hline $\begin{array}{l}\text { Cadeia de } \\
\text { valor }\end{array}$ & 4 & Mercado & $\begin{array}{l}\text { - Acesso a rede Endeavor e parceria com bancos } \\
\text { - Trouxe advisors importantes para o desenvolvimento } \\
\text { do negócio. } \\
\text { - Parcerias com universidades para trabalhar com } \\
\text { questões relativas ao comportamento do consumidor. } \\
\text { - Sócios possuíam uma cadeia de contatos interessantes } \\
\text { que foi essencial para empresa conseguir os primeiros } \\
\text { clientes. }\end{array}$ \\
\hline $\begin{array}{l}\text { Segmento de } \\
\text { mercado }\end{array}$ & 2 & Mercado & - Segmento de mercado novo. \\
\hline Inovação & 3 & Técnico & - Nova tecnologia com testes limitados. \\
\hline Recursos & 2 & Técnico & $\begin{array}{l}\text { - Equipe era incompleta e com experiência limitada em } \\
\text { projetos parecidos. }\end{array}$ \\
\hline Interação & 5 & Usuário & $\begin{array}{l}\text { - Principalmente por meio do benchmarking, procurou } \\
\text { entender a necessidade do usuário. } \\
\text { - Por meio da versão web do consultor financeiro, } \\
\text { anterior ao aplicativo, foram realizadas mais de } 40 \text { mil } \\
\text { consultorias. }\end{array}$ \\
\hline Especificação & 2 & Usuário & $\begin{array}{l}\text { - Foi o primeiro em um novo mercado. } \\
\text { - Introduziu um novo design para o mercado brasileiro. }\end{array}$ \\
\hline
\end{tabular}


A tabela 33 apresenta as características observadas no caso MercadoPago de forma resumida:

Tabela 33 - Pontuação do NPVR no Caso 03 (MercadoPago)

\begin{tabular}{|c|c|c|c|}
\hline Avaliação & Pontuação & $\begin{array}{c}\text { Risco } \\
\text { relacionado }\end{array}$ & Evidências \\
\hline $\begin{array}{l}\text { Cadeia de } \\
\text { valor }\end{array}$ & 4 & Mercado & $\begin{array}{l}\text { - Estar no ecossistema do MercadoLivre (Mercado Envios, o } \\
\text { Mercado ETC, e KPL). } \\
\text { - Oportunidades para obtenção de economias de escala, } \\
\text { escopo e maior controle sobre a cadeia de valor. } \\
\text { - Experiência do usuário mais uniforme que compele os } \\
\text { consumidores a investir em toda a sua linha de produtos } \\
\text { - Parcerias com empresas que possuem ativos e } \\
\text { competências complementares ao seu negócio. }\end{array}$ \\
\hline $\begin{array}{l}\text { Segmento de } \\
\text { mercado }\end{array}$ & 5 & Mercado & $\begin{array}{l}\text { - O Mercado Livre era líder no segmento de mercado-alvo } \\
\text { na época. }\end{array}$ \\
\hline Inovação & 3 & Técnico & $\begin{array}{l}\text { - Uma nova tecnologia, mas com protótipos desenvolvidos e } \\
\text { testados. } \\
\text { - A concepção de carteira digital era inexplorada no ano de } \\
2004 \text {. }\end{array}$ \\
\hline Recursos & 4 & Técnico & $\begin{array}{l}\text { - Equipe era completa, nova e com experiência em projetos } \\
\text { de tecnologia da informação. } \\
\text { - Não existiam especialistas em pagamento online no Brasil } \\
\text { e o time foi formado internamente. }\end{array}$ \\
\hline Interação & 5 & Usuário & $\begin{array}{l}\text { - Procurou entender o usuário em todas as fases do } \\
\text { desenvolvimento dos produtos. } \\
\text { - Realizou pesquisas frequentes com compradores e } \\
\text { vendedores para entender as suas necessidades. } \\
\text { - Benchmarking com outras empresas. }\end{array}$ \\
\hline Especificação & 3 & Usuário & $\begin{array}{l}\text { - Apresentou um novo design para um segmento de mercado } \\
\text { já existente, mas novo no Brasil. }\end{array}$ \\
\hline
\end{tabular}


A tabela 34 apresenta as características observadas no caso Betalabs de forma resumida:

Tabela 34 - Pontuação do NPVR no Caso 04 (Betalabs)

\begin{tabular}{|c|c|c|c|}
\hline Avaliação & Pontuação & $\begin{array}{c}\text { Risco } \\
\text { relacionado }\end{array}$ & Evidências \\
\hline $\begin{array}{l}\text { Cadeia de } \\
\text { valor }\end{array}$ & 2 & Mercado & $\begin{array}{l}\text { - Quando lançou o serviço a empresa não possuía } \\
\text { nenhum programa de parceiros. } \\
\text { - Sócios possuíam uma cadeia de contatos interessantes } \\
\text { que foi essencial para empresa conseguir os primeiros } \\
\text { clientes. }\end{array}$ \\
\hline $\begin{array}{l}\text { Segmento de } \\
\text { mercado }\end{array}$ & 3 & Mercado & $\begin{array}{l}\text { - Não era líder no mercado. } \\
\text { - Vendia outros produtos no mesmo segmento. }\end{array}$ \\
\hline Inovação & 2 & Técnico & $\begin{array}{l}\text { - Sistema estava em fase de prova de conceito. } \\
\text { - O teste foi realizado no próprio cliente. } \\
\text { - Menos de } 50 \% \text { do produto estava pronto e muitas } \\
\text { funcionalidades não funcionavam. }\end{array}$ \\
\hline Recursos & 3 & Técnico & $\begin{array}{l}\text { - Equipe nova com pouco conhecimento prévio em } \\
\text { ERP. }\end{array}$ \\
\hline Interação & 3 & Usuário & $\begin{array}{l}\text { - Não realizou pesquisa com usuário. } \\
\text { - Adotou um modelo de construção do produto em } \\
\text { conjunto com o cliente. }\end{array}$ \\
\hline Especificação & 3 & Usuário & $\begin{array}{l}\text { - Clientes que optaram por contratar o ERP eram } \\
\text { familiarizados com tecnologia, mas não } \\
\text { necessariamente com ERP. } \\
\text { - Não havia domínio sobre o funcionamento do ERP. }\end{array}$ \\
\hline
\end{tabular}


A tabela 35 apresenta a distribuição dos riscos entre os casos:

\begin{tabular}{c|c|c|c}
\multicolumn{4}{c}{ Tabela 35 - Distribuição dos riscos entre os casos } \\
\hline Startup & Risco de usuário & Risco de mercado & Risco Técnico \\
\hline Catarse & $30 \%$ & $30 \%$ & $50 \%$ \\
GuiaBolso & $70 \%$ & $60 \%$ & $50 \%$ \\
MercadoPago & $80 \%$ & $90 \%$ & $70 \%$ \\
Betalabs & $60 \%$ & $50 \%$ & $50 \%$
\end{tabular}

A tabela 36 apresenta a distribuição das ações empreendedoras entre os casos:

\begin{tabular}{c|c|c|c|c|c}
\multicolumn{5}{|c}{ Tabela 36 - Distribuição das ações empreendedoras entre os casos } \\
\hline Startup & Efetivação & Selecionismo & $\begin{array}{c}\text { Aprendizado por } \\
\text { Tentativa/Erro }\end{array}$ & Lean Startup & $\begin{array}{c}\text { Business plan por } \\
\text { projeto }\end{array}$ \\
\hline Catarse & & & \\
GuiaBolso \\
MercadoPago \\
Betalabs
\end{tabular}


A tabela 37 apresenta a distribuição dos elementos de comunicação entre os casos:

Tabela 37 - Distribuição dos elementos de comunicação entre os casos

\begin{tabular}{c|c|c|c|c}
\hline Startup & Networking & Comunicação Interna & Controle de atividades & Marketing Online \\
\hline Catarse & & & \\
GuiaBolso & & & \\
MercadoPago & & & \\
Betalabs & & \\
\hline
\end{tabular}

A tabela 38 apresenta a distribuição dos elementos de desenvolvimento de produto entre os casos:

Tabela 38 - Distribuição dos elementos de desenvolvimento de produto entre os casos

\begin{tabular}{l|c|c|c|c}
\hline Startup & Oportunidade & Benchmarking & Inovação & Amadurecimento do produto \\
Catarse & \\
GuiaBolso \\
MercadoPago \\
Betalabs
\end{tabular}

A tabela 39 apresenta os riscos observados em cada caso:

Tabela 39 - Riscos observados em cada caso

\begin{tabular}{c|c|c|c}
\multicolumn{4}{c}{ Tabela 39 - Riscos observados em cada caso } \\
\hline Startup & Catarse & GuiaBolso & MercadoPago \\
\hline Maturity level in enterprise risk management & $\begin{array}{c}\text { Imagem, operacional, } \\
\text { fornecedores, } \\
\text { legislação }\end{array}$ & Equipe e cliente & Imagem, operacional, ético, tecnológico e de \\
segurança & Imagem e \\
operacional & & \\
\hline
\end{tabular}


Apesar dessas diferenças, o ambiente de incerteza, a geração de uma inovação a partir de uma oportunidade, a aplicação dos modelos de aprendizado por tentativa-e-erro e lean startup foram percebidos em todos os casos.

Analisando ainda pela ótica das ações empreendedoras sobre incerteza, percebe-se que quanto mais uma startup possui um modelo próximo ao do MercadoPago, mais planejamento acontece antes das tomadas de decisões de investimento. Comparando-as nesse requisito, no MercadoPago ocorreu o desenvolvimento de business plan por cada projeto implementado. Além disso, o fator comunicação para a gestão dos projetos foi relevante, bem como o de marketing online para relacionamento com os clientes.

No extremo oposto, o Catarse conduziu os processos estratégicos de maneira menos estruturada e não se observou a adoção de um business plan. Segundo o entrevistado (E1Caso01), os sócios tinham somente uma folha de papel que traduzia os agentes do modelo, mas sem avaliação mais profunda sobre cada elemento. Ademais, em relação ao acompanhamento de execução das atividades, no início o trabalho no Catarse era remoto, o que ocasionava dificuldade de controle e diminuição da agilidade de tomada de decisão.

Considerando os fatores limitantes da Risk management matrix - tempo e recurso, nota-se que as empresas mais próximas do modelo boostrapping tinham maior dificuldade para gerir recursos necessários para se manter no mercado e isso aumentava o risco financeiro da operação. Possuir recursos, todavia, não as tornavam economicamente viáveis, como é o caso do GuiaBolso, mas as permitiam ter melhores condições para planejar ações estratégicas com um prazo maior.

Tempo dedicado ao planejamento também foi um fator reduzido em empresas como o Catarse que evoluem por anos sem muitas vezes possuir um organograma e ferramentas para medição de desempenho. Não possuir recursos, todavia, não é um fator que exclui a possibilidade de planejamento, pois no caso da Betalabs, que também não foi investida, o planejamento estratégico aconteceu. Notoriamente, com o decorrer do tempo as startups tendem a evoluir seus processos internos e as ações empreendedoras tornam-se mais estruturadas.

Com relação à geração da inovação, observa-se que nas quatro empresas estudadas ocorreu benchmarking com empresas estrangeiras, o que pode ser um reflexo do estágio incipiente do empreendedorismo tecnológico no Brasil, considerando a premissa de que copiar tende a ser menos complexo e envolver menos risco do que a geração e validação de um modelo inédito. Todavia, nota-se que "tropicalizar" um modelo estrangeiro acarreta, na 
maioria dos casos, em aperfeiçoamentos do modelo original. Por exemplo, o mercado brasileiro requer a disponibilidade de boleto bancário para sistemas de pagamento como o MercadoPago, o que não faz sentido para o modelo de negócio do Paypal, empresa similar ao MercadoPago, sediada nos Estados Unidos. Ou seja, as estratégias de marketing, canais de distribuição, segmentos de clientes, forma de interação com o mercado e outras variáveis devem ser analisadas e repensadas, não podendo ser simplesmente copiadas.

Ainda com relação ao produto, existem dois extremos que foram observados: no caso da Betalabs, em que o primeiro lançamento possuía menos de $50 \%$ do produto final; e no caso da GuiaBolso, em que o primeiro lançamento já apresentava uma versão mais completa. Todavia, em todos os casos a evolução do produto foi percebida e procurou corresponder as demandas dos usuários, seguindo a filosofia do Lean Startup.

Um item importante observado nos quatro casos foi o investimento em marketing online como meio para se aproximar do mercado potencial. Nota-se que essa estratégia foi utilizada com a finalidade de comunicar as ações da empresa, torná-la relevante no mercado, gerar tração para os sites e fornecer uma oportunidade para o estabelecimento de canais de comunicação mais próximos dos consumidores com um orçamento significativamente reduzido. Com essa estratégia foi possível medir os padrões de consumo, as inclinações e as preferências dos usuários e, com a mesma rapidez, ajustar-se a tais condições para melhor atendê-los.

Quanto à comunicação interna (responsável pela distribuição das informações entre os colaboradores e o gerenciamento das metas da empresa) conclui-se que poderia ser aprimorada na maioria dos casos, sendo que o MercadoPago se apresentou com a melhor estrutura nesse quesito.

Com relação aos riscos analisados pela Maturity Level in Enterprise Risk Management, nota-se que não existe um padrão, pois os contextos estudados pela matriz são muito abrangentes, envolvendo desde política à economia. Observa-se, todavia, que existem riscos que podem ser evitados caso a empresa invista mais em seu planejamento. No caso do Catarse, por exemplo, o risco operacional de controle dos fluxos financeiros que, no começo, era feito em uma planilha do software Microsoft Excel (r), poderia ser mitigado por meio da implementação de um software específico para isso.

Ainda no que diz respeito ao Catarse, nota-se que o risco assumido foi alto e as perdas seriam pequenas, caso o negócio não retornasse o investimento. Não é possível generalizar esse cenário para todas as empresas de tecnologia devido à pequena amostra estudada, todavia 
é um ponto crítico para futuras pesquisas a análise de correlação entre startups de maior risco com as que receberam menor investimento.

Por fim, no que tange às ações empreendedoras, pode-se concluir que no começo de negócios menos estruturados a efetivação e o selecionismo são dominantes, porque o empreendedor tende a focar mais na execução do que no planejamento, como foi no caso do Catarse. Essa ação viabiliza o negócio mais rapidamente, todavia no médio prazo exige que a empresa se ajuste para não ter problemas gerenciais e tecnológicos, considerando que com o seu crescimento as demandas não planejadas emergirão. Como exemplo, o Catarse não possuía no seu lançamento um sistema para controle financeiro e o site não aceitava boleto bancário. Dois problemas não planejados que exigiram da empresa ações de correção.

No outro extremo, com maior investimento e tempo de execução, as empresas tendem a planejar mais suas ações, devidos principalmente aos maiores riscos envolvidos. Nesse caso, o MercadoPago é o caso mais expressivo.

Aprendizado por tentativa-e-erro e Lean startup são ações observadas em todas as empresas principalmente por lidarem com inovação que se traduz em incertezas estratégicas, de produto e de mercado.

Conclui-se que estratégias com altos retornos esperados geralmente exigem que a empresa assuma riscos significativos, e o gerenciamento desses riscos é um fator-chave na geração de ganhos potenciais. Para isso é necessário um modelo concebido para reduzir a probabilidade de que os riscos assumidos realmente se concretizem. É importante enfatizar que a matriz proposta por essa pesquisa não tem como objetivo impedir que ocorram empreendimentos arriscados; ao contrário, ela permite às empresas que a adotam assumir empreendimentos de maior retorno do que as concorrentes que possuem uma gestão de risco menos eficaz. 


\section{CONCLUSÕES E RECOMENDAÇÕES}

O objetivo deste capítulo é apresentar as conclusões da pesquisa, evidenciando as implicações para a teoria e para a prática e, ao seu final, discorresse sobre suas limitações e as possíveis oportunidades que poderão ser exploradas por trabalhos futuros. Nesse sentido, a pergunta de pesquisa que orientou esta dissertação foi: Quais são os riscos de introdução de novas tecnologias no mercado, quão expostas estão as startups a esses riscos e como é possível gerenciá-los?

Para responder ao questionamento orientador, a abordagem metodológica escolhida foi a qualitativa, com a utilização de estudo de casos quanto aos seus procedimentos. Em paralelo, a revisão da literatura abrangeu trabalhos sobre startups, inovação, oportunidade, incerteza, risco e ação empreendedora. Nos estudos de casos foram analisadas quatro startups que desenvolveram projetos nas seguintes áreas: crowdfunding, sistema de pagamento, aplicativo de controle financeiro e sistema ERP. A escolha dos casos foi feita com base em dimensões que foram consideradas importantes para os resultados da pesquisa como um todo, tendo sido escolhidos casos expressivos no ecossistema de startups brasileiras.

Com base nos resultados obtidos, conclui-se que os principais riscos na introdução de uma nova tecnologia no mercado são os técnicos, mercadológicos e de usuário, apresentados na visão NPVR. Complementar a esses riscos, existem os abordados pela Maturity Level in Enterprise Risk Management (OLIVA, 2015), que podem ser de diferentes naturezas e de diferentes graus de importância para cada empresa.

Com relação ao grau de exposição aos riscos dessas startups, foi possível calculá-los por meio do uso da fórmula da abordagem NPVR, levando em consideração as avaliações da cadeia de valor, segmento de mercado, inovação, capacidades de interação e de especificação e os pesos de M (de mercado), T (técnico) e U (usuário) que são escolhidos de acordo com a categoria do produto.

Do ponto de vista de gerenciamento dos riscos, foram propostas as ações empreendedoras: selecionismo, aprendizado por tentativa-e-erro, efetivação, lean startup, plano e modelo de negócio.

Sobre as contribuições adicionais à questão de pesquisa foi observada uma relação entre retornos positivos para o negócio com a comunicação, tanto para o público externo quanto interno. Além disso, envolvendo todo esse processo, que foi representado por meio da Risk management matrix, existem os fatores tempo e recursos que são limitantes e devem ser considerados. 
Por fim, foi proposta uma sistematização da análise dos riscos no processo de desenvolvimento de produtos em startups descrita na Risk management matrix que é apresentada de forma mais detalhada na Figura 27.

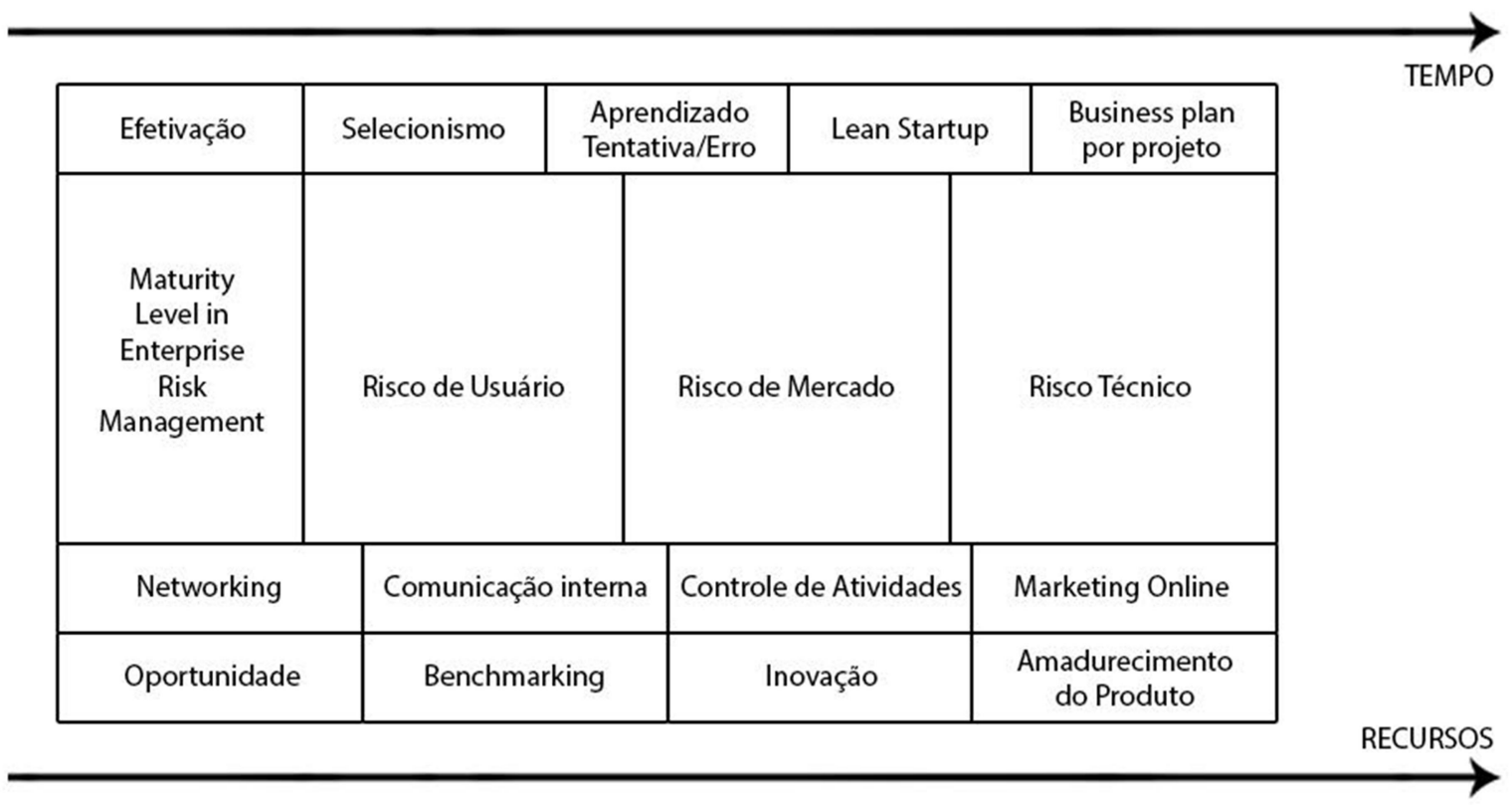

Figura 27 - Risk Management Matrix

Nos extremos da Risk management matrix, encontram-se tempo e recursos. Adicionaram-se esses elementos, pois tempo para startups é um elemento escasso, visto que na maioria dos casos exige-se que uma startup tenha velocidade, foco e visão para crescer rapidamente, apesar de ter uma equipe pequena, poucos recursos e marcas não estabelecidas. Paradoxalmente, apesar do fato de tempo ser importante, a maioria dos empresários não se concentram na sua gestão de forma sistemática e estratégica. Vários problemas distintos se manifestam como causas: trabalho realizado de forma lenta; a não compreensão do problema do usuário; trabalho com pouco foco ou perfeccionismo excessivo, por exemplo. Naturalmente, a quantidade de tempo necessário para produzir a entrega estará diretamente relacionada à quantidade de requisitos que fazem parte do resultado final (escopo), juntamente com a quantidade de recursos alocados para o projeto, todavia em uma startup muitas vezes o escopo não está definido.

Para acelerar um projeto (tempo), um empreendedor pode reduzir características (escopo), ou ampliar os recursos (custo). Para aumentar o escopo, pode-se ampliar a equipe, estratégia que aumentará a velocidade do trabalho, mas também o custo. Além dessa alternativa, pode-se prorrogar o prazo (tempo) ou ambos. Para concluir um projeto dentro do 
orçamento (custo), pode-se reduzir o escopo, ou reduzir o número de trabalhadores o que ampliará a quantidade de tempo para terminá-lo.

Nota-se assim, que o papel do empreendedor no equilíbrio dessas variáveis é fundamental. Por mais simples que aparente ser, a capacidade de compreender e gerenciar as três variáveis (sendo as mais importantes - tempo e recursos, no caso das startups, visto que o escopo é pouco definido no começo) muitas vezes determina se o projeto será bem-sucedido.

Dando continuidade, na primeira linha da matriz, têm-se os elementos que se referem ao desenvolvimento do produto, processo que envolve uma série de etapas que nos casos estudados giravam em torno das seguintes áreas-chave: a identificação da oportunidade, o processo de benchmarking, a geração da inovação e o seu processo de amadurecimento.

Esse processo pode ser explicado da seguinte maneira: cada produto começa com uma ideia. Em alguns casos, isso pode ser bastante simples, como nos casos de ideias baseadas em produtos já existentes em outros mercados, por exemplo. Em outros casos, pode ser algo revolucionário e único, o que pode aumentar a complexidade desse processo. Dentro desse contexto, nas empresas estudadas, foi observado a prática de benchmarking com empresas estrangeiras em todos os casos, sendo então esse um item relevante e por isso selecionado para compor a matriz.

Ainda sobre o processo de desenvolvimento de um produto, por meio das análises dos casos, considerou-se que a sua composição ideal possui algumas etapas como, por exemplo, a de pesquisa de mercado, que procura entender se há demanda para o produto e também quais características específicas devem ser desenvolvidas a fim de melhor atender as necessidades do cliente potencial. Esse processo seria o mais adequado, mas não necessariamente aconteceu em todas as empresas estudadas. Após essa fase de pesquisa, se verificaria o desenvolvimento de protótipos que são validados com alguns clientes. Isso é importante, pois por meio de informações provindas dessa primeira interação é possível realizar decisões estratégicas que serão essenciais para o desenvolvimento do negócio, como por exemplo, a definição do preço e modelo de cobrança. Finalmente, quando o produto é apresentado ao mercado, torna-se importante a gestão do seu ciclo de vida com a finalidade de torná-lo tão longo e rentável possível.

Um segundo nível estudado foi o processo de comunicação, composto pelos seguintes itens: networking, comunicação interna, controle de atividades e marketing online. Nos contextos deste estudo, o networking teve implicações de importância. Observou-se, por exemplo, que a chance de que um empreendedor identifique uma oportunidade inexplorada, 
consiga investimento para o seu empreendimento de risco, recrute equipe, construa parcerias e clientes se relaciona com a sua posição em uma estrutura social.

Por sua vez, comunicação interna está associada com o processo de monitoramento do ciclo de vida do projeto, pois por meio dela é possível garantir que as informações necessárias para as partes interessadas na empresa, como status das entregas para um lançamento específico, previsões de custos, relatório de desempenho de pessoal e progresso do cronograma estejam disponíveis de forma organizada. Foi observado que entre empresas estudadas, as que possuíam um sistema de gestão de informações para esse controle, obtinham melhor desempenho.

O elemento da matriz "controle de atividades", se refere às pessoas, processos e ferramentas utilizadas para planejar, gerenciar e atenuar problemas de custo e cronograma e quaisquer eventos de risco que possam afetar um projeto. Apesar de ser um elemento importante para uma empresa, notou-se que nas startups estudadas existiam casos em que não ocorreu a sua utilização de forma adequada.

O último elemento do nível comunicação é o marketing online que foi inserido por ter sido adotado em todos os casos. Marketing digital consiste na promoção de produtos ou marcas através de mídias eletrônicas e difere do marketing tradicional na medida em que envolve o uso de canais e métodos que permitem a ampliação do alcance das campanhas com menor custo e maior eficiência.

Os elementos do nível produto e comunicação foram construídos a partir da análise dos casos estudados. O nível superior a eles - "riscos" - engloba as abordagens do NPVR e Maturity Level in Enterprise Risk Management já exploradas nessa dissertação. Esses riscos tendem a serem maiores quando a empresa apresenta ações empreendedoras (efetivação, selecionismo, aprendizado por tentativa-e-erro, lean startup e plano de negócio) mais próximas da extrema esquerda da matriz.

Além da construção da matriz, que pode ser considera a principal contribuição desse estudo, foi possível também validar a fórmula do NPVR para o cálculo do risco de cada negócio analisado, verificar os riscos aos quais as startups estavam expostas, colaborar para a elaboração de uma abordagem sobre incerteza e risco em startups (apresentados na revisão teórica) e por fim entender como esse modelo poderia contribuir para o primeiro lançamento da Polinize (motivação desse estudo). 


\subsection{Limitações da pesquisa e recomendações para trabalhos futuros}

Esta dissertação possui limitações oriundas de suas próprias características. A primeira é a capacidade de generalização dos resultados, uma vez que a estratégia metodológica utilizada (estudo de casos múltiplos) não possui essa orientação. A segunda limitação se refere ao número de atores entrevistados em cada empresa - foram entrevistados os principais gestores, como fundadores ou diretores, pois era necessário ter a visão de alguém que participou de forma decisiva dos processos de desenvolvimento do produto, todavia para cada empresa o número de entrevistas se limitou a um. De forma complementar, em todos os casos, foi possível buscar evidências em fontes secundárias, tais como sites e documentos fornecidos pelos empreendedores.

A pesquisa permitiu que emergissem diversas questões, as quais não foram possíveis de explorar em sua totalidade, por estar além do escopo do estudo. Por exemplo, os métodos ágeis como o scrum, que foi observado nas entrevistas, mas não aprofundado nessa dissertação.

Como sugestão de continuidade de pesquisa, entende-se que serão necessários estudos para aperfeiçoar a abordagem da Risk management matrix, com o objetivo de analisar uma variedade ampla de casos e contextos em que a introdução de novas tecnologias ocorre. Pesquisas futuras serão importantes para validar e aprimorar os resultados obtidos, pois esta dissertação analisou a trajetória de startups que estavam em fase de estabilidade ou crescimento de faturamento, todavia essa situação não é definitiva, e já existem casos de startups que chegaram a esse estágio e depois diminuíram de tamanho, foram adquiridas ou entraram em processo de falência. Novos estudos podem incluir empresas que passaram por essas outras fases e, assim, avançar no conhecimento sobre a evolução dos riscos nesses casos. Outra área de estudo complementar seria a comparação entre empresas investidas e não investidas, pois é muito provável que as investidas tenham uma gestão mais profissional do que as não investidas, fato observado nesse estudo, mesmo com a pequena amostra. Além disso, é possível a realização de estudos comparativos, entre startups de diferentes países para entender como fatores externos influenciam a distribuição de riscos.

Por fim, sugere-se a criação de uma curva de evolução dos riscos das startups por meio de um estudo quantitativo de maneira que se consiga identificar fases do ciclo de vida das empresas e as características em comum de cada fase no que diz respeito às práticas de marketing, finanças, recursos humanos, operações e retorno sobre investimento e compará-lo com a matriz proposta. 


\section{REFERÊNCIAS}

AULET, Bill. Disciplined entrepreneurship: 24 steps to a successful startup. John Wiley \& Sons, 2013.

ARRUDA, Carlos et al. Causas da mortalidade de startups brasileiras: o que fazer para aumentar as chances de sobrevivência no mercado. Núcleo de Inovação e Empreendedorismo: Fundação Dom Cabral, 2014.

BRASIL. Instituto Brasileiro de Geografia e Estatística - IBGE. Principais destaques da evolução do mercado de trabalho nas regiões metropolitanas abrangidas pela pesquisa. Brasília, 2013

BRASIL. Secretária de Assuntos Estratégicos. $1^{\circ}$ Relatório Novas Vozes da Classe Média. Brasília, 2012

BRASIL. Banco Central do Brasil. Relatório de inclusão financeira. Brasília, 2015

BLANK, Steve; DORF, Bob. The startup owner's manual. K\&S; Ranch, 2012.

BLANK, Steve. Why the lean start-up changes everything. Harvard Business Review, v. 91, n. 5, p. 63-72, 2013.

BHIDE, Amar. The origin and evolution of new businesses. Oxford University Press, 2000.

BOGDAN, Robert C. et al. Investigação qualitativa em educação: uma introdução à teoria e aos métodos. 1994.

COOPER, Brant; VLASKOVITS, Patrick. The lean entrepreneur: how visionaries create products, innovate with new ventures, and disrupt markets. John Wiley \& Sons, 2013

COOPER ROBERT, G. Doing it right, Winning at new Products. Ivey Business Journal July/August, 2000.

COOPER, Robert G. Stage-gate systems: a new tool for managing new products. Business horizons, v. 33, n. 3, p. 44-54, 1990.

COOPER, Robert G. What's Next?: After Stage-Gate. Research-Technology Management, v. 57, n. 1, p. 20-31, 2014.

COSO. Gerenciamento de Riscos Corporativos - Estrutura Integrada. 2007. Disponível em: $<$ http://www.coso.org/documents/COSO_ERM_ExecutiveSummary_Portuguese.pdf $>$

Acesso em: 24/05/2015.

CRESWELL, John W. Projeto de pesquisa métodos qualitativo, quantitativo e misto. In: Projeto de pesquisa métodos qualitativo, quantitativo e misto. Artmed, 2010.

CUSUMANO, Michael A. Evaluating a startup venture. Communications of the ACM, v. 56, n. 10, p. 26-29, 2013.

CHRISTENSEN, Clayton. The innovator's dilemma: when new technologies cause great firms to fail. Harvard Business Review Press, 2013.

DAVIS, Craig R. Calculated risk: A framework for evaluating product development. MIT Sloan Management Review, v. 43, n. 4, p. 71, 2002.

DEW, Nicholas et al. Effectual versus predictive logics in entrepreneurial decision-making: Differences between experts and novices. Journal of business venturing, v. 24, n. 4, p. 287 309, 2009.

GAGE, Deborah. The venture capital secret: 3 out of 4 start-ups fail. Wall Street Journal, v. 20, 2012.

GARCIA, Rosanna; BARDHI, Fleura; FRIEDRICH, Colette. Overcoming consumer resistance to innovation. MIT Sloan management review, v. 48, n. 4, p. 82, 2007.

GALIA, Fabrice; LEGROS, Diego. Complementarities between obstacles to innovation: evidence from France. Research policy, v. 33, n. 8, p. 1185-1199, 2004. 
GARCIA, Rosanna; CALANTONE, Roger. A critical look at technological innovation typology and innovativeness terminology: a literature review.Journal of product innovation management, v. 19, n. 2, p. 110-132, 2002.

GIARDINO, Carmine et al. What do we know about software development in startups?

Software, IEEE, v. 31, n. 5, p. 28-32, 2014.

GVcia, FGV-EAESP. Pesquisa Anual do Uso de TI nas Empresas. São Paulo, 2015.

GRÉGOIRE, Denis A. et al. Is There Conceptual Convergence in Entrepreneurship Research? A Co-Citation Analysis of Frontiers of Entrepreneurship Research, 1981-2004. Entrepreneurship theory and practice, v. 30, n. 3, p. 333-373, 2006.

GRAHAM,Paul.Want to start a startup.2012. Disponível em: $<$ http://www.paulgraham.com/ growth.html> Acesso em: 24/05/2015.

GODOY, Arilda S., Introdução à pesquisa qualitativa e suas possibilidades. Revista de Administração de Empresas, v.35, n.2, p. 57-63, 1995 a.

GODOY, Arilda S, Pesquisa qualitativa.- tipos fundamentais, Revista de Administração de Empresas, v.35, n.3, 1995b, p. 20-29,1995b.

HALL, D.; HULETT, D. Projeto de riscos universais. Newton Squaer: PMI, 2002.

HANSEN, David J.; SHRADER, Rodney; MONLLOR, Javier. Defragmenting Definitions of Entrepreneurial Opportunity*. Journal of Small Business Management, v. 49, n. 2, p. 283304, 2011.

INSIGHTS, C. B. The top 20 reasons startups fail. October, v. 7, p. 2014, 2014.

JORION, Philippe. Risk management lessons from the credit crisis.European Financial Management, v. 15, n. 5, p. 923-933, 2009.

KAHNEMAN, Daniel. Rápido e devagar: duas formas de pensar. Editora Objetiva, 2012.

KAMBIL, Ajit; MAHIDHAR, Vikram. Disarming the value killers. Strategic Risk, p. 10-13, 2005.

KAPLAN, Robert S.; MIKES, Anette. Managing risks: A new framework.Harvard Business Review, v. 90, n. 6, p. 48-60, 2012.

KAUFFMAN FOUNDATION. The state_of_entrepreneurship_address, 11/02/2015.

Disponível em:

http://www.kauffman.org/ /media/kauffman_org/resources/2015/soe/2015 state_of_entrepre neurship address.pdf. Acesso em: 12/05/2016

LEIFER, Richard; O'CONNOR, Gina Colarelli; RICE, Mark. Implementing radical innovation in mature firms: The role of hubs. The Academy of Management Executive, v. 15, n. 3, p. 102-113, 2001.

LOCH, Christoph H.; SOLT, Michael E.; BAILEY, Elaine M. Diagnosing unforeseeable uncertainty in a new venture*. Journal of product innovation management, v. 25, n. 1, p. 28-46, 2008.

MASSOLUTION. 2015CF Crowdfunding Industry Report. Los Angeles, 07/04/2015.

Disponível em:

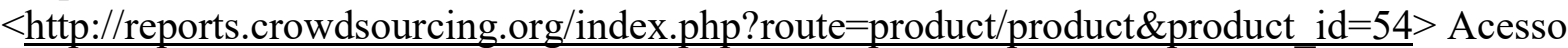
em: $12 / 03 / 2016$

MILES, Matthew B.; HUBERMAN, A. Michael; SALDANA, Johnny.Qualitative data analysis: A methods sourcebook. SAGE Publications, Incorporated, 2014.

MONITOR, Global Entrepreneurship. empreendedorismo no Brasil. Relatório global, 2015. NOHRIA, Nitin; STEWART, Thomas A. Risk, uncertainty, and doubt. Harvard Business Review, v. 84, n. 2, p. 39-40, 2006.

OLIVA, Fábio et al. Risks and strategies in a Brazilian innovation-flexfuel technology.

Journal of Manufacturing Technology Management, v. 25, n. 6, p. 916-930, 2014.

OLIVA, Fábio Lotti. A maturity model for enterprise risk management.International

Journal of Production Economics, v. 173, p. 66-79, 2015. 
OITO em cada dez consumidores acreditam que comprarão pelo celular no futuro. Época Negócios. São Paulo, 07/01/2015. Disponível em:

$<$ http://epocanegocios.globo.com/Informacao/Resultados/noticia/2014/12/oito-em-cada-dezconsumidores-acreditam-que-comprarao-pelo-celular-no-futuro.html $>$. Acesso em:

$12 / 03 / 2016$

OSTERWALDER, Alexander; PIGNEUR, Yves. Business model generation: a handbook for visionaries, game changers, and challengers. John Wiley \& Sons, 2010.

POLO, Edison; PEIXE, Maicol; GALEGALE, Gustavo. Estudo Bibliométrico da Produção Científica de Gerenciamento de Riscos entre os Anos de 2000 e 2012. Association for Information Systems AIS Electronic Library (AISeL), v. 5, 2013.

RIES, Eric. The lean startup: How today's entrepreneurs use continuous innovation to create radically successful businesses. Random House LLC, 2011.

REYNOLDS, Paul et al. Global entrepreneurship monitor. Executive Report, 2000.

ROMER, Rafael. MercadoLivre fatura US\$ $651 \mathrm{mi}$ em 2015 e ganha espaço frente a varejo offline. Canaltech. São Paulo, 02.03.2016. Disponível em:

$<$ http://corporate.canaltech.com.br/noticia/resultados-financeiros/mercadolivre-fatura-us-651mi-em-2015-e-ganha-espaco-frente-a-varejo-offline-59023/>. Acesso em: 12/04/2016.

SARASVATHY, Saras D. Causation and effectuation: Toward a theoretical shift from economic inevitability to entrepreneurial contingency. Academy of management Review, v. 26, n. 2, p. 243-263, 2001.

SETTI, Renan;CRUZ,Melissa. Modelo de financiamento pela web, 'crowdfunding' avança no Brasil. Mas há barreiras. O Globo. Rio de Janeiro. 03/11/2011. Disponível em:< http://oglobo.globo.com/sociedade/tecnologia/modelo-de-financiamento-pela-web-

crowdfunding-avanca-no-brasil-mas-ha-barreiras-2773332>. Acesso em: 12/03/2016.

SOMMER, Svenja C.; LOCH, Christoph H. Selectionism and learning in projects with complexity and unforeseeable uncertainty. Management science, v. 50, n. 10, p. 1334-1347, 2004.

SOMMER, Svenja C.; LOCH, Christoph H.; DONG, Jing. Managing complexity and unforeseeable uncertainty in startup companies: An empirical study. Organization Science, v. 20, n. 1, p. 118-133, 2009.

SOUZA, Cesar Alexandre. Sistema integrado de gestão empresarial: estudos de casos de implementação de sistemas de ERP. São Paulo, 2000. Dissertação (Mestrado em Administração de Empresas) - Programa de PósGraduação em Administração, Departamento de Administração, Faculdade de Economia, Administração e Contabilidade da Universidade de São Paulo.

STRINGER, Robert. How to manage radical innovation. California Management Review, v. 42, n. 4, p. 70-88, 2000.

STRAUSS, Anselm L.; CORBIN, Juliet. Pesquisa qualitativa: técnicas e procedimentos para o desenvolvimento de teoria fundamentada. Artmed, 2008.

TIDD, Joe; BESSANT, John; PAVITT, Keith. Gestão da Inovação. $3^{\text {a }}$ edição.Artmed Editora, 2008.

TOZETTO, Claudia. Número de startups brasileiras cresce $18 ; 5 \%$ em seis meses. Portal

Estadão. São Paulo, 18/01/2016 . Disponível em:<

http://link.estadao.com.br/noticias/inovacao,numero-de-startups-brasileiras-cresce-185-em-

seis-meses, $10000028610>$.Acesso em: 12/08/2016

UTTERBACK, James M. Dominando a dinâmica da inovação. Qualitymark, 1996.

YIN, Robert K. Estudo de Caso-: Planejamento e Métodos. Bookman editora, 2010.

ZACHARAKIS, Andrew; SPINELLI, Stephen; TIMMONS, Jeffry. Business Plans that

Work: A Guide for Small Business 2/E. McGraw Hill Professional, 2011. 
52 milhões de brasileiros usam o cartão de crédito como forma de pagamento.SPCBrasil.São Paulo, 27/05/2015. Disponível em: <https://www.spcbrasil.org.br/pesquisas/pesquisa/936> Acesso em: 12/03/2016 


\section{APÊNDICE I - ROTEIRO PARA A ENTREVISTA}

EMPRESA: ENTREVISTADO:

DATA/HORA: CARGO:

\section{1) Avaliação da Oportunidade}

1.1) Como nasceu a empresa? Qual oportunidade foi explorada?

A) Espera-se identificar a oportunidade de negócio e o estágio do desenvolvimento do mercado e da tecnologia no lançamento do negócio.

1.2) Foi escrito um plano de negócios antes do desenvolvimento da tecnologia? Foi utilizada alguma técnica de planejamento?

B) Analisar se foi seguida a lógica da efetivação ou ocorreu planejamento do negócio.

1.3) Diante da seguinte classificação:

New Ventures - são os "novos para o mundo", que representam o primeiro de seu tipo e necessitam da criação de um mercado totalmente novo - por exemplo, MP3 players.

Novas categorias - são "novos para a empresa" e incluem novas linhas de produtos, que têm como alvo um mercado estabelecido em que a empresa não compete atualmente.

Novas plataformas - frequentemente são adições às linhas de produtos existentes, embora os próprios produtos possam ser bastante inovadores.

Novos produtos - são derivados de melhorias e revisões de produtos existentes, incluindo reduções de custos.

Em qual categoria se enquadra o produto lançado?

C) O objetivo foi de selecionar o tipo de empreendimento para o cálculo do risco segundo a abordagem NPVR.

\section{2) Avaliação do Mercado}

2.1) Quais foram os mercados inicialmente identificados para o produto?

D) O objetivo foi de compreender se ocorreu um planejamento do posicionamento da empresa.

2.2) Todos os elementos da cadeia de valor exigido para se alcançar seus clientes potenciais, como capacidades da força de vendas, canais de distribuição, capacidades de fabricação e suporte ao cliente existiam internamente na empresa no lançamento? Foram construídas parcerias?

E) O objetivo é entender o grau de risco na cadeia de valor do negócio no lançamento.

2.3) A empresa já possuía presença no segmento mercado? Se sim, era líder? 
F) O objetivo foi de entender o grau de risco de segmento de mercado.

2.4) Quais foram os canais desenhados para se aproximar do mercado-alvo?

G) Observar se os empreendedores aplicaram a estratégia de selecionismo, a lógica da efetivação ou um plano de negócio.

\section{3) Avaliação do Usuário}

3.1) Os primeiros clientes possuíam conhecimento sobre a proposta de valor/design da inovação? O que o foi feito para aumentar o conhecimento do cliente sobre isso?

H) Identificar como os empreendedores gerenciaram as incertezas sobre os produtos. Esta pergunta procura mensurar o grau de especificação.

3.2) Quem definiu os atributos do produto? Houve uma pesquisa com o usuário antecipadamente?

I) Objetivo de identificar o grau de interação do produto.

\section{4) Tecnologia e recursos}

4.1) Qual era o estágio do desenvolvimento da tecnologia no lançamento do produto?

J) Objetivo de identificar o estágio do desenvolvimento da tecnologia atrelado ao risco da inovação.

4.2) A tecnologia já existia no mercado ou era um novo conceito?

K) Objetivo de mensurar o risco da inovação.

4.3) Quais foram as incertezas que surgiram durante o desenvolvimento do produto?

L) O objetivo foi de identificar quais incertezas influenciaram o desenvolvimento do produto.

4.4) A equipe já possuía experiência em projetos semelhantes? Diante das necessidades iniciais, pode-se considerar que a equipe era completa?

M) Objetivo de mensurar o risco de recursos.

\section{5) Avaliação geral do risco}

5.1) Fazendo uma análise a posteriori quais riscos você enxerga que a startup estava submetida no lançamento do produto?

N) O objetivo foi de selecionar riscos não observados nas teorias apresentadas. Foi apresentada a seguinte tabela de apoio, para facilitar a análise do empreendedor: 
Tabela 40 - Riscos no ambiente de valor

\begin{tabular}{cc}
\hline & Riscos mais Importantes no Ambiente de Valor \\
\hline Agentes & Riscos mais Importantes \\
Organização & Estratégico, Operacionais, Ético e Imagem \\
Clientes & Sociais e Imagem \\
Fornecedores & Estratégico, Operacionais, Ético e Imagem \\
Concorrentes & Financeiro, Inovação, Tecnológico, Ético e Imagem \\
Distribuidores & Estratégico, Operacionais, Ético e Imagem \\
Governo & Econômico \\
Sociedade & Sustentabilidade Ambiental e Meio Ambiente Oliva
\end{tabular}

Fonte: Oliva (2015) 